UNIVERSIDADE DE BRASÍLIA

FACULDADE DE TECNOLOGIA

DEPARTAMENTO DE ENGENHARIA ELÉTRICA

\title{
PLANEJAMENTO E ANÁLISE DE DESEMPENHO DE SISTEMAS WIMAX
}

\author{
MANUELLA DE FARIAS NARDELLI COSTA \\ MARTIM JALES HON \\ RAFAEL BOTELHO CARVALHO \\ RODRIGO MILÁN YAMAGUTI \\ WILSON DINIZ WELLISCH
}

ORIENTADOR: PAULO HENRIQUE PORTELA CARVALHO

TRABALHO DE CONCLUSÃO DE CURSO EM ENGENHARIA ELÉTRICA 
BRASÍLIA/DF: DEZEMBRO - 2008 
UNIVERSIDADE DE BRASÍLIA

FACULDADE DE TECNOLOGIA

DEPARTAMENTO DE ENGENHARIA ELÉTRICA

\title{
PLANEJAMENTO E ANÁLISE DE DESEMPENHO DE SISTEMAS WIMAX
}

\author{
MANUELLA DE FARIAS NARDELLI COSTA \\ MARTIM JALES HON \\ RAFAEL BOTELHO CARVALHO \\ RODRIGO MILÁN YAMAGUTI \\ WILSON DINIZ WELLISCH
}

DISSERTAÇÃO SUBMETIDA AO DEPARTAMENTO DE ENGENHARIA ELÉTRICA DA FACULDADE DE TECNOLOGIA DA UNIVERSIDADE DE BRASÍLIA COMO PARTE DOS REQUISITOS NECESSÁRIOS PARA A OBTENÇÃO DO GRAU DE ENGENHEIRO.

APROVADA POR:

Prof. Paulo Henrique Portela Carvalho, PhD (ENE-UnB) (Orientador)

Prof. Leonardo Rodrigues Araujo Xavier de Menezes, PhD (ENE-UnB) (Examinador Interno)

Eng. Paulo Eduardo Mine (TIM)

(Examinador Externo)

Eng. Ailfran Moraes Martins (ANATEL)

(Examinador Externo)

BRASÍLIA/DF, 9 DE DEZEMBRO DE 2008. 


\section{FICHA CATALOGRÁFICA}

COSTA, MANUELLA DE FARIAS NARDELLI

HON, MARTIM JALES

CARVALHO, RAFAEL BOTELHO

YAMAGUTI, RODRIGO MILÁN

WELLISCH, WILSON DINIZ

Planejamento e Análise de Desempenho de Sistemas WiMAX [Distrito Federal] 2008.

xvii, 103p., 210 x 297 mm (ENE/FT/UnB, Engenheiro Eletricista, Engenharia Elétrica, 2008).

Trabalho de Conclusão de Curso de Graduação - Universidade de Brasília. Faculdade de Tecnologia.

Departamento de Engenharia Elétrica.

1.Telecomunicações

2.WiMAX

3.Planejamento

4.Drive Tests

I. ENE/FT/UnB

II. Título (série)

\section{REFERÊNCIA BIBLIOGRÁFICA}

COSTA, MANUELLA DE F. N. ; HON, MARTIM J. ; CARVALHO, RAFAEL B. ; YAMAGUTI, RODRIGO M. ; WELLISCH, WILSON D. Planejamento e Análise de Desempenho de Sistemas WiMAX. (Trabalho de Conclusão de Curso de Graduação), Dezembro/2008, Departamento de Engenharia Elétrica, Universidade de Brasília, Brasília, DF, 97p. 


\section{CESSÃO DE DIREITOS}

AUTOR: Manuella de Farias Nardelli Costa, Martim Jales Hon, Rafael Botelho Carvalho, Rodrigo Milán Yamaguti e Wilson Diniz Wellisch.

TÍTULO: Planejamento e Análise de Desempenho de Sistemas WiMAX.

GRAU/ANO: Engenheiro Eletricista/2008

É concedida à Universidade de Brasília permissão para reproduzir cópias deste trabalho de conclusão de curso de graduação e para emprestar ou vender tais cópias somente para propósitos acadêmicos e científicos. Os autores reservam outros direitos de publicação e nenhuma parte desse trabalho de conclusão de curso de graduação pode ser reproduzida sem autorização por escrito dos autores.

Manuella de Farias Nardelli Costa

SQS 314, Bl. E, Apt. 201, Asa Sul.

CEP: 70.383-050

Brasília - DF - Brasil.

Martim Jales Hon

Condomínio Solar de Brasília, Qd. 03, Conj. 16, Cs. 03, Lago Sul.

CEP: 71.680-349

Brasília - DF - Brasil.

Rafael Botelho Carvalho

SQSW 504, B1. A, Apt. 101, Setor Sudoeste.

CEP: 70.673-501

Brasília - DF - Brasil.

Rodrigo Milán Yamaguti

SQN 310, B1. B, Apt 404, Asa Norte.

CEP: 70.756-020

Brasília - DF - Brasil.

Wilson Diniz Wellisch

Condomíno Ville De Montagne, Qd. 32, Cs. 50, Lago Sul.

CEP: 71.680-357

Brasília - DF - Brasil. 


\section{AGRADECIMENTOS}

Aos meus pais, por terem feito do conhecimento uma prioridade na minha vida e oferecido todas as ferramentas necessárias para que eu pudesse transformar o meu potencial em realidade.

Ao professor Paulo Portela, pelos conselhos e esclarecimentos prestados ao longo de todo o trabalho e pelo tempo dedicado à nossa orientação. Admiração e respeito sem medidas.

A todos os amigos que me acompanharam e apoiaram nessa jornada, proporcionando momentos de alegria que nunca serão esquecidos. Uma nova época começa e, com ela, muitas novas festas, viagens, churrascos, sempre com muitas histórias pra contar e morrer de rir no dia seguinte.

Manuella de Farias Nardelli Costa

Aos meus pais queridos e amados, Américo e Liege, por estarem incondicionalmente ao meu lado, em todos os bons e maus momentos de minha vida.

Ao meu irmão Miguel, por ter sido, durante esses 23 anos, meu "irmão mais velho".

Ao professor Paulo Portela, pela amizade e pela dedicação na orientação deste trabalho.

À Raquel, por proporcionar os melhores momentos destes últimos 2 anos.

Aos companheiros eletricistas e membros do Laboratório de Estruturas de Microondas e Ondas Milimétricas, pelo companheirismo e apoio durante esses longos 5 anos.

Aos amigos, pelo apoio.

Martim Jales Hon 
Primeiramente, aos meus pais por toda dedicação, amor e apoio que tornaram possível a conquista de mais um objetivo em minha vida.

A minha irmã que sempre esteve presente nessa gloriosa caminhada, sendo meu incentivo para alcançar os meus objetivos.

Aos meus avós por serem minha fonte de inspiração e meu alicerce para enfrentar os obstáculos presentes em minha vida.

A Denise e sua família por todo amor, carinho e respeito despendidos ao longo desses 5 anos.

Ao Prof. Paulo Portela pelos conhecimentos transmitidos, dedicação e apoio ao longo desse último ano.

Aos guerreiros do LEMOM pelo companheirismo, conhecimentos compartilhados e pelas amizades construídas.

Aos amigos pelo apoio, compreensão e por me proporcionar momentos intensos de alegria, tornando possível a realização deste sonho.

Rafael Botelho Carvalho

À minha família (Pai, Mãe e Irmãos), por todo apoio, respeito e amor que sempre pude sentir durante esses 5 anos de dedicação à minha formação profissional.

Aos meus primos, tios e amigos pelos momentos de descontração.

Ao prof. Dr. Paulo Henrique Portela de Carvalho, pela dedicação, atenção e colaboração.

A todos meus companheiros de graduação presentes nos eventos festivos, futebolísticos e de muita ralação nas vésperas das provas.

Aos colegas do LEMOM pelo companheirismo e apoio técnico dado.

Rodrigo Milán Yamaguti 
À minha mãe: base, admiração e responsável por tudo que conquistei até hoje.

Ao meu pai, minha inspiração e espelho profissional.

À minha irmã, Bárbara, pelos momentos de amizade e ternura.

Aos meus amigos que em momentos de alegrias propícias e desesperos polêmicos, estiveram ao meu lado.

Ao professor Paulo Henrique Portela, por toda a dedicação em nos preparar para uma das etapas mais importantes da graduação e que fez deste trabalho algo possível.

Ao Danilo, colega de trabalho, pela ajuda prestada.

Aos amigos do LEMOM, pelas horas de auxílio e companheirismo nas penosas noites passadas em claro.

Finalmente, à Luciana, por ser meu porto seguro e por me suportar nos momentos mais difíceis.

A todos, obrigado!

Wilson Diniz Wellisch 


\section{RESUMO}

A crescente necessidade por mobilidade e altas taxas para o tráfego de dados tem sido o maior incentivo aos trabalhos de pesquisa e inovação na área de telecomunicações, em que os sistemas sem fio exercem papel de destaque. Entre as novas gerações de sistemas wireless de comunicação, as redes WiMAX mostram-se promissoras, fornecendo alta capacidade e cobertura, e dão liberdade para o desenvolvimento de novas propostas de algoritmos de alocação de recursos.

A partir dessa motivação, este trabalho apresenta um estudo sobre as principais características do sistema WiMAX. Posteriormente, é proposta uma metodologia, desenvolvida no software MATLAB, para planejamento inicial de uma rede, com base em parâmetros de serviço e características do meio e dos sistemas de transmissão e recepção.

São, então, analisados resultados obtidos em sistemas WiMAX implantados no Brasil e disponibilizados por duas grandes operadoras de telecomunicação atuantes no país, para avaliação do desempenho realmente alcançado por esses sistemas. 


\section{ABSTRACT}

The growing need for mobility and high data traffic rates has been the biggest incentive for research and innovation in the field of telecommunications, in which the wireless systems perform a prominent role. Among the new generations of wireless communication systems, WiMAX networks have shown a promising performance, providing high capacity and large coverage areas, and given flexibility to develop new proposals of resource allocation algorithms.

This work presents a study on the main features of WiMAX systems. Then, an initial network planning methodology is developed using MATLAB. It was based on service parameters and on environment and transmission/ reception systems characteristics.

Some results obtained in real WiMAX systems implemented in Brazil were analyzed. Those results were released by two major telecommunication operators to evaluate the performance of an actual WiMAX network. 


\section{SUMÁRIO}

FICHA CATALOGRÁFICA..........................................................................................................................IV

REFERÊNCIA BIBLIOGRÁFICA..........................................................................................................

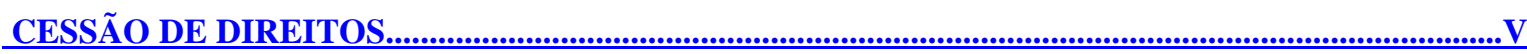

AGRADECIMENTOS........................................................................................................................................

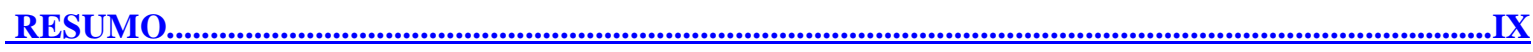

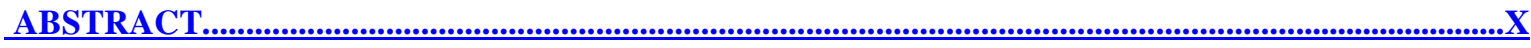

SUMÁRIO.

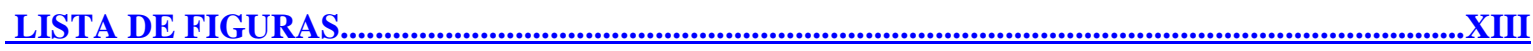

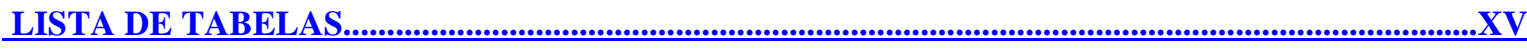

LISTA DE SÍMBOLOS, NOMENCLATURAS E ABREVIAC ÕES............................................XVII

1. INTRODUCCÃ

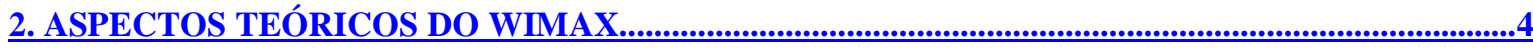

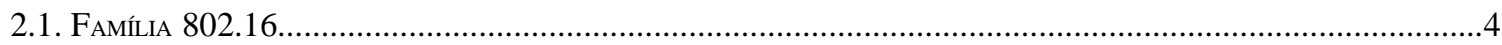

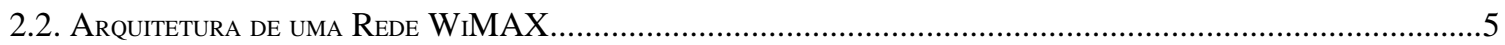

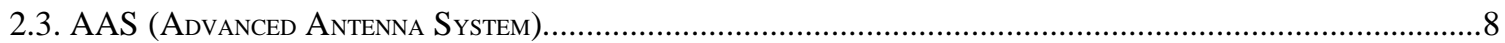

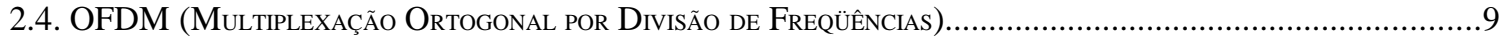

2.4.1. Blocos de Transmissão Separados por Intervalos de Guarda......................................................11

2.4.2. Transformada de Fourier Discreta (DFT - Discrete Fourier Transform)....................................12

2.5. OFDMA (Múltiplo Acesso Ortogonal por Divisão em FreqüÊnCias).................................................16

2.5.1. Permutação de subportadoras em WiMAX OFDMA PHY.........................................................19

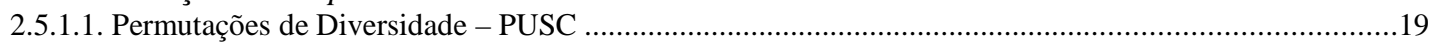

2.5.1.2. Permutações Contínuas - Modulação e Codificação Adaptativas (AMC)...............................................23

2.5.2. Diversidade de Multiusuários........................................................................................................26

2.5.3. Algoritmos de Alocação de Recursos em OFDMA....................................................................28

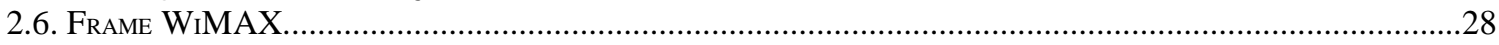

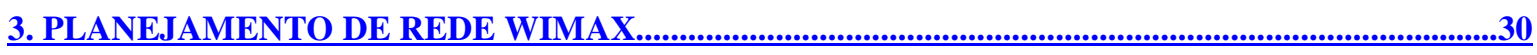

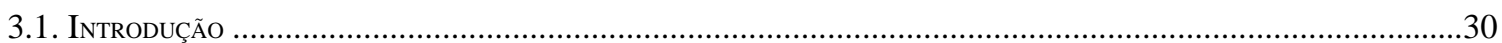

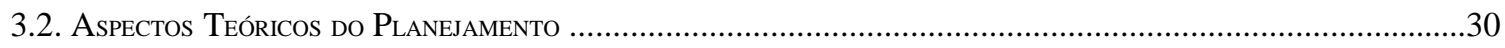

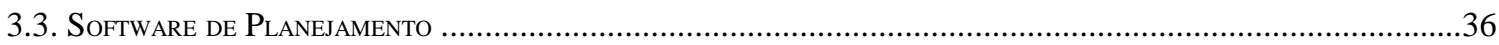

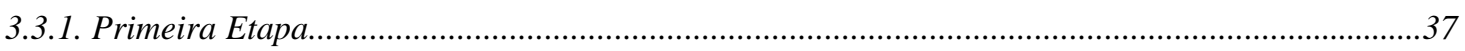

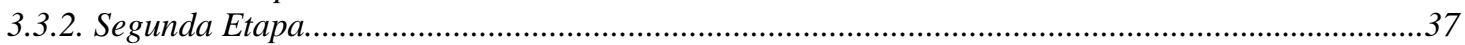

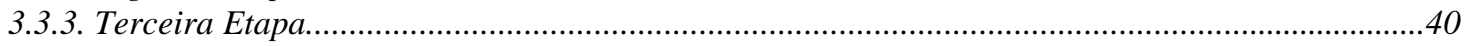

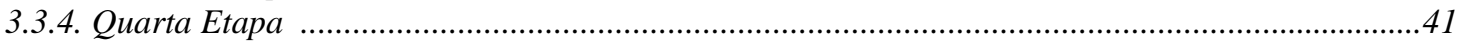

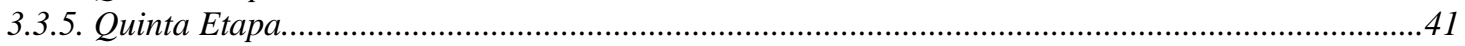

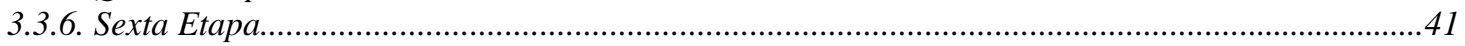

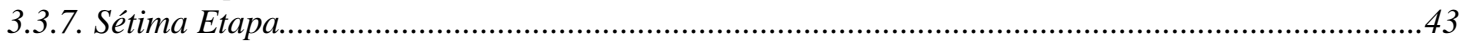

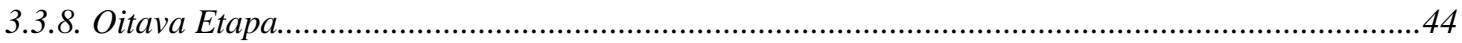

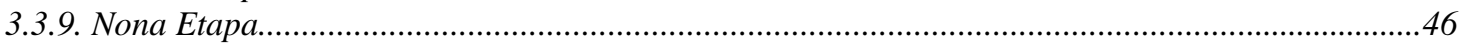

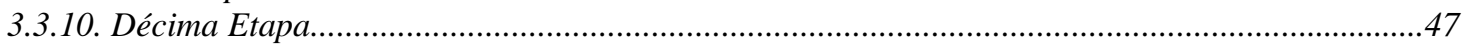

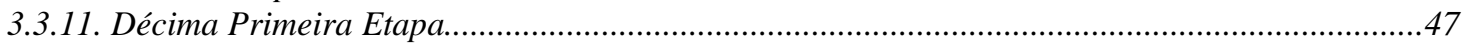

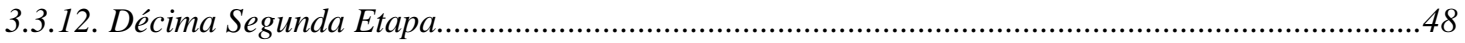

3.4. Fluxograma do Algoritmo do Software de Planejamento...............................................................49

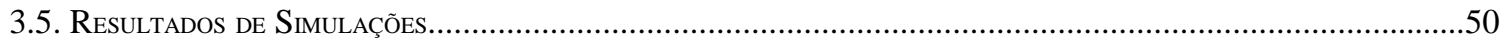

3.5.1. Comparação entre Freqüências................................................................................................51

3.5.2. Comparação em relação à banda do canal..............................................................................55

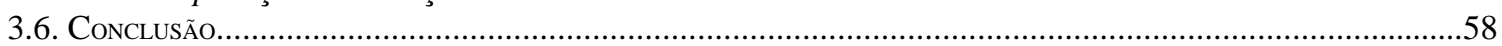




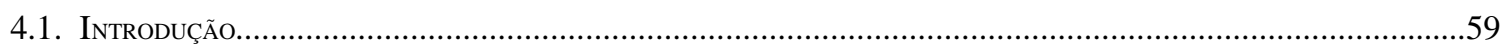

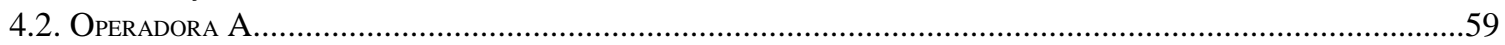

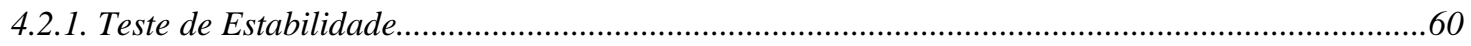

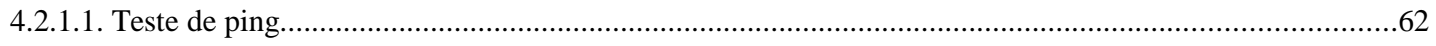

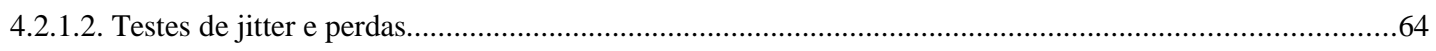

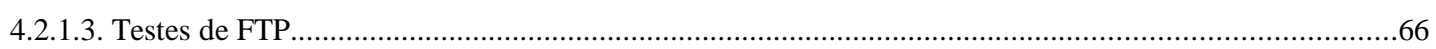

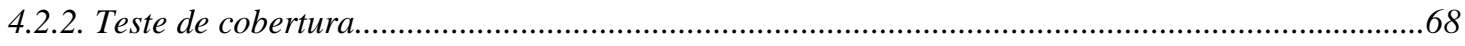

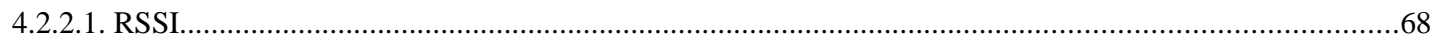

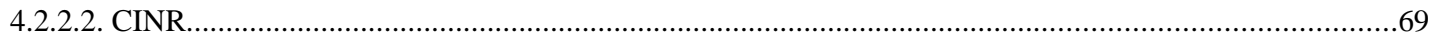

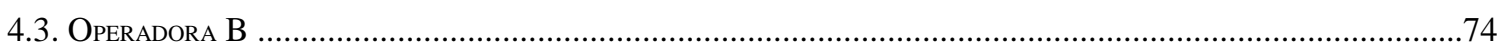

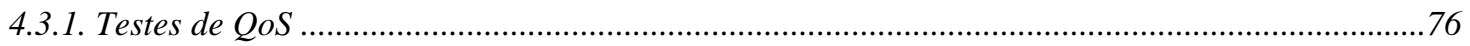

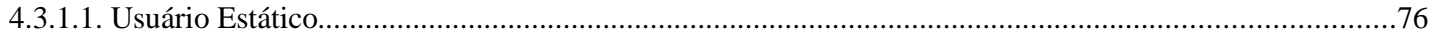

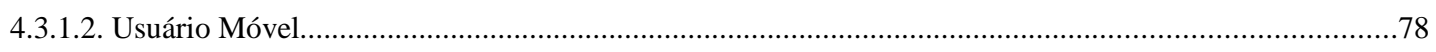

4.3.2. Cobertura e Calibragem do Software de Predição........................................................................79

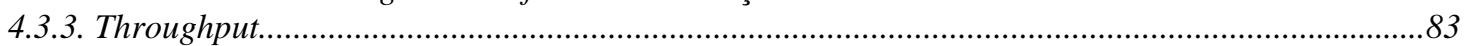

4.3.4. Comparação dos testes de throughput das operadoras A e B...................................................92

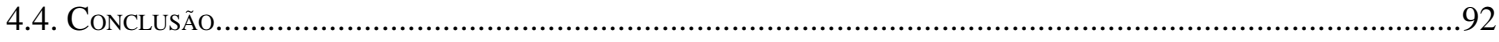

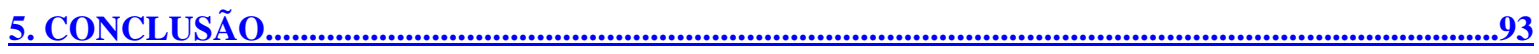

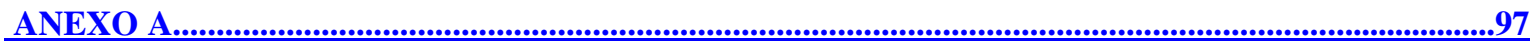

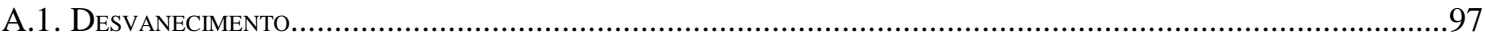

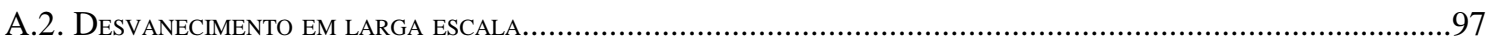

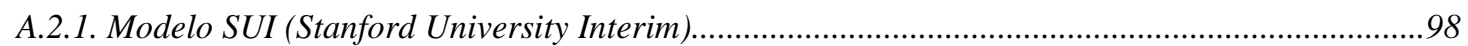

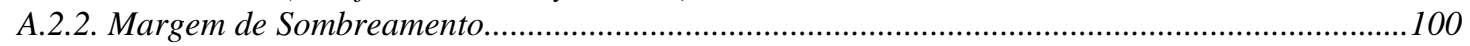

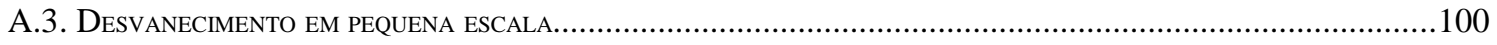




\section{LISTA DE FIGURAS}

FIGURA 2.1: MODELO DE REFERÊNCIA DE REDE PARA WIMAX. ADAPTADO DE [1].............6

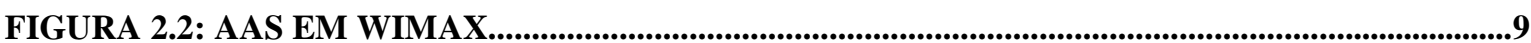

FIGURA 2.3: TRANSMISSOR BÁSICO DE MULTIPORTADORAS. ADAPTADO DE [1]................10 FIGURA 2.4: SINAL COM MULTIPORTADORAS. ADAPTADO DE [1]............................................11 FIGURA 2.5: PERÍODO DE GUARDA ENTRE SÍMBOLOS OFDM. ADAPTADO DE [1].................12 FIGURA 2.6: PREFIXO CÍCLICO NO SÍMBOLO OFDM. ADAPATADO DE [1].................................13 FIGURA 2.7: SINAL OFDM COM BANDA DE GUARDA NULA. ADAPTADO DE [1]......................13 FIGURA 2.8: FORMAÇÃO DO SINAL OFDM. ADAPTADO DE [1].......................................................14 FIGURA 2.9: REPRESENTAÇÃO DE UM SÍMBOLO OFDM NOS DOMÍNIOS DO TEMPO (A) E DA FREQÜÊNCIA (B). ADAPTADO DE [1]..........................................................................................15

FIGURA 2.10: SUBPORTADORAS OFDM. ADAPTADO DE [2].........................................................16

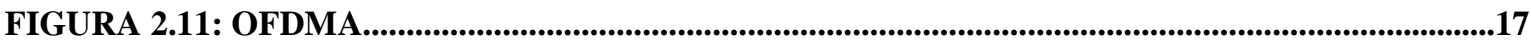

FIGURA 2.12: ALOCAÇÃO DE SUBPORTADORAS PILOTO. ADAPTADO DE [2]...........................21

FIGURA 2.13: MODO DE PERMUTAÇÃO PUSC...............................................................................23

FIGURA 2.14: DIAGRAMA DE BLOCOS DE UM SISTEMA AMC. ADAPTADO DE [1].................25 FIGURA 2.15: THROUGHPUT OBTIDO PARA OS DIVERSOS PERFIS, A PARTIR DA SINR

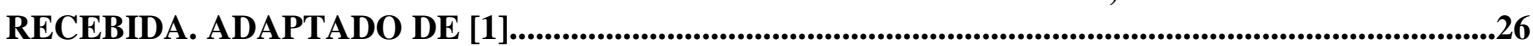

FIGURA 2.16: PDF DE HMAX. ADAPTADO DE [1].........................................................................27

FIGURA 2.17: CAPACIDADE E BER PARA DIVERSOS VALORES DE K. ADAPTADO DE [1]....28 FIGURA 2.18: FRAME WIMAX. ADAPTADO DE [1]..............................................................29 FIGURA 3.19: TAXA TOTAL (MBPS) EM FUNÇÃO DA MODULAÇÃO E CODIFICAÇÃO............35 FIGURA 3.20: TAXA TOTAL EM FUNÇÃO DA BANDA DISPONÍVEL..............................................35

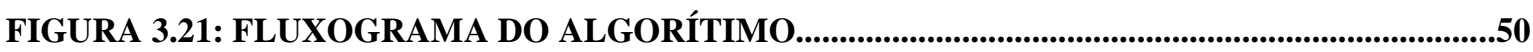
FIGURA 3.22: NÚMERO DE CÉLULAS NA COMPARAÇÃO ENTRE FREQÜÊNCIAS....................53 FIGURA 3.23: NÚMERO USUÁRIOS POR CÉLULA NA COMPARAÇÃO ENTRE FREQÜÊNCIAS FIGURA 3.24: TAXA POR CÉLULA NA COMPARAÇÃO ENTRE FREQÜÊNCIAS............................55 FIGURA 3.25: TAXA POR CÉLULA NA COMPARAÇÃO ENTRE BANDA.........................................56 FIGURA 3.26: NÚMERO DE CÉLULAS NA COMPARAÇÃO ENTRE FREQÜÊNCIAS.....................57 FIGURA 3.27: NÚMERO DE USUÁRIOS POR CÉLULA NA COMPARAÇÃO ENTRE FREQÜÊNCIAS....................................................................................................................................57

FIGURA 4.28: MAPA DE COBERTURA DA CIDADE A - MOMENTO 1.........................................71

FIGURA 4.29: MAPA DE COBERTURA DA CIDADE A - MOMENTO 2..............................................72

FIGURA 4.30: COMPARATIVO ENTRE AS PDFS DOS DOIS MOMENTOS AVALIADOS.............73 FIGURA 4.31: COBERTURA OBTIDA EM TESTES DO SETOR 1 DO SITE BBB (PRIMEIRO

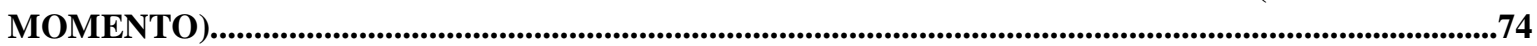

FIGURA 4.32: TOPOLOGIA DA REDE WIMAX UTILIZADA..........................................................75

FIGURA 4.33: ILUSTRAÇÃO DAS MEDIDAS DE RSSI EM DBM PARA O WBS01B..........................80 
FIGURA 4.34: ILUSTRAÇÃO DAS MEDIDAS DE CNIR EM DB PARA O WBSO1B.

FIGURA 4.35: ILUSTRAÇÃO DAS MEDIDAS DA POTÊNCIA DE TRANSMISSÃO EM DBM

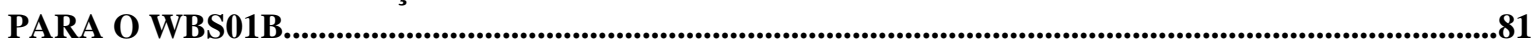

FIGURA 4.36: ILUSTRAÇÃO DA DISTÂNCIA MÁXIMA ALCANÇADA PARA O WBSO1B..........82 FIGURA 4.37: ILUSTRAÇÃO DOS RESULTADOS DE THROUGHPUT NO DOWNLINK PARA UMA VELOCIDADE DE $20 \mathrm{KM} / \mathrm{H}$.

FIGURA 4.38: ILUSTRAÇÃO DOS RESULTADOS DE THROUGHPUT NO DOWNLINK PARA UMA VELOCIDADE DE 40 KM/H.....................................................................................................88

FIGURA 4.39: ILUSTRAÇÃO DOS RESULTADOS DE THROUGHPUT NO DOWNLINK PARA UMA VELOCIDADE DE $60 \mathrm{KM} / \mathrm{H}$..............................................................................................88 FIGURA 4.40: ILUSTRAÇÃO DOS RESULTADOS DE THROUGHPUT NO UPLINK PARA UMA VELOCIDADE DE 20 KM/H...............................................................................................................89

FIGURA 4.41: ILUSTRAÇÃO DOS RESULTADOS DE THROUGHPUT NO UPLINK PARA UMA VELOCIDADE DE 40 KM/H................................................................................................................89

FIGURA 4.42: ILUSTRAÇÃO DOS RESULTADOS DE THROUGHPUT NO UPLINK PARA UMA VELOCIDADE DE $60 \mathrm{KM} / \mathrm{H}$.......................................................................................................90 FIGURA 4.43: ILUSTRAÇÃO DOS RESULTADOS DE THROUGHPUT APRESENTADOS NA FIGURA 4.12 ..........................................................................................................................................91 FIGURA A.44: COMPORTAMENTO DO DESVANECIMENTO DA ENVOLTÓRIA DE UM

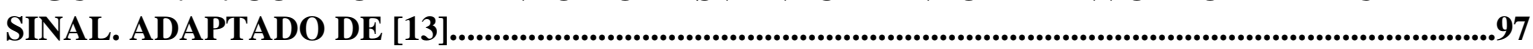
FIGURA A.45: INTERFERÊNCIA CONSTRUTIVA(A) E DESTRUTIVA(B). ADAPTADO DE [1] 


\section{LISTA DE TABELAS}

TABELA 2.1: PONTOS DE REFERÊNCIA DO NRM........................................................................7

TABELA 2.2: PARÂMETROS DEFINIDOS PARA O WIMAX...........................................................18

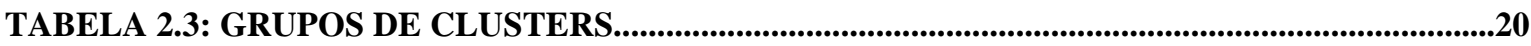

TABELA 2.4: FAIXA DE SUBCANAIS PARA GRUPOS DE SUBPORTADORAS...............................22

TABELA 2.5: ESQUEMAS DE MODULAÇÃO E CODIFICAÇÃO SUPORTADOS PELO WIMAX

TABELA 2.6: BURST PROFILES PARA DOWNLINK E UPLINK NO PADRÃO 802.16E.

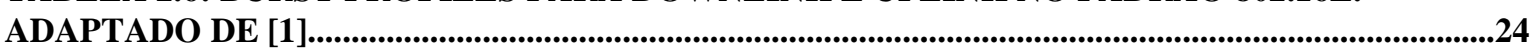

TABELA 3.7: FATOR DE AMOSTRAGEM...........................................................................................33

TABELA 3.8: LÍMITE DE SNR POR MODULAÇÃO/CODIFICAÇÃ̃..................................................39

TABELA 3.9: VALORES PARA O FATOR DE MODULAÇÃO............................................................43

TABELA 3.10: VALORES DE CMAX E L PARA CADA ESQUEMA

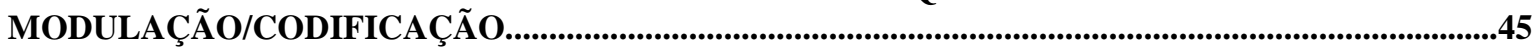

TABELA 3.11: VALORES DA CONSTANTE C1 PARA O CÁLCULO DA BER.....................................46

TABELA 3.12: PARÂMETROS DE ENTRADA 1..........................................................................50

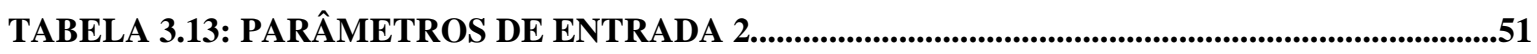

TABELA 3.14: RESULTADOS DA COMPARAÇÃO ENTRE FREQÜÊNCIAS.......................................51

TABELA 3.15: RESULTADOS PARA A COMPARAÇÃO ENTRE BANDAS..........................................56

TABELA 4.16: APLICAÇÕES DE WIMAX MÓVEL E QOS [9]............................................................60

TABELA 4.17: LIMITES APLICADOS AOS SERVIÇO DO SISTEMA WIMAX [9].............................62

TABELA 4.18: RESULTADO DE TESTES DE PING PARA SETORES DOS SITES BBB E AAA (DRIVE TEST REALIZADO PELA EMPRESA A)...............................................................................64

TABELA 4.19: RESULTADO DE TESTES DE JITTER E PERDAS PARA DIFERENTES PERFIS DE USUÁRIOS. (DRIVE TEST REALIZADO PELA EMPRESA A)....................................................65

TABELA 4.20: RESULTADO DE TESTES DE FTP PARA DIVERSOS SETORES E SITUAÇÕES. [DRIVE TEST REALIZADO PELA EMPRESA A).................................................................................66

TABELA 4.21: TAXAS SUSTENTADAS PELA OPERADORA A E SIMULADAS PELO SOFTWARE DE PLANEJAMENTO.

TABELA 4.22: INFORMAÇÕES DE CADA SETOR DOS SITES IMPLANTADOS NA CIDADE A

(DRIVE TEST REALIZADO PELA EMPRESA A)...........................................................................70

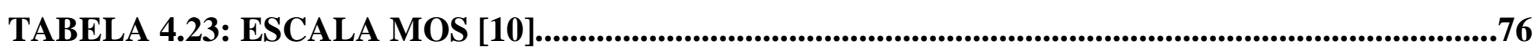

TABELA 4.24: RESULTADOS DA MEDIDA UTILIZANDO O SERVIÇO ERTVR..............................77

TABELA 4.25: RESULTADOS DA MEDIDA UTILIZANDO O SERVIÇO UGS.....................................77

TABELA 4.26: RESULTADOS DA MEDIDA UTILIZANDO O SERVIÇO ERTVR................................78

TABELA 4.27: RESULTADOS DA MEDIDA UTILIZANDO O SERVIÇO UGS.....................................79

TABELA 4.28: VALORES DE CINR PARA CADA BS...............................................................82

TABELA 4.29:PARÂMETROS DE DEFINIÇÃO DOS AMBIENTES DE PROPAGAÇÃO..................83

TABELA 4.30: VALORES ENCONTRADOS PARA O ENSAIO NO DOWNLINK A UMA

VELOCIDADE DE $20 \mathrm{KM} / \mathrm{H}$. .84 
TABELA 4.31: VALORES ENCONTRADOS PARA O ENSAIO NO DOWNLINK A UMA

VELOCIDADE DE $40 \mathrm{KM} / \mathrm{H}$

TABELA 4.32: VALORES ENCONTRADOS PARA O ENSAIO NO DOWNLINK A UMA

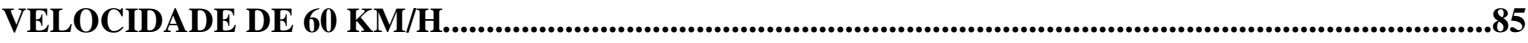

TABELA 4.33: VALORES ENCONTRADOS PARA O ENSAIO NO UPLINK A UMA

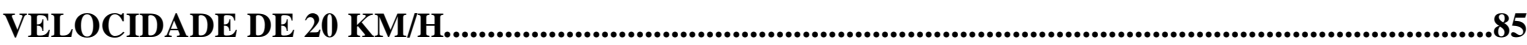

TABELA 4.34: VALORES ENCONTRADOS PARA O ENSAIO NO UPLINK A UMA

VELOCIDADE DE 40 KM/H........................................................................................................................86

TABELA 4.35: VALORES ENCONTRADOS PARA O ENSAIO NO UPLINK A UMA

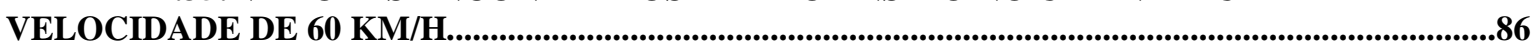

TABELA 4.36: VALORES SIMULADOS E MEDIDOS PARA OS DIFERENTES TIPOS DE

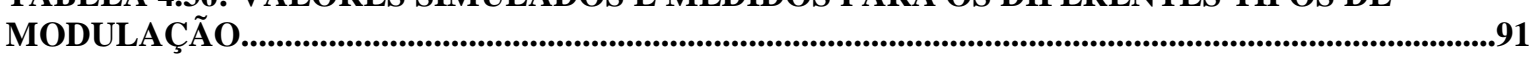

TABELA A.37: VALORES DOS PARÂMETROS QUANTO AO TIPO DE TERRENO..........................99 


\section{LISTA DE SÍMBOLOS, NOMENCLATURAS E ABREVIAÇÕES}

\begin{tabular}{|c|c|}
\hline AAA & Authentication, Authorization, and Accounting \\
\hline AAS & Advanced Antenna Systems \\
\hline AMC & Adaptive Modulation and Coding \\
\hline ASN & Access Services Network \\
\hline ASN-GW & ASN Gateway \\
\hline $\mathrm{BE}$ & Best-Effort \\
\hline BER & Bit Error Rate \\
\hline BLER & Block Error Rate \\
\hline BPSK & Binary Phase Shift Keying \\
\hline BS & Base Station \\
\hline BTC & Block Turbo Code \\
\hline $\mathrm{CC}$ & Convolutional Coding \\
\hline CINR & Carrier to Interference-plus-Noise Ratio \\
\hline $\mathrm{CP}$ & Cyclic Prefix \\
\hline $\mathrm{CPE}$ & Customer Premise Equipment \\
\hline $\mathrm{CSN}$ & Connectivity Services Network \\
\hline CTC & Convolutional Turbo Code \\
\hline $\mathrm{DC}$ & Direct Current \\
\hline DFT & Discrete Fourier Transform \\
\hline DL & Downlink \\
\hline DSL & Digital Subscriber Line \\
\hline DVB & Digital Video Broadcasting \\
\hline DVB-T & DVB-Terrestrial \\
\hline ertPS & extended real-time Polling Service \\
\hline ertVR & extended real-time Variable Rate \\
\hline ETSI & European Telecommunication Standards Institute \\
\hline $\mathrm{FCH}$ & Frame Control Header \\
\hline FDD & Frequency Division Duplexing \\
\hline
\end{tabular}


FDMA Frequency Division Multiple Access

FFT Fast Fourier Transform

FTP File Transfer Protocol

FUSC Full Usage of Subchannels

IEEE Institute of Electrical and Electronics Engineers

IFFT Inverse Fast Fourier Transform

IP Internet Protocol

ISI Intersymbol Interference

ITU International Telecommunication Union

LDPC Low-Density Parity Codes

LN Logical Number

LOS Line-of-Sight

MAC Media Access Control

MAN Metropolitan Area Network

MAP Media Access Protocol

MCS Modulation and Coding Scheme

MIMO Multiple-Input Multiple-Output

MMDS Multipoint Multichannel Distribution System

MOS Mean Opinion Score

NAP Network Access Provider

NLOS non Line-of-Sight

NRM Network Reference Model

nrtPS non-real-time Polling Service

NSP Network Services Provider

NWG Network Working Group

OFDM Orthogonal Frequency Division Multiplexing

OFDMA Orthogonal Frequency Division Multiple Access

OFUSC Optional FUSC

OPUSC Optional PUSC

PAPR Peak-to-Average Power Ratio

PCMCIA Personal Computer Memory Card International Association

PDF Probability Density Function 


$\begin{array}{ll}\text { PHY } & \text { Physical Layer } \\ \text { PN } & \text { Physical Number } \\ \text { PUSC } & \text { Partial Usage of Subchannels } \\ \text { QAM } & \text { Quadrature Amplitude Modulation } \\ \text { QoS } & \text { Quality of Service } \\ \text { QPSK } & \text { Quadrature Phase Shift Keying } \\ \text { RSSI } & \text { Received Signal Strenght Indicator } \\ \text { RTG } & \text { Receive/Transmit Transition Gap } \\ \text { rtPS } & \text { real-time Polling Service } \\ \text { SNR } & \text { Signal Noise Ratio } \\ \text { SS } & \text { Subscriber Station } \\ \text { SUI } & \text { Stanford University Interim } \\ \text { TDD } & \text { Time Division Duplexing } \\ \text { TDM } & \text { Time Division Multiplexing } \\ \text { TDMA } & \text { Time Division Multiple Access } \\ \text { TTG } & \text { Transmit/Receive Transition Gap } \\ \text { TUSC } & \text { Tile Usage of Subchannels } \\ \text { UDP } & \text { User Datagram Protocol } \\ \text { UGS } & \text { Unsolicited Grant Service } \\ \text { UL } & \text { Uplink } \\ \text { VoIP } & \text { Woice over Internet Protocol } \\ \text { WAC } & \text { Windows Access } \\ \text { WiFi } & \text { Wireless Fidelity } \\ \text { WiMAX } & \text { Worldide Interoperability for Microwave Access } \\ \text { Wetwork } \\ \text { Whan }\end{array}$





\section{INTRODUÇÃO}

O consumo imediato, foco principal do sistema capitalista, predominante no cenário mundial atual, reflete-se também no que diz respeito à troca de informações. A crescente necessidade de velocidade e de instantaneidade nas comunicações foi a grande responsável pela popularização dos sistemas sem fio banda larga presenciada na atualidade.

Nesse sentido, o principal avanço ocorreu com o surgimento da tecnologia WiFi (Wireless Fidelity), que veio transformar a experiência desses usuários finais com o acesso banda larga. Dispositivos, como notebooks, que rapidamente mostraram uma tendência a tornarem-se mais viáveis economicamente, permitiram o acesso a redes sem fio locais (WLANs) e à Internet de alta velocidade - da ordem de Mbps -, a um custo relativamente baixo.

Entretanto, com um raio de cobertura bastante restrito, essas redes não eram capazes de integrar banda larga e a possibilidade de mobilidade plena, como a experimentada pelos usuários nas redes de telefonia celular. Tais redes celulares, apesar de oferecerem os atrativos de amplas áreas de cobertura, disponibilizavam serviços de dados a taxas na casa dos kbps e a preços ainda hoje altos para os serviços a que se propõem.

Esse cenário incentivou o surgimento do grupo 802.16, fundado pelo IEEE (Institute of Electrical and Electronics Engineers) em 1998, que se dispôs a criar um padrão de rede de alta velocidade que atendesse a áreas metropolitanas (WMAN). A padronização resultante dessa iniciativa recebeu o nome de WiMAX (World Interoperability for Microwave Access), ou seja, um acesso por microondas com uma interoperabilidade a nível mundial.

Foram incorporadas a este sistema diversas tecnologias para otimização do alcance, da potência utilizada e do espectro disponível para que o sistema pudesse ter o desempenho desejado. Entre elas, a técnica de múltiplo acesso ortogonal por divisão em frequiências (OFDMA), a modulação adaptativa e a utilização de antenas inteligentes têm lugar de destaque. 
A sofisticação do sistema, que definiu diversos perfis de QoS que incluem, por exemplo, serviços de vídeo em tempo real, elevou o nível de complexidade do planejamento, dos esquemas de alocação de recurso; exigindo uma maior capacidade de processamento dos equipamentos e um maior reaproveitamento do espectro, relativamente escasso.

Ainda em fase de desenvolvimento, esse sistema tem mostrado cada vez mais aceitação, tendo sido implementado, em sua versão nômade, em países como Estados Unidos da América, Japão, Inglaterra e, inclusive, no Brasil. Sua versão móvel está em um grau de desenvolvimento ainda menor, encontrando-se disponível em poucas localidades. Na América do Norte, a primeira cidade a conhecê-la foi Baltimore, nos EUA, em Outubro de 2008.

No Brasil, ainda não foi regulamentada a implantação de sistemas WiMAX móveis. Apesar disso, grandes empresas tem iniciado a implementação do sistema WiMAX fixo utilizando o OFDMA como técnica de múltiplo acesso. Para coibir a performance móvel do sistema, desabilitam-se as funções associadas à mobilidade, como handoffs.

Este trabalho final de graduação foi desenvolvido no intuito de compreender melhor o funcionamento de sistemas WiMAX, que se mostram promissores no futuro das telecomunicações. Para isso, analisou-se o desempenho desses sistemas a partir de dados reais e desenvolveu-se um algoritmo para o planejamento de redes a serem implementadas, com base em parâmetros de serviço, características de terrenos e sistemas de transmissão/recepção.

Para apresentar os resultados obtidos, ele foi estruturado em cinco capítulos. Após esta introdução, o segundo capítulo descreve as características técnicas principais do sistema, relativas às camadas física e de acesso.

No terceiro capítulo, é apresentada uma metodologia para o planejamento inicial de uma rede WiMAX, bem como sua implementação no software Matlab. São analisados resultados alcançados por algumas simulações executadas com esse aplicativo para diferentes situações de terreno, banda disponível e frequiência central.

No quarto capítulo, são apresentados e analisados resultado relativos a desempenho estabilidade e cobertura. Os dados apresentados nesse capítulo foram obtidos em drive 
tests de redes WiMAX em implantação no Brasil e disponibilizados por duas grandes operadoras de telecomunicações que atuam no país.

Enfim, o quinto capítulo contém as conclusões a respeito do que foi apresentado e perspectivas de trabalhos futuros. 


\section{ASPECTOS TEÓRICOS DO WIMAX}

Neste capítulo, são descritas as principais características das camadas física e de acesso ao meio do sistema WiMAX, consideradas relevantes ao trabalho.

\subsection{Família 802.16}

O grupo 802.16 foi fundado em 1998 pelo IEEE para desenvolver padrões de redes metropolitanas sem fio (WMAN - Wireless Metropolitan Area Network). Seus estudos concentraram-se nas freqüências entre $10 \mathrm{GHz}$ e $66 \mathrm{GHz}$, que seriam capazes de fornecer conexões rápidas a edifícios. Para isso, utilizar-se-iam antenas externas, comunicando-se com uma estação base de maneira ponto-a-ponto. O desempenho médio almejado era de 70 Mbps, com picos de $268 \mathrm{Mbps}$, sendo basicamente uma alternativa a redes de acesso cabeadas, como a DSL (Digital Subscriber Line), por exemplo.

Em dezembro de 2001, o grupo IEEE 802.16 aprovou o padrão Wireless MAN-SC cuja camada física (PHY - Physical Layer) faz uso de técnicas de modulação com uma única portadora. A camada de controle de acesso de mídias (MAC - Media Access Control) utiliza a multiplexação por divisão no tempo (TDM - Time Division Multiplexing), que suporta tanto a duplexação por divisão no tempo (TDD - Time Division Duplexing), como a por divisão de freqüência (FDD - Frequency Division Duplexing). Nesse padrão, é considerada apenas a propagação em ambientes com linha de visada (LOS - Line of Sight).

Em 2003, foi desenvolvido o padrão IEEE 802.16a, voltado para freqüências de 2 a $11 \mathrm{GHz}$. Com isso, permitiam-se situações sem linha de visada (NLOS - Non Line of Sight), com o uso de OFDM (Orthogonal Frequency Division Multiplexing) na camada física, suporte para OFDMA e com uma configuração MMDS (Multichannel Multipoint Distribution System). Neste mesmo ano, criou-se o IEEE 802.16b, para freqüências de 5 a $6 \mathrm{GHz}$, que trata de aspectos relacionados a qualidade de serviço (QoS - Quality of Service). Em julho de 2003, o IEEE 802.16c foi desenvolvido para atuar nas faixas de freqüências não licenciadas (de 10 a $66 \mathrm{GHz}$ ) e especificava perfis de sistema. 
Os padrões 802.16, 802.16a e 802.16c foram substituídos pelo IEEE 802.16-2004, também chamado de 802.16d, WiMAX fixo ou nômade. Um fato importante que marcou esse padrão foi a junção de duas tecnologias antes independentes (802.16 e ETSI HiperMAN). O IEEE 802.16d faz uso de OFDM com 256 portadoras, permite tanto FDD como TDD, utiliza as freqüências de 2 a 11 GHz (NLOS) e 10 a 66 GHz (LOS).

O padrão seguinte, IEEE 802.16e, finalizado em dezembro de 2005, foi desenvolvido para aplicações móveis. Também conhecido por WiMAX móvel, sua interface aérea adota OFDMA em ambientes NLOS, suportando larguras de banda escalonáveis de 1,25 a $20 \mathrm{MHz}$ e utiliza freqüências entre 2 e $6 \mathrm{GHz}$.

\subsection{Arquitetura de uma Rede WiMAX}

O desenvolvimento de uma rede banda larga com interoperabilidade como a desejada para o WiMAX não se resume apenas à definição das camadas PHY e MAC do sistema. Assim, o grupo NWG (Network Working Group) do WiMAX Forum estabeleceu um padrão de arquitetura fim a fim para a rede, mas que não foi incorporado ao padrão IEEE 802.16e.

A Figura 2.1 ilustra o modelo de referência de rede (NRM) definido. Esse modelo estabelece, basicamente, uma representação lógica da arquitetura de rede, identificando as entidades funcionais e os pontos de referência para interoperabilidade entre elas. 


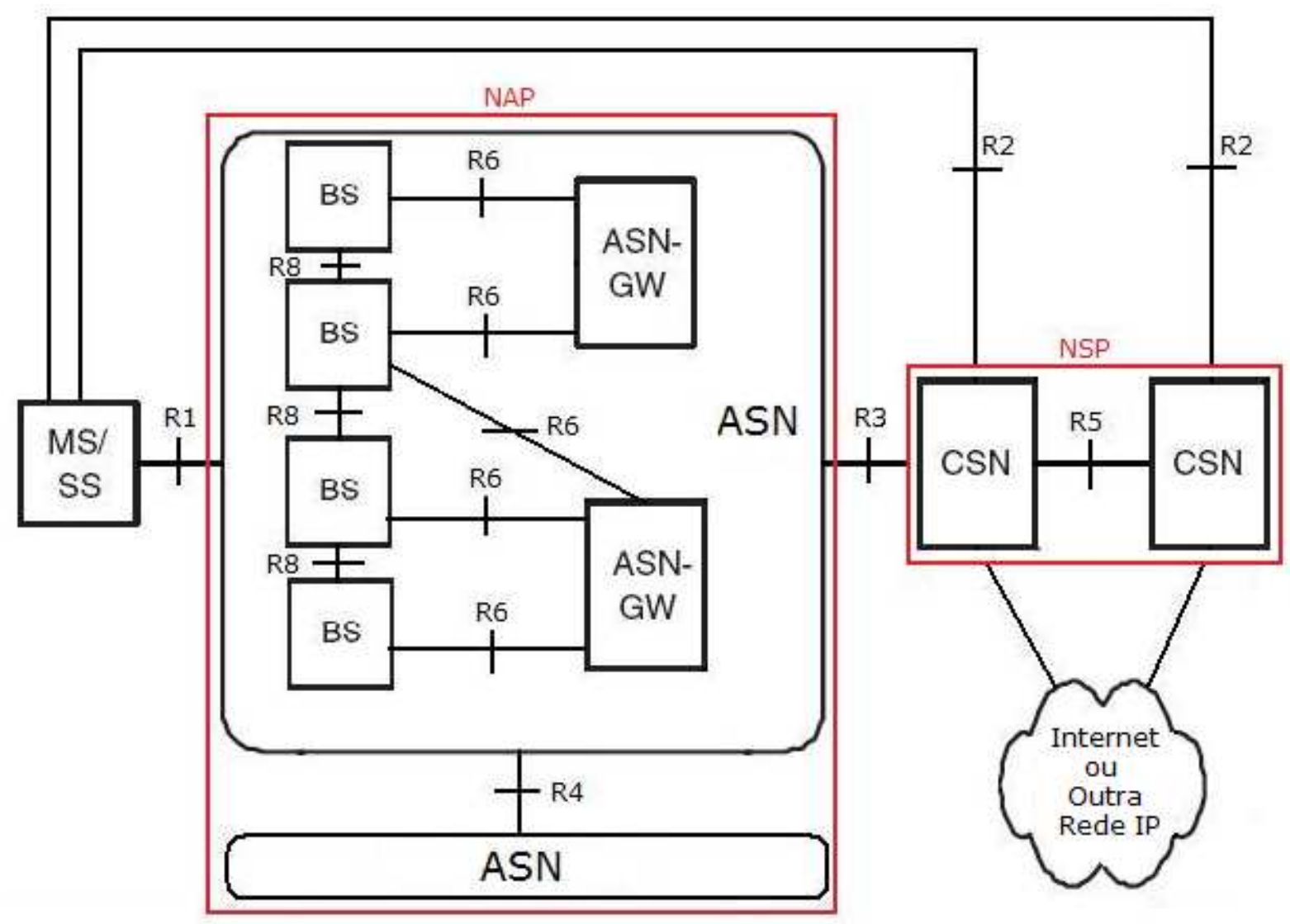

Figura 2.1: Modelo de Referência de Rede para WIMAX. Adaptado de [1]

O sistema é dividido em quatro partes lógicas:

- MS/SS (Mobile/Subscriber Station): compreende os equipamentos móveis dos usuários, responsáveis por acessar a rede WiMAX. Estes equipamentos podem ser terminais celulares, cartões PCMCIA para laptops, modems;

- ASN (Access Service Network): formado por uma ou mais estações-base (BS) e um ou mais ASN-Gateways. Em conjunto, formam o provedor de acesso à rede (NAP - (Network Access Provider), responsável pelo gerenciamento e pela alocação de recursos de rádio baseados em QoS, serviços relacionados à mobilidade (handovers, paging), entre outros.

- CSN (Connectivity Service Network): provê conectividade IP e todas as outras funções relacionadas ao core IP da rede, incluindo serviços de autenticação, autorização, faturamento e tunelamento para suporte ao roaming. Um ou mais CSNs formam o provedor de serviços de rede (NSP - Network Service Provider) 
A Tabela 2.1 apresenta uma descrição resumida dos pontos de referência destacados na Figura 2.1:

Tabela 2.1: Pontos de Referência do NRM

\begin{tabular}{|c|c|c|}
\hline Interface & $\begin{array}{c}\text { Entidades } \\
\text { Interconectadas }\end{array}$ & Descrição \\
\hline R1 & MS/ ASN & $\begin{array}{r}\text { Implementa as especificações da interface aérea, podendo } \\
\text { incluir protocolos de gerenciamento. }\end{array}$ \\
\hline R2 & MS/ CSN & $\begin{array}{c}\text { Apenas uma interface lógica, para autenticação, autorização e } \\
\text { gerenciamento de mobilidade e configuração do host IP. }\end{array}$ \\
\hline R3 & ASN/ CSN & $\begin{array}{c}\text { Auxilia as funções de AAA e de gerenciamento de } \\
\text { mobilidade, bem como os métodos de transporte de payload } \\
\text { (como tunelamento, por exemplo) entre as entidades às quais } \\
\text { está ligada. }\end{array}$ \\
\hline R4 & ASN/ ASN & $\begin{array}{c}\text { Engloba um conjunto de protocolos de controle e transporte } \\
\text { que coordenam a mobilidade dos usuários entre as ASNs, } \\
\text { sendo a única interface de interoperação entre ASNs . }\end{array}$ \\
\hline R5 & CSN/CSN & $\begin{array}{c}\text { Formada por um conjunto de protocolos de controle e } \\
\text { transporte para interoperação entre as redes caseira e visitada. }\end{array}$ \\
\hline R6 & BS/ ASN-GW & $\begin{array}{c}\text { Constituída por um conjunto de protocolos de controle e } \\
\text { transporte para comunicação entre a BS e o ASN-GW, } \\
\text { servindo também como condutor para troca de informações } \\
\text { sobre mudanças de estado na camada MAC entre BSs } \\
\text { vizinhas. }\end{array}$ \\
\hline
\end{tabular}

Também nas BSs, é feito um controle de potência por meio de algoritmos que informam ao SS o ajuste de potência necessário para que a conexão exista, de acordo com a distância entre o assinante e a estação. Dessa forma evita-se que haja desperdício de energia. 


\subsection{AAS (Advanced Antenna System)}

Em sistemas sem fio NLOS, principalmente, o sinal é refletido em diversos obstáculos que variam de acordo com o instante em que o sinal é enviado. Esse tipo de propagação é denominado propagação por multipercursos, e representa um desafio aos sistemas sem fio, por ocasionar degradação do sinal e atrasos relativos entre símbolos transmitidos em diferentes intervalos de tempo.

Como uma forma de driblar essas adversidades, são utilizadas sistemas de antenas AAS, que não só superam esses desafios, como são capazes de beneficiar-se da propagação por multipercursos, tornando o sistema mais robusto. O WiMAX permite o uso de antenas AAS nas BSs, sendo os principais tipos denominados Matriz A e Matriz B - em que não são utilizadas informações para estimação do canal - e beamforming - em que o transmissor utiliza informações sobre o canal de forma a otimizar a comunicação com o receptor em questão.

No esquema Matriz A, uma mesma informação é enviada em diversas antenas ortogonalmente, reduzindo a interferência entre elas e aumentando a probabilidade de o receptor distinguir os sinais. Com isso, existe uma grande chance de o receptor identificar qual dos sinais foi menos afetado pelo meio, melhorando a recepção. Esse esquema é fundamentalmente utilizado para aumento de cobertura do sistema.

No Matriz B, o sinal a ser transmitido é dividido e cada parte é enviada por uma das antenas, em uma mesma freqüência de operação. Várias antenas são utilizadas na recepção e os sinais provenientes de diversos percursos podem ser distinguidos. Essa forma de multiplexação espacial é capaz de fornecer incrementos de capacidade relevantes.

Outra opção por vezes adotada é a utilização de sistemas de feixes (beamformings) capazes de selecionar uma direção específica e suprimir interferências pelo ajuste da largura e do ângulo do seu diagrama de radiação (Figura 2.2). Com isso, aumenta-se o ganho do sinal e diminui-se a margem de desvanecimento, uma vez que os sinais provenientes de multipercursos que chegam aos lóbulos laterais e posteriores são suprimidos e reduzem o atraso por espalhamento. 


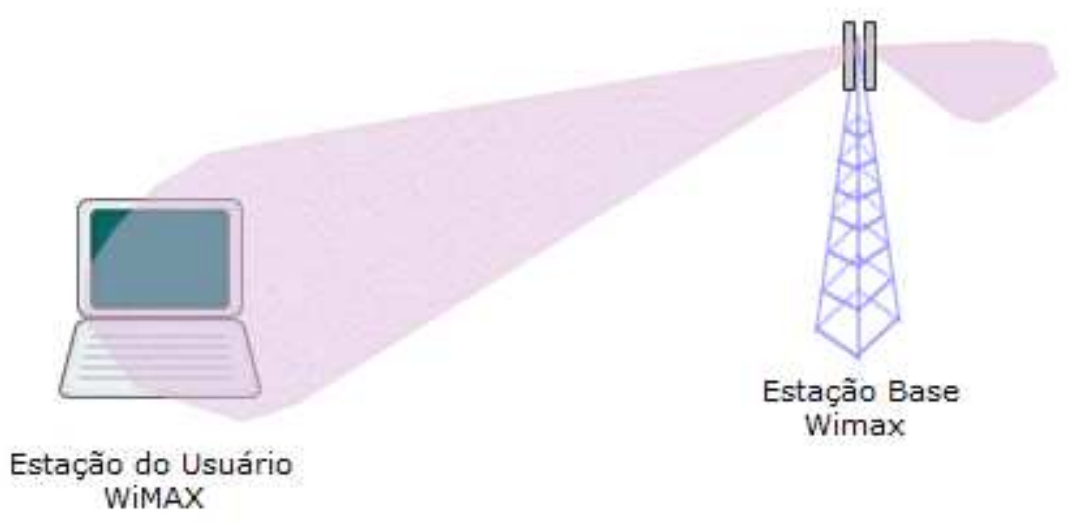

Figura 2.2: AAS em WiMAX

\subsection{OFDM (Multiplexação Ortogonal por Divisão de Freqüências)}

O atraso, $\tau$, introduzido pelo canal durante a transmissão de dados é o principal responsável pelo aparecimento da Interferência Intersimbólica (ISI) no sistema. Se esse atraso for maior que o período de duração de um símbolo, $T_{s}$, a taxa de erro de bit torna-se insuportável e a comunicação é interrompida.

Por natureza, sistemas que trabalham com altas taxas de frequiência e em ambientes NLOS, como o WiMAX, apresentam $\tau \gg T_{s}$, visto que o período de um símbolo é relativamente mais curto e o atraso, maior, pela propagação em longas distâncias. Assim, torna-se necessária a introdução de novas técnicas de transmissão e/ou recepção, para que essas dificuldades possam ser vencidas.

OFDM é uma técnica de modulação baseada na transmissão simultânea de várias portadoras, também chamadas subportadoras, e que tem encontrado cada vez mais aceitação em uma vasta gama de sistemas que oferecem altas taxas de transmissão de dados (LANs, DSL, DVB).

Essa técnica foi patenteada nos Estados Unidos da América (em 1966) pelo Bell Labs. Seu uso em comunicações móveis foi sugerido pela primeira vez em 1985 por Cimini. Em 1997, a ETSI (European Telecommunications Standards Institute) incluiu a técnica OFDM no seu padrão de Televisão Digital DVB-T (Digital Video Broadcasting - 
Terrestrial). Já em 1999, o IEEE considerou o OFDM para a camada física do padrão WiFi IEEE 816.11g.

A idéia básica de uma modulação com multiportadoras é, justamente, aumentar o período $T_{s}$, dividindo-se o sinal banda larga de entrada em $L$ seqüências de taxas menores. Esse conjunto é, então, enviado por $L$ subcanais, idealmente ortogonais entre si, de forma a manter a taxa total desejada. O transmissor de um sistema com multiportadoras pode ser ilustrado esquematicamente como mostrado na Figura 2.3.

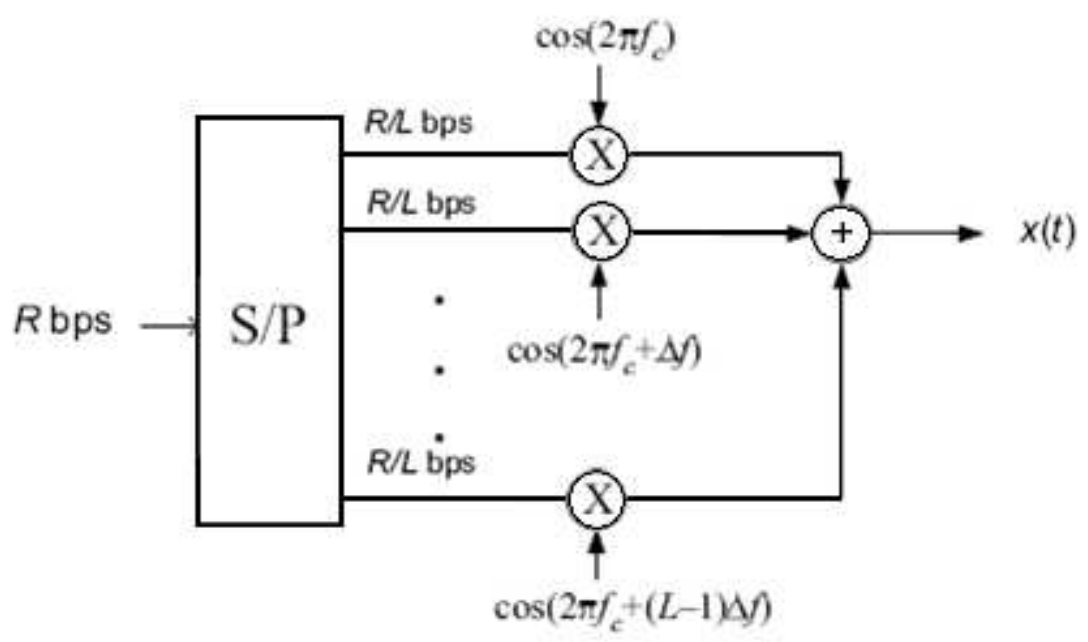

Figura 2.3: Transmissor Básico de Multiportadoras. Adaptado de [1]

O número total de subportadoras a ser utilizado é escolhido de forma que cada uma delas tenha uma banda inferior à banda de coerência do canal. Com isso, garante-se que cada subcanal experimentará um desvanecimento plano (flat fading), apesar de o canal como um todo ser seletivo em freqüência. Na Figura 2.4, pode-se observar um exemplo de um sinal recebido em um determinado instante, em que a banda de uma subportadora, $B / L$, é inferior à banda de coerência do canal, $B_{c}$. 


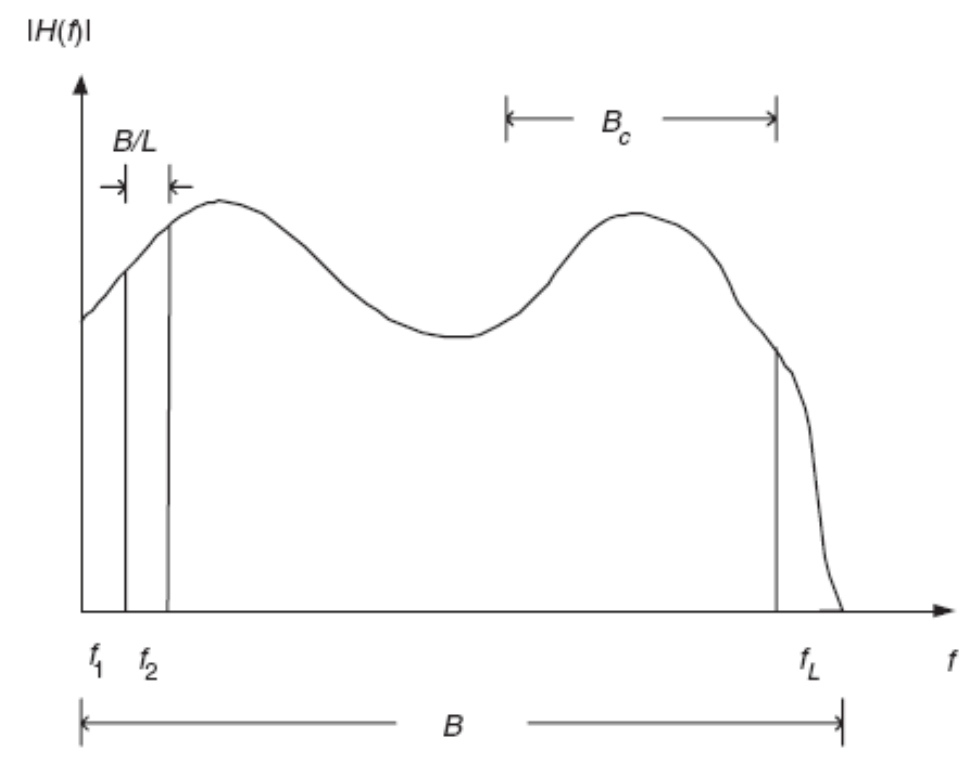

Figura 2.4: Sinal com Multiportadoras. Adaptado de [1]

Entretanto, para efeitos de implementação, o esquema descrito não é o mais adequado. A manutenção da ortogonalidade entre as subportadoras no receptor exigiria o emprego de filtros passa-baixas de alta qualidade e custo e, ainda nesse esquema, seriam necessários L unidades de rádio e conjuntos de demodulação. Além disso, as subportadoras deveriam ser transmitidas como um pulso retangular perfeito e ainda serem limitadas no tempo. Para contornar esses problemas, a técnica OFDM lança mão de alguns artifícios.

\subsubsection{Blocos de Transmissão Separados por Intervalos de Guarda}

O símbolo OFDM é formado pelo agrupamento de um conjunto $L$ de símbolos, sendo o período total, $T$, de um símbolo OFDM dado por:

$$
T=L T_{s}
$$

De forma a evitar que haja interferência entre símbolos, é introduzido um período, $T_{g}$, de guarda entre eles.

Assim, na recepção de uma seqüência de símbolos OFDM, desde que $T_{g}$ seja maior que $\tau$, a interferência intersimbólica será suprimida e restará apenas a interferência existente entre as portadoras no interior de um símbolo OFDM, como mostra a Figura 2.5. 


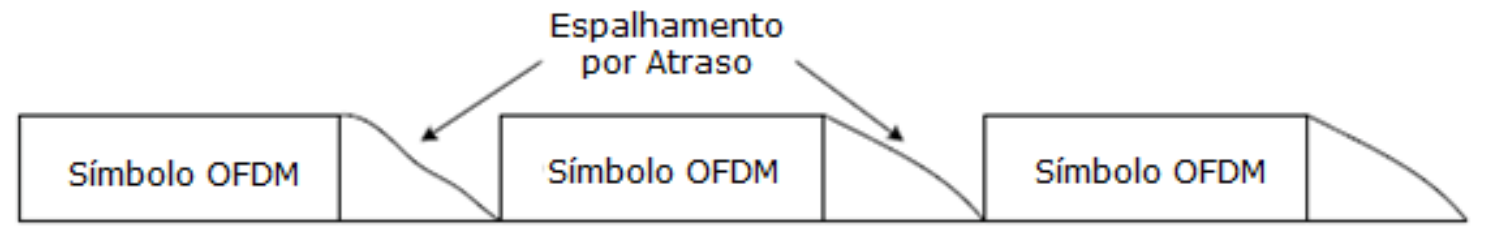

Figura 2.5: Período de Guarda entre Símbolos OFDM. Adaptado de [1]

\subsubsection{Transformada de Fourier Discreta (DFT - Discrete Fourier Transform)}

No intuito de remover a interferência existente no interior de cada símbolo OFDM, assume-se que o sinal recebido y[n], após passar por um canal de função de transferência $\mathrm{h}[\mathrm{n}]$, pode ser computado por meio de uma convolução circular [1]:

$$
y[n]=h[n] \otimes x[n]=x[n] \otimes h[n]
$$

Sendo $\mathrm{x}[\mathrm{n}]$ o sinal transmitido

Assim, tomando-se a DFT do sinal de saída y[n], tem-se:

$$
\operatorname{DFT}\{y[n]\}=\operatorname{DFT}\{h[n] \otimes x[n]\} \rightarrow Y[m]=H[m] X[m]
$$

Assim, o sinal no domínio da freqüência, $\mathrm{Y}[\mathrm{m}]$, é dado por uma simples multiplicação entre o sinal transmitido e a função de transferência do canal. Mesmo aparentemente simples, essa fórmula caracteriza um canal livre de ISI.

Para recuperação do símbolo inicial, sendo conhecida a resposta em freqüência do canal $\mathrm{H}[\mathrm{m}]$, faz-se:

$$
\hat{X}[m]=\frac{Y[m]}{H[m]}
$$

Apesar de $\hat{X}[m]$ continuar sendo uma estimativa - devido a ruídos aditivos, interferência co-canal, estimativa imperfeita do canal - em princípio a ISI é mitigada. 
Pode-se simular uma convolução circular pela adição de um prefixo cíclico, $\mathrm{CP}$, antes do símbolo OFDM. Esse prefixo deve ser construído a partir da parte final do símbolo em questão [1]:

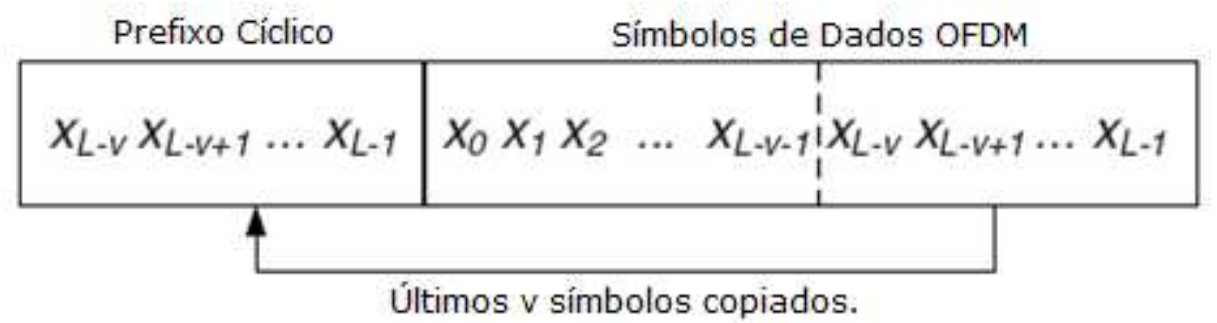

Figura 2.6: Prefixo Cíclico no símbolo OFDM. Adapatado de [1]

Apesar de relativamente simples, o prefixo cíclico carrega a desvantagem de desperdiçar banda e potência do sistema de transmissão. Gasta-se parte da banda disponível para transmitir dados que carregam informação repetida e a potência perdida nesse processo é particularmente nociva para sistemas sem fio, por aumentar a interferência entre usuários distintos.

Uma forma de diminuir os prejuízos causados pelo gasto de potência é a utilização de um prefixo nulo, a chamada banda de guarda nula. No receptor, a parte final do símbolo recebido é adicionada ao início do mesmo, recriando o efeito do prefixo cíclico (Figura 2.6). Tal esquema, entretanto, aumenta a potência gasta pelo receptor - visto que a parte final do símbolo não pode ser ignorada -, além de adicionar ao sinal o ruído que fora incorporado à parte final do símbolo, como mostrado na Figura 2.7.

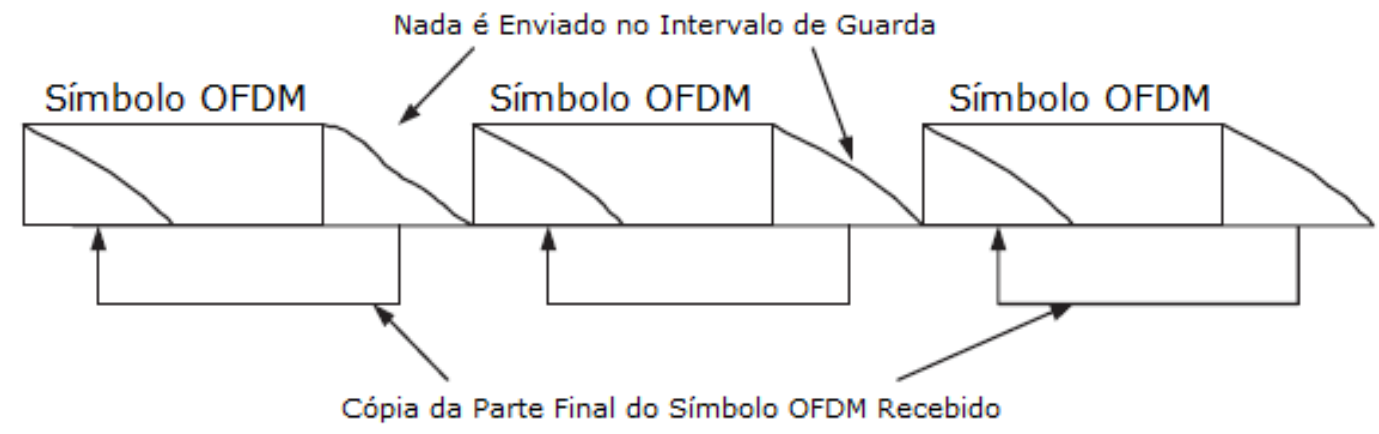

Figura 2.7: Sinal OFDM com Banda de Guarda Nula. Adaptado de [1] 
Em sistemas que implementam a técnica OFDM, o operador FFT (Fast Fourier Transform) é o algoritmo que permite que a DFT seja computada com mais rapidez. A FFT trabalha com qualquer número, $N$, de subportadoras, porém é simplificada quando $\mathrm{N}$ é uma potência de 2 .

O operador IFFT (Inverse Fast Fourier Transform) realiza a operação reversa. Uma IFFT de magnitude $N$, aplicada a $N$ símbolos, gera um sinal OFDM, onde cada símbolo é transmitido em uma das $N$ subportadoras ortogonais. Os referidos símbolos são símbolos de dados do tipo BPSK, QPSK, 16QAM ou 64 QAM. A Figura 2.8 exemplifica esse esquema.

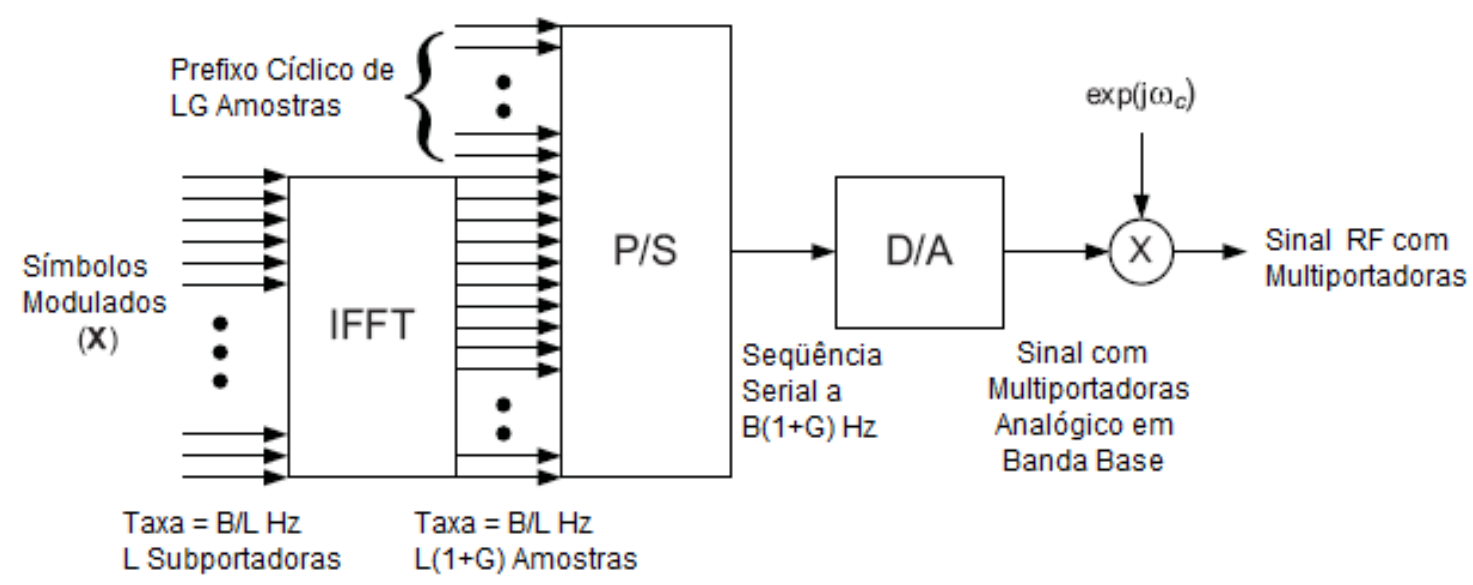

Figura 2.8: Formação do Sinal OFDM. Adaptado de [1]

O parâmetro $G$ da figura é definido, em WiMAX, como a razão $T_{g} / T_{d}$, sendo $T_{d} \mathrm{O}$ período do símbolo OFDM excluindo-se o prefixo cíclico.

Se a duração de um símbolo de dados modulado transmitido é $T_{d}$, então $T_{d}=1 / \Delta f$, onde $\Delta f$ é a largura de banda das freqüências ortogonais, que também pode ser visto como a distância entre os máximos de duas portadoras OFDM adjacentes (Figura 2.9). 

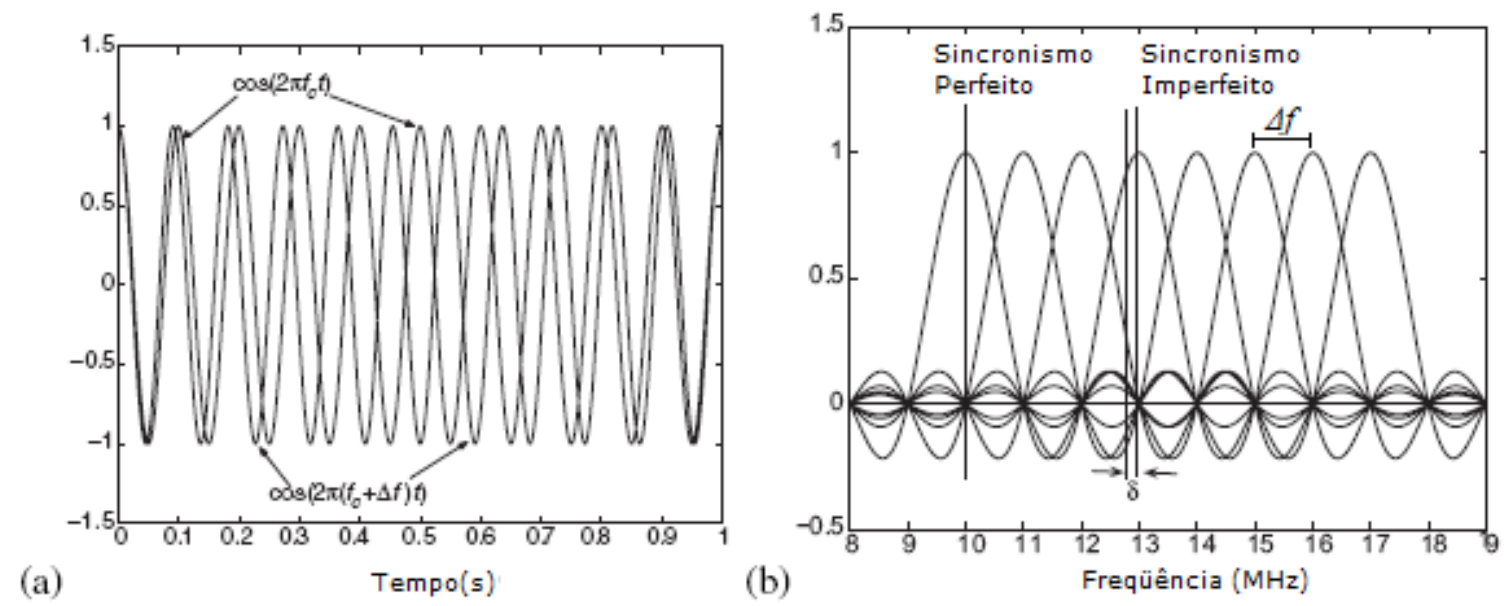

Figura 2.9: Representação de um Símbolo OFDM nos Domínios do Tempo (a) e da Freqüência (b).

Adaptado de [1]

Na Figura 2.9, observa-se também a ortogonalidade existente entre as portadoras de um símbolo OFDM. No ponto em que uma delas alcança seu valor máximo, as demais se anulam. Na realidade, a duração de um símbolo OFDM real é um pouco maior, devido a presença do prefixo cíclico (CP).

O elevado grau de eficiência espectral alcançado pela técnica OFDM carrega o ônus de ser bastante sensível a offsets de freqüência. Quaisquer desvios nas subportadoras ilustradas na Figura 2.9 ocasiona a sobreposição das mesmas nos pontos em que elas deveriam se anular.

Assim, para que o sincronismo em freqüência seja mantido, utiliza-se a transmissão de portadoras piloto. Sendo conhecida a informação transmitida nessas portadoras, é relativamente fácil estabelecer sincronismo tanto na frequiência como no tempo, pela comparação do que deveria ter sido recebido com o que efetivamente chegou ao receptor. As portadoras piloto também desempenham papel fundamental na estimação do comportamento do canal, entretanto o preço a ser pago pela transmissão dessas portadoras é uma redução da capacidade do sistema.

Além das subportadoras que carregam informação e das piloto, existem ainda outros tipos de subportadoras em um símbolo OFDM, a saber (Figura 2.10):

- Subportadora nula - não transmite informação alguma, sendo utilizada como banda de guarda; 
- Subportadora DC - é a subportadora cuja freqüência é igual à frequiência central do canal.

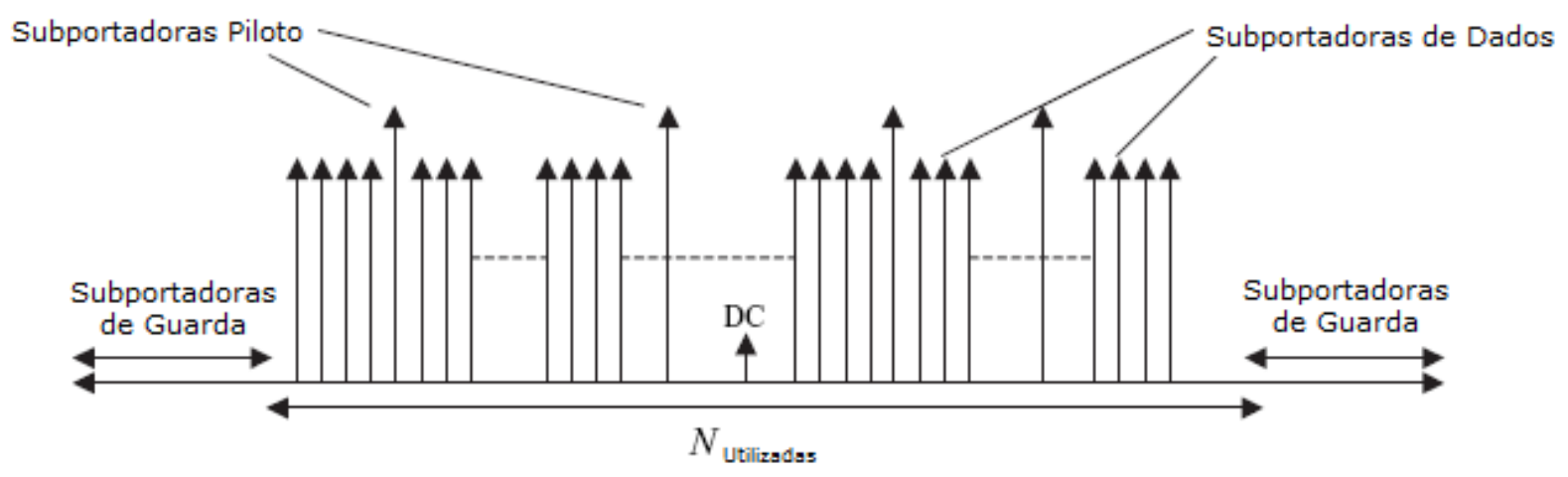

Figura 2.10: Subportadoras OFDM. Adaptado de [2]

Outro parâmetro importante de um sistema OFDM é a razão de potência de pico/ potência média (Peak-to-Average Power Ratio - PAPR). Uma transmissão OFDM pode ter uma alta PAPR quando comparado a uma transmissão Single Carrier, visto que ela resulta da soma de vários sinais de banda estreita (Figura 2.9(a)). Esse alto valor de PAPR alcançado pelo sistema - diretamente proporcional ao número de subportadoras - reduz a eficiência e, por isso, aumenta o custo com amplificadores de potência RF [1].

Várias soluções são propostas para reduzir o PAPR, geralmente incluindo o uso de algumas subportadoras para este propósito. Estas subportadoras deixam de ser utilizadas para transmissão de dados, reduzindo-se, assim, tanto a potência, quanto a taxa de transmissão.

\subsection{OFDMA (Múltiplo Acesso Ortogonal por Divisão em Freqüiências)}

No sistema WiMAX, as subportadoras disponíveis podem ser divididas em vários grupos denominados subcanais. O padrão 802.16 admite que seja implementada subcanalização no OFDM apenas no uplink e define 16 subcanais para essa modalidade. Podem ser alocados 1, 2, 4, 8 ou todos os subcanais para um usuário, dessa forma, a SS pode transmitir utilizando apenas uma fração da banda alocada para ela, economizando a bateria disponível do equipamento. 
No OFDMA, a subcanalização é aceita em ambos os sentidos, downlink e uplink, e o subcanal forma a menor unidade de recurso em freqüência que pode ser alocada pela BS. Dessa forma, subcanais diferentes podem ser alocados para usuários distintos, constituindo um mecanismo de múltiplo acesso denominado OFDMA. Estratégias de múltiplo acesso têm como finalidade principal prover canais de comunicação não interferentes aos diversos usuários ativos, de forma a possibilitar que a banda disponível seja suficiente para atendêlos com altas taxas de transferência e baixa latência.

O OFDMA é essencialmente uma junção entre os esquemas FDMA e TDMA: são dinamicamente designadas subportadoras aos usuários (FDMA) em diferentes slots de tempo (Figura 2.11).

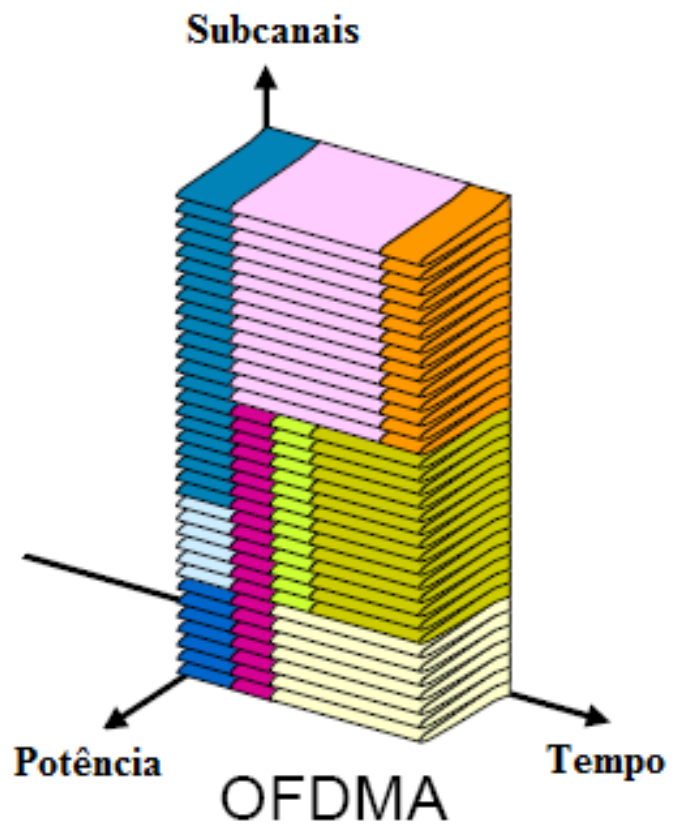

Figura 2.11: OFDMA

O múltiplo acesso é realizado digitalmente e é anterior à manipulação IFFT, proporcionando uma alocação dinâmica e eficiente da banda por meio de algoritmos de alocação sofisticados. Outra vantagem dessa tecnologia é a redução da potência transmitida e do problema relacionado ao PAPR [1]. Como a banda total é repartida entre várias SSs de uma célula, cada SS transmite com uma PAPR relativamente menor - visto que ela é proporcional ao número de subportadoras - e com uma potência bem inferior àquela que seria necessária para transmitir pela banda total. 
A Tabela 2.2 resume alguns dos principais parâmetros dos padrões 802.16:

Tabela 2.2: Parâmetros definidos para o WiMAX

\begin{tabular}{|c|c|c|c|c|c|}
\hline Parâmetro & WiMAX Fixo & \multicolumn{4}{|c|}{ WiMAX Móvel (OFDMA-PHY) } \\
\hline Tamanho da FFT & 256 & 128 & 512 & 1024 & 2048 \\
\hline $\begin{array}{l}\text { Número de subportadoras } \\
\text { de dados }\end{array}$ & 192 & 72 & 360 & 720 & 1440 \\
\hline $\begin{array}{l}\text { Número de subportadoras } \\
\text { piloto }\end{array}$ & 8 & 12 & 60 & 120 & 240 \\
\hline $\begin{array}{c}\text { Número de subportadoras } \\
\text { de guarda }\end{array}$ & 56 & 44 & 92 & 184 & 368 \\
\hline Prefixo Cíclico $(\mathrm{Tg} / \mathrm{Tb})$ & \multicolumn{5}{|c|}{$1 / 32,1 / 16,1 / 8,1 / 4$} \\
\hline $\begin{array}{c}\text { Taxa de Sobreamostragem } \\
\qquad(\mathrm{Fs} / \mathrm{BW})\end{array}$ & \multicolumn{5}{|c|}{$\begin{array}{l}\text { Depende da largura de banda: 7/6 para 256 OFDM, } \\
8 / 7 \text { para múltiplos de } 1,75 \mathrm{MHz} \text { e bandas não } \\
\text { especificadas, e } 28 / 25 \text { para múltiplos de } 1,25 / 1,5 / 2 / \\
2,75 \mathrm{MHz} \\
\end{array}$} \\
\hline $\begin{array}{c}\text { Largura de banda do canal } \\
(\mathrm{MHz})\end{array}$ & 3,5 & 1,25 & 5 & 10 & 20 \\
\hline $\begin{array}{c}\text { Espaçamento em frequiência } \\
\text { entre as subportadoras }\end{array}$ & 15,625 & \multicolumn{4}{|c|}{10,94} \\
\hline Tempo útil de símbolo ( $\mu \mathrm{s})$ & 64 & \multicolumn{4}{|c|}{91,4} \\
\hline $\begin{array}{c}\text { Tempo de guarda } \\
\text { assumindo } 12,5 \%(\mu \mathrm{s})\end{array}$ & 8 & \multicolumn{4}{|c|}{11,4} \\
\hline $\begin{array}{c}\text { Duração do símbolo OFDM } \\
(\mu \mathrm{s})\end{array}$ & 72 & \multicolumn{4}{|c|}{102,9} \\
\hline $\begin{array}{l}\text { Número de símbolos OFDM } \\
\text { em um frame de } 5 \mathrm{~ms}\end{array}$ & 69 & \multicolumn{4}{|c|}{48} \\
\hline
\end{tabular}

Visando maximizar o desempenho do sistema, a tecnologia OFDMA faz uso de algumas técnicas/princípios para que as condições favoráveis do canal sejam exploradas na alocação de recursos: as técnicas de permutação e a diversidade multiusuário. 


\subsubsection{Permutação de subportadoras em WiMAX OFDMA PHY}

A distribuição de subportadoras pelos subcanais é um processo complexo e que envolve uma gama de fatores, como mobilidade, critérios de otimização e suporte a antenas do tipo AAS.

Visando a obtenção de uma distribuição eficiente, diversos modos de permutação foram padronizados por [3]. Esses modos são divididos em duas famílias [2]:

- Permutações de Diversidade (Distribuídas): baseiam-se em algoritmos pseudoaleatórios para distribuição das subportadoras entre os subcanais e comportam modos de permutação FUSC (Full Usage of Subchannels), PUSC (Partial Usage of Subchannels), OPUSC (Optional PUSC), OFUSC (Optional FUSC) e TUSC (Tile Usage of Subchannels). As permutações distribuídas diminuem a probabilidade de se utilizar subportadoras em setores adjacentes; apesar de dificultarem a estimação do canal, por distribuírem as subportadoras no espectro.

- Permutações Contínuas (Adjacentes): consideram grupos contínuos de subportadoras sobre o subcanal. Dentre elas, está o modo de permutação AMC (Adaptative Modulation and Coding), que permite a escolha da faixa de melhor situação do espectro. São mais sucessíveis a interferências de canais adjacentes e podem gerar situações em que determinados usuários recebem o sinal degradado em relação aos demais, devido ao desvanecimento seletivo em freqüência.

São definidas zonas de permutação a partir de um conjunto de símbolos OFDM adjacentes, seja no downlink ou no uplink. Nessas zonas, são utilizados os mesmos modos de permutação.

Será dado um foco especial aos modos de permutação PUSC e AMC, por sua importância nos assuntos a serem tratados nos capítulos 3 e 4 .

\subsubsection{Permutações de Diversidade - PUSC}

No modo de permutação PUSC, o princípio de alocação de subportadoras em um subcanal segue os seguintes passos:

1) Divisão de subportadoras em clusters. 
Após a remoção das subportadoras de guarda e DC, as subportadoras restantes são consideradas úteis (subportadoras piloto e de dados). A partir das subportadoras úteis são selecionados grupos de 14 subportadoras adjacentes, chamados clusters.

Um sistema OFDMA com 1024 subportadoras, por exemplo, possui 840 subportadoras úteis (720 subportadoras de dados +120 subportadoras piloto) [3]. Com isso, no caso, obtém-se um total de 60 clusters, que recebem uma Numeração Física (PN) variando de 0 a 59.

2) Renumeração dos clusters

Após a etapa de enumeração dos clusters, é criada uma nova numeração, denominada Numeração Lógica (LN), que também varia de 0 a 59, para o caso de 1024 subportadoras. Para isso, utiliza-se um algoritmo pseudo-randômico, empregando-se a base de permutação, denominada DL_PermBase - um inteiro que varia de 0 a 31. Segundo [3], a numeração lógica do cluster é obtida da seguinte forma:

\section{LogicalCluster \\ $=\left\{\begin{array}{l}\text { Re numberingSequence }(\text { PhyicalCluster }) \\ \text { Re numberingSequence }\left((\text { PhysicalCluster })+13 \cdot D L_{-} \text {PermBase }\right) \bmod \text { Nclusters }\end{array}\right.$}

Onde o Renumbering Sequence (i) é a i-ésima entrada do seguinte vetor:

$[6,48,37,21,31,40,42,56,32,47,30,33,54,18,10,15,50,51,58,46,23,45,16,57$, $39,35,7,55,25,59,53,11,22,38,28,19,17,3,27,12,29,26,5,41,49,44,9,8,1,13$, $36,14,43,2,20,24,52,4,34,0]$.

Como para 1024-FFT, $N_{\text {clusters }}=60$, o vetor acima possui 60 elementos.

3) Alocação dos clusters em grupos

Após a renumeração dos clusters, os mesmos são alocados em grupos. Para o caso que esta sendo analisado, os 60 clusters são divididos em 6 grupos da seguinte forma (Tabela 2.3):

Tabela 2.3: Grupos de Clusters

\begin{tabular}{|l|l|}
\hline Grupo & Índice do \\
\hline
\end{tabular}




\begin{tabular}{|l|l|}
\hline & Cluster \\
\hline 0 & LN $0-11$ \\
\hline 1 & LN $12-19$ \\
\hline 2 & LN20 - 31 \\
\hline 3 & LN32-39 \\
\hline 4 & LN $40-51$ \\
\hline 5 & LN52-59 \\
\hline
\end{tabular}

4) Distribuição de subportadoras sobre o subcanal

O subcanal é formado por 24 subportadoras de dados e 4 subportadoras piloto. Cada grupo de clusters é usado separadamente para a formação dos subcanais, ou seja, um subcanal não possuirá subportadoras de grupos diferentes e todas as subportadoras de um subcanal pertencem a um mesmo símbolo OFDMA.

As subportadoras piloto são alocadas, primeiramente, de acordo com a paridade do símbolo OFDMA. A Figura 2,12 mostra como esta alocação deve ser feita:

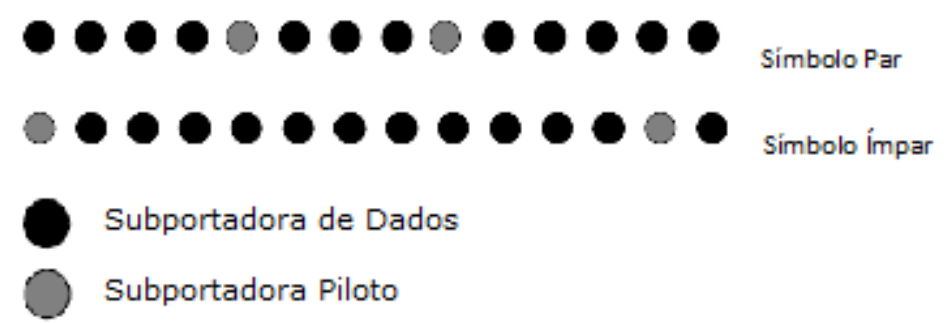

Figura 2.12: Alocação de subportadoras piloto. Adaptado de [2]

As subportadoras de dados são, então, renumeradas de acordo com a paridade do grupo utilizado para montar o subcanal. Para grupos com numeração par, as subportadoras de dados são numeradas de 0 a 143. Para grupos com numeração ímpar, as subportadoras de dados são numeradas de 0 a 95. A fórmula a seguir é, então, utilizada para alocação dessas subportadoras:

$\operatorname{subportadora}(k, s)=N_{\text {subcanais }} \cdot n_{k}+\left\{p_{s}\left[n_{k} \bmod N_{\text {subcanais }}\right]+D L_{-}\right.$PermBase $\} \bmod N_{\text {subcanais }}$

Onde $N_{\text {subcanais }}$ corresponde ao número de subcanais no grupo (igual a 6 no caso de grupos com numeração impar e 4 para grupos com numeração par); $\operatorname{subcanais(~} k, s)$ é o 
índice lógico da subportadora $k$ (variando de 0 a 23 , no subcanal s); s é o índice do subcanal (variando de 0 a 29) e ${ }^{n_{k}}$ é definido da seguinte forma:

$$
n_{k}=(k+13 s) \bmod N_{\text {subportadoras }}
$$

Onde $N_{\text {subportadoras }}$ é o número de subportadoras de dados alocadas para um subcanal (24 subportadoras para o caso em análise); $\mathrm{p}_{\mathrm{s}}[\mathrm{j}]$ é a série obtida rotacionando-se as bases de permutação ciclicamente para a esquerda s vezes (PermutationBase6[3,2,0,4,5,1] para grupos com numeração par e PermutationBase4[3,0,2,1] para grupos com numeração ímpar).

A Tabela 2.4 especifica os subcanais correspondentes aos grupos, respectivamente.

Tabela 2.4: Faixa de Subcanais para Grupos de Subportadoras

\begin{tabular}{|c|c|}
\hline $\begin{array}{c}\text { Grupo de } \\
\text { Subportadoras } \\
\text { Principal }\end{array}$ & $\begin{array}{c}\text { Faixa de } \\
\text { Subcanais }\end{array}$ \\
\hline 0 & $0-5$ \\
\hline 1 & $6-9$ \\
\hline 2 & $10-15$ \\
\hline 3 & $16-19$ \\
\hline 4 & $20-25$ \\
\hline 5 & $26-29$ \\
\hline
\end{tabular}

A Figura 2.13 resume os passos de formação do subcanal no modo de permutação PUSC, para o caso de 1024 subportadoras e base de permutação DL_PermBase igual a 5. 


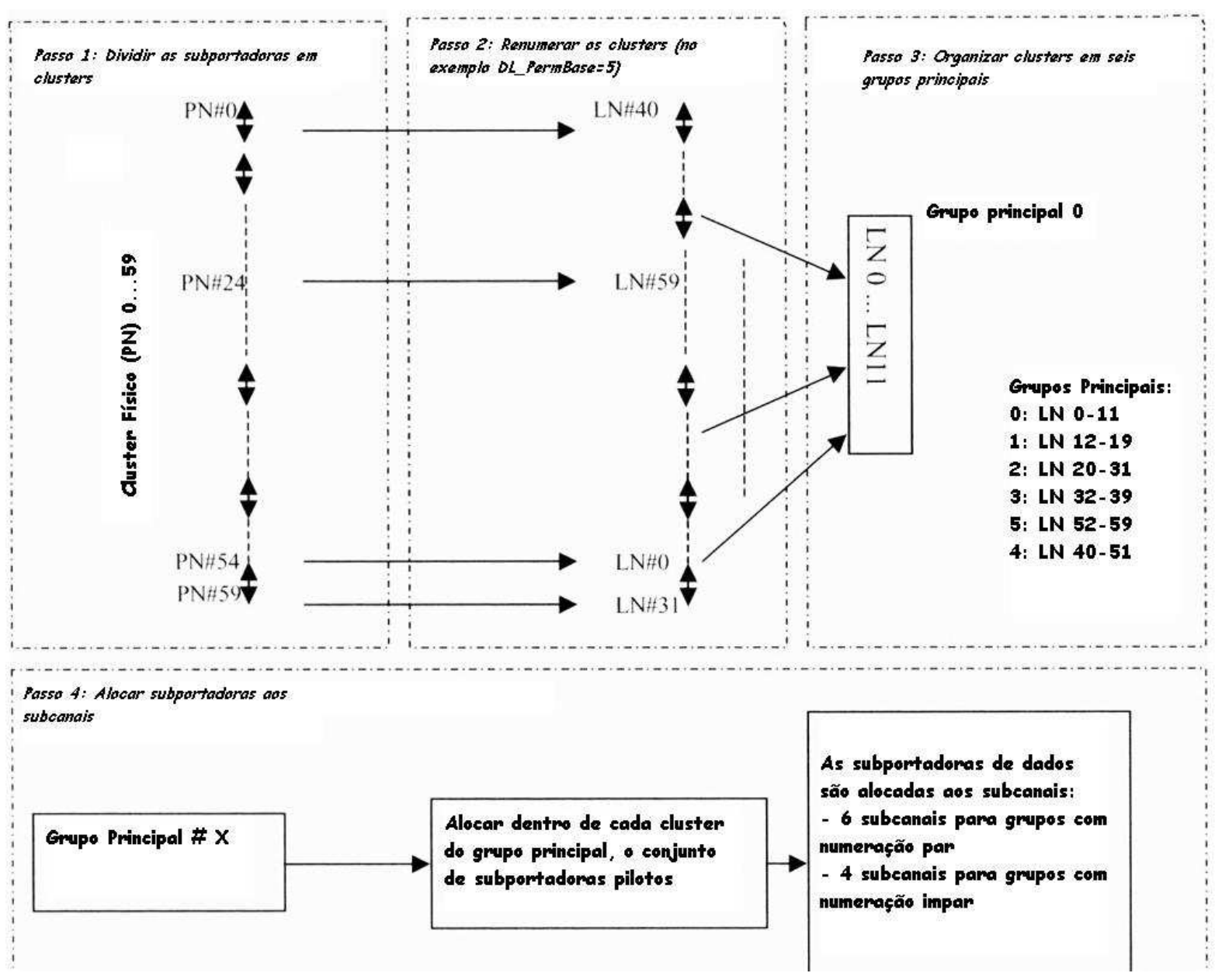

Figura 2.13: Modo de Permutação PUSC

\subsubsection{Permutações Contínuas - Modulação e Codificação Adaptativas (AMC)}

O sistema WiMAX utiliza os esquemas de modulação e codificação adaptativas (Tabela 2.5), no intuito de tirar vantagem das flutuações do canal.

Tabela 2.5: Esquemas de Modulação e codificação suportados pelo WiMAX

\begin{tabular}{|c|c|c|}
\hline & Downlink & Uplink \\
\hline Modulação & $\begin{array}{c}\text { BPSK, QPSK, 16-QAM, 64-QAM; } \\
\text { sendo BPSK opcional }\end{array}$ & $\begin{array}{c}\text { BPSK; QPSK; 16-QAM; 64-QAM } \\
\text { opcional }\end{array}$ \\
\hline Codificação & $\begin{array}{l}\text { Obrigatório: Códigos convolucionais a } \\
\text { taxas 1/2, 2/3, 3/4, 5/6. Opcionais: } \\
\text { CTC (Convolutional Turbo Codes) a } \\
\text { taxas } 1 / 2,2 / 3,3 / 4,5 / 6 \text {; códigos de } \\
\text { repetição a taxas 1/2, 1/3, 1/6; LDPC; } \\
\text { RS-Codes para OFDM-PHY. }\end{array}$ & $\begin{array}{l}\text { Obrigatório: Códigos convolucionais } \\
\text { a taxas 1/2, 2/3, 3/4, 5/6. Opcionais: } \\
\text { CTC (Convolutional Turbo Codes) a } \\
\text { taxas 1/2, 2/3, 3/4, 5/6; códigos de } \\
\text { repetição a taxas 1/2, 1/3, 1/6; LDPC. }\end{array}$ \\
\hline
\end{tabular}


A idéia básica é transmitir a maior taxa de dados possível, quando as condições do canal são favoráveis; e reduzir essa taxa se o canal não estiver muito propício à propagação, evitando uma perda de pacotes excessiva. Assim, taxas menores de transmissão são alcançadas utilizando-se constelações menores, como QPSK, e códigos de correção de erro mais robustos, como a taxa 1/2 convolucional; enquanto as maiores utilizam constelações mais espaças e códigos de erro menos robustos, como 64-QAM com taxa 3/4 convolucional [1].

Existem diversas configurações possíveis, formadas pela combinação de códigos de correção de erro e modulações. Entretanto, o padrão 802.16e estabelece a utilização de apenas uma fração delas. Cada uma dessas configurações recebe o nome de burst profile (Tabela 2.6). Na versão 802.16d, é também aceita a modulação BPSK.

Tabela 2.6: Burst Profiles para Downlink e Uplink no padrão 802.16e. Adaptado de [1]

\begin{tabular}{|c|c|c|c|c|c|c|c|}
\hline & Formato & & Formato & & Formato & & Formato \\
\hline 0 & QPSK CC $\mathrm{CC}^{\mathrm{a}} \mathrm{I} / 2$ & 14 & Reserved & 28 & 64 QAM ZCC $3 / 4$ & 42 & 64 QAM LDPC $2 / 3$ \\
\hline 1 & QPSK CC $3 / 4$ & 15 & QPSK CTC $^{b} 3 / 4$ & 29 & QPSK LDPC $1 / 2$ & 43 & 64 QAM LDPC $3 / 4$ \\
\hline 2 & $16 \mathrm{QAM} \mathrm{CC} \mathrm{I/2}$ & 16 & 16 QAM CTC $1 / 2$ & 30 & QPSK LDPC $2 / 3$ & $44^{c}$ & QPSK CC $1 / 2$ \\
\hline 3 & 16 QAM CC $3 / 4$ & 17 & 16 QAM CTC $3 / 4$ & 31 & QPSK LDPC $3 / 4$ & $45^{\mathrm{c}}$ & QPSK CC $3 / 4$ \\
\hline 4 & 64 QAM CC $1 / 2$ & 18 & 64 QAM CTC $1 / 2$ & 32 & 16 QAM LDPC $1 / 2$ & $46^{c}$ & $16 \mathrm{QAM} \mathrm{CC} 1 / 2$ \\
\hline 5 & 64 QAM CC $2 / 3$ & 19 & 64 QAM CTC $2 / 3$ & 33 & 16 QAM LDPC $2 / 3$ & $47^{\circ}$ & 16 QAM CC $3 / 4$ \\
\hline 6 & 64 QAM CC $3 / 4$ & 20 & 64 QAM CTC $3 / 4$ & 34 & 16 QAM LDPC 3/4 & $48^{\circ}$ & 64 QAM CC $2 / 3$ \\
\hline 7 & QPSK BTC $1 / 2$ & 21 & 64 QAM CTC $5 / 6$ & 35 & 64 QAM LDPC 1/2 & $49^{\circ}$ & 64 QAM CC $3 / 4$ \\
\hline 8 & QPSK BTC 3/4 & 22 & QPSK ZCC ${ }^{\mathrm{e}} 1 / 2$ & 36 & 64 QAM LDPC $2 / 3$ & 50 & QPSK LDPC 5/6 \\
\hline 9 & $\begin{array}{l}\text { 16 QAM BTC } \\
3 / 5\end{array}$ & 23 & QPSK ZCC $3 / 4$ & 37 & 64 QAM LDPC 3/4 & 51 & 16 QAM LDPC $5 / 6$ \\
\hline 10 & $\begin{array}{l}\text { 16 QAM BTC } \\
4 / 5\end{array}$ & 24 & $16 \mathrm{QAM} \mathrm{ZCC} 1 / 2$ & $38^{\mathrm{f}}$ & QPSK LDPC $2 / 3$ & 52 & 64 QAM LDPC 5/6 \\
\hline 11 & $\begin{array}{l}64 \text { QAM BTC } \\
5 / 8\end{array}$ & 25 & 16 QAM ZCC $3 / 4$ & $39^{f}$ & QPSK LDPC $3 / 4$ & & $>52$ reserved \\
\hline 12 & $\begin{array}{l}64 \text { QAM BTC } \\
4 / 5\end{array}$ & 26 & 64 QAM ZCC $1 / 2$ & $40^{f}$ & 16 QAM LDPC $2 / 3$ & & \\
\hline 13 & QPSK CTC $1 / 2$ & 27 & $64 \mathrm{QAM} Z \mathrm{ZCC} 2 / 3$ & $41^{f}$ & 16 QAM LDPC $3 / 4$ & & \\
\hline
\end{tabular}
a. Convolutional Code
b. Convolutional Turbo Code
c. Utilizam o Interleaving opcional com os $\mathrm{CC}$ 

d. $\quad$ Block Turbo Codes
e. $\quad$ CC terminado em zeros
f. Utilizam o código B para o LDPC

Esquematicamente, pode-se entender os sistemas AMC a partir da Figura 2.14:

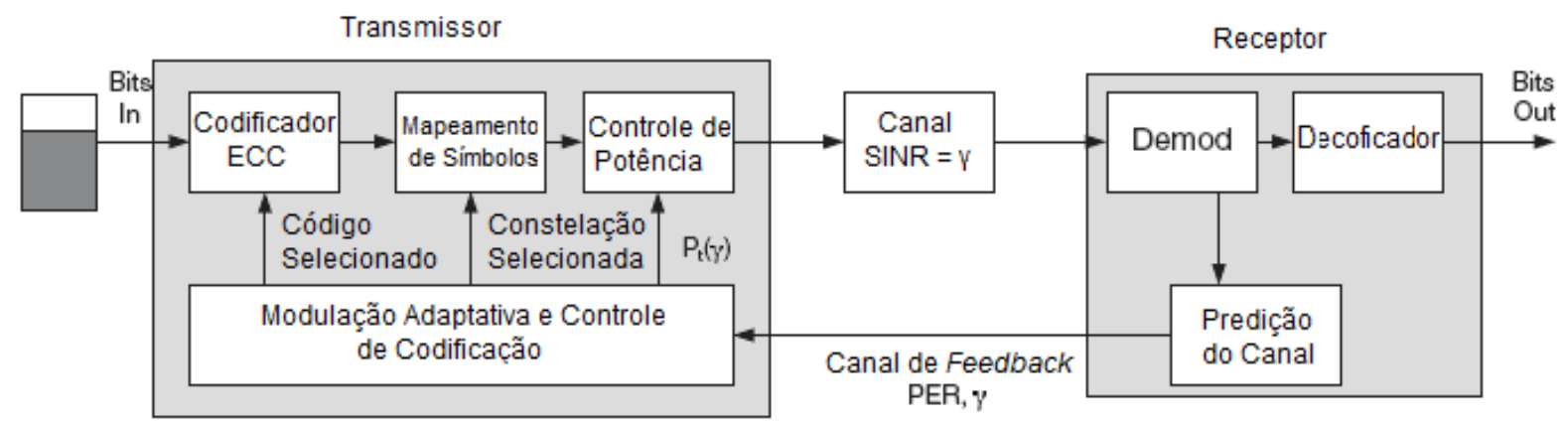

Figura 2.14: Diagrama de Blocos de um Sistema AMC. Adaptado de [1]

Da figura, nota-se o papel fundamental do canal de feedback, visto que é através dele que o transmissor recebe informações a respeito da CINR do canal - parâmetro de decisão do perfil de modulação e codificação a ser adotado para o usuário. A CINR do canal é obtida como:

$$
C I N R_{\text {recebida }}=\operatorname{Pot}_{\text {transmitida }} \cdot \operatorname{CINR}_{\text {canal }} \rightarrow C I N R_{\text {canal }}=\frac{\text { CINR }_{\text {recebida }}}{\text { Pot }_{\text {transmitida }}}
$$

A partir dos burst profiles, são disponibilizados diversos valores de eficiência espectral, calculados pela fórmula [1]:

$$
T[\text { bps } / H z]=(1-B L E R) r \log _{2}(M)
$$

Onde BLER (Block Error Rate) avalia a quantidade de blocos que apresentam pelo menos uma ocorrência de erro em relação à quantidade total de blocos recebida, $r \leq 1$ é a taxa de codificação e $M$ é o número de pontos da constelação. A relação entre $T$ e CINR, para os diversos perfis, é resumida na Figura 2.15. 


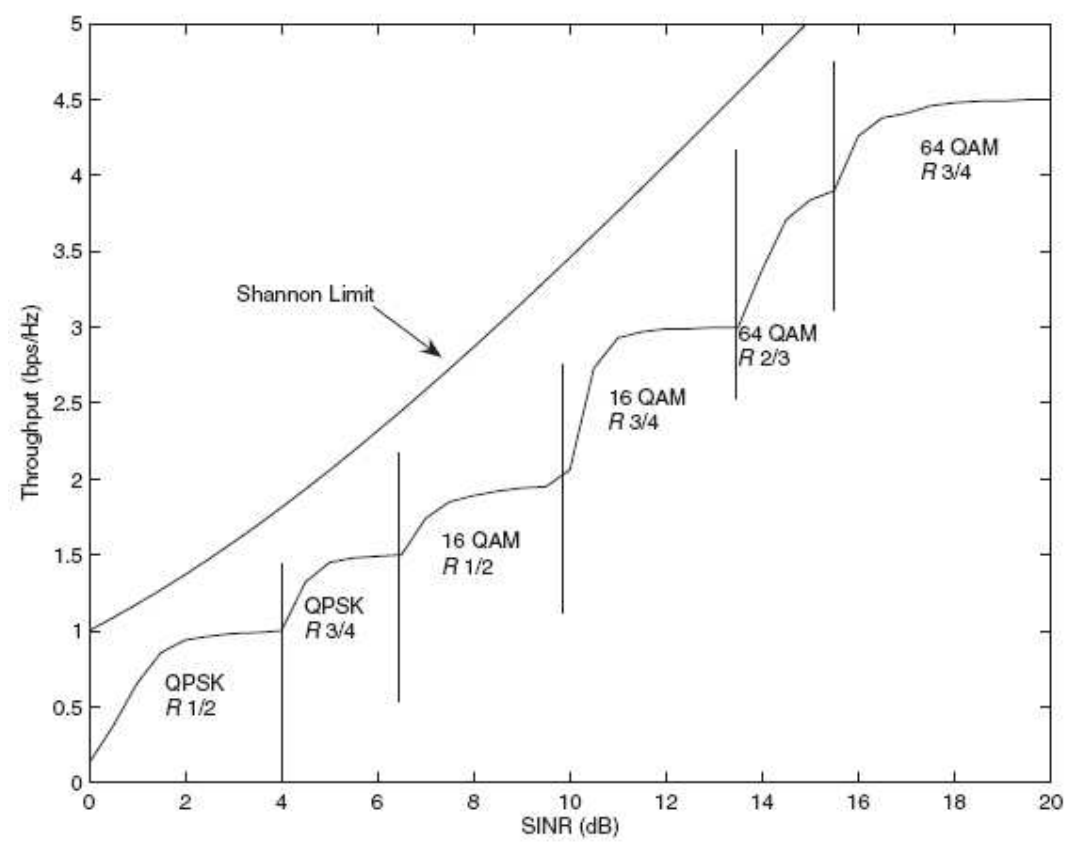

Figura 2.15: Throughput obtido para os diversos perfis, a partir da SINR recebida. Adaptado de [1]

O maior desafio na implementação do AMC é estabelecer um controle simultâneo e eficaz, por parte do controlador ilustrado na Figura 2.14, de três grandezas: potência, taxa transmitidas e taxa de codificação.

O padrão 802.16 estabelece a utilização dos esquemas de duplexação TDD e FDD. Apesar disso, a maior parte das redes WiMAX tem apresentado uma tendência a utilizar o primeiro deles, por suas vantagens, como a simplificação do projeto de transceptores [1].

\subsubsection{Diversidade de Multiusuários}

A principal motivação para a alocação dinâmica de subportadoras é a exploração da diversidade multiusuário.

No contexto dos sistemas sem fio, o termo diversidade refere-se à técnica de criar diversos percursos entre o transmissor e o receptor, para que o desvanecimento em cada um desses percursos possa ser considerado como independente. A idéia básica desse esquema é que, com o aumento do número de percursos possíveis, há um aumento da probabilidade de ao menos um desses canais experimentar um desvanecimento relativamente pequeno. 
Uma forma de diversidade é a chamada diversidade multiusuário, que pode ser explorada avaliando-se o canal de cada usuário e transmitindo-se apenas aos receptores que apresentarem a melhor qualidade.

Assim, considerando-se um sistema com $K$ usuários. Supondo que as subportadoras experimentem um desvanecimento i.i.d Rayleigh (independent and identically distributed Rayleigh), a PDF do ganho do canal do usuário $k, h_{k}$, é dada por [1]:

$$
\begin{aligned}
& p\left(h_{k}\right)=2 h_{k} e^{-h_{k}^{2}}, \text { para } h_{k} \geq 0 \\
& p\left(h_{k}\right)=0, \text { para } h_{k}<0
\end{aligned}
$$

Se a estação transmitir apenas ao usuário com o maior ganho de canal, $h_{\max }=$ $\operatorname{Max}\left\{h_{1}, h_{2}, \ldots, h_{k}\right\}$, a PDF de $h_{\max }$ será dada por:

$$
p\left(h_{\max }\right)=2 K h_{\max }\left(1-e^{-h_{\max }^{2}}\right)^{K-1} e^{-h_{\max }^{2}}
$$

O aumento do número de usuários provoca um deslocamento para a direita dessa PDF, mostrando que, quanto mais usuários estiverem conectados ao sistema, maior a probabilidade de ser obtido um alto ganho de canal (Figura 2.16).

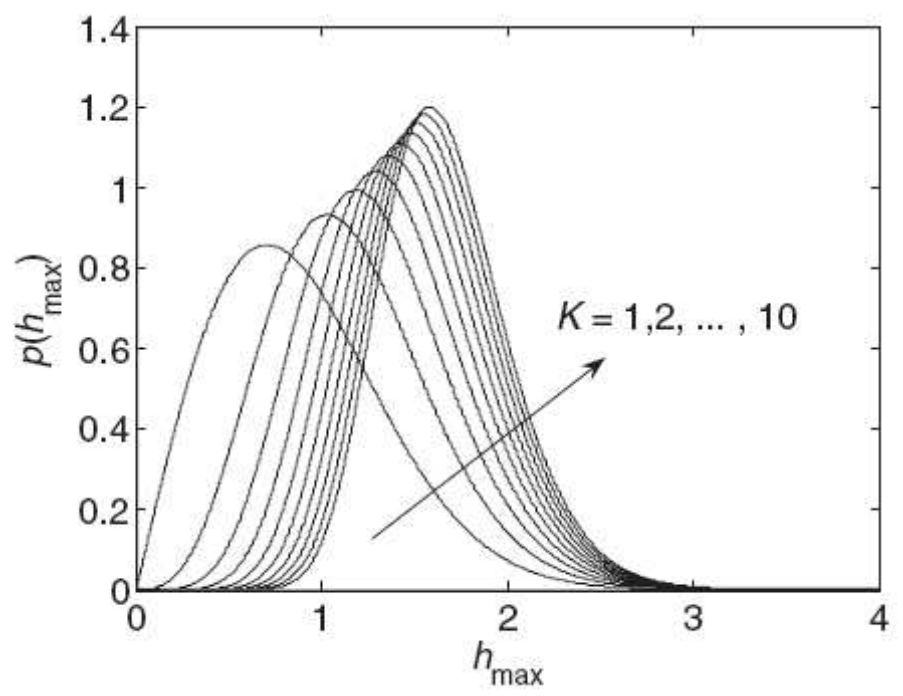

Figura 2.16: PDF de hmax. Adaptado de [1]

Esse ganho de canal aumentado melhora o desempenho do sistema, aumentando sua capacidade e reduzindo sua taxa de erro de bit (BER). A Figura 2.17 avalia essa melhora para uma modulação QPSK não-codificada: 


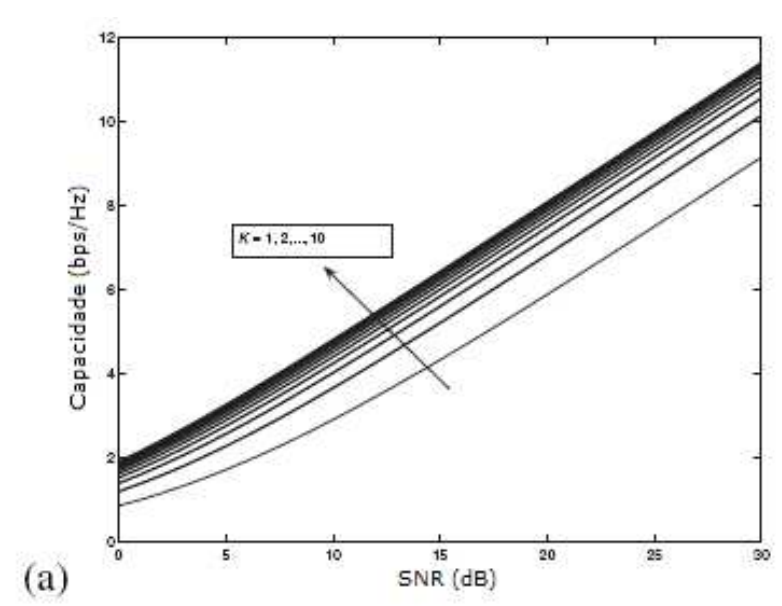

(a)

(b)

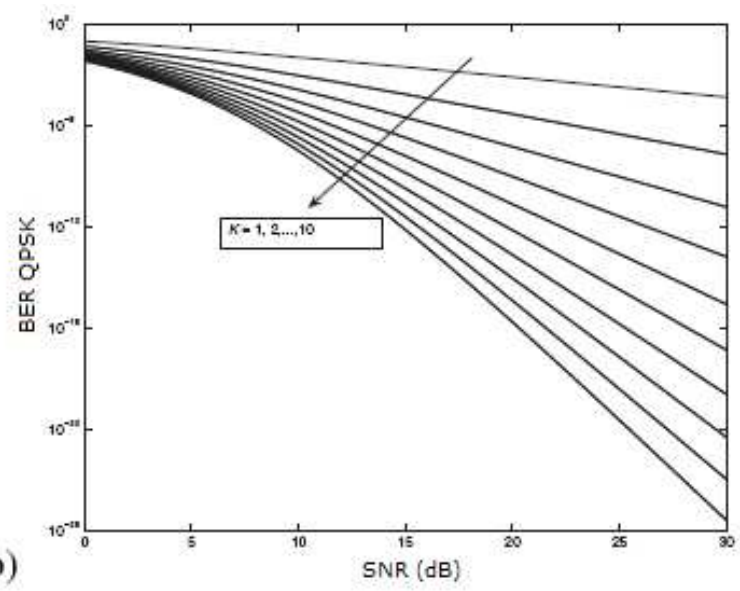

Figura 2.17: Capacidade e BER para diversos valores de K. Adaptado de [1]

A diversidade multiusuário aliada a tecnologias de múltiplas antenas pode elevar o desempenho do sistema consideravelmente. Apesar de ter sido enfatizado o aumento do throughput, o ganho pela diversidade multiusuário às vezes se traduz em maior área de cobertura e confiabilidade da conexão.

\subsubsection{Algoritmos de Alocação de Recursos em OFDMA}

Há inúmeras formas de se otimizar as vantagens oferecidas pela diversidade de multiusuários e pelas técnicas de permutação em sistemas OFDMA.

O padrão 802.16 não define um algoritmo comum a ser implementado na alocação de recursos, de forma que cada desenvolvedor é livre para propor/implementar o algoritmo que julgar mais adequado.

A alocação de recursos é normalmente formulada a partir de um problema de otimização, para (1) minimizar a potência total transmitida ou (2) maximizar a taxa total de dados alcançada [1].

\subsection{Frame WiMAX}

O frame WiMAX é dividido em dois subframes: o de downlink e o de uplink, separados por uma banda de guarda (Figura 2.18). 


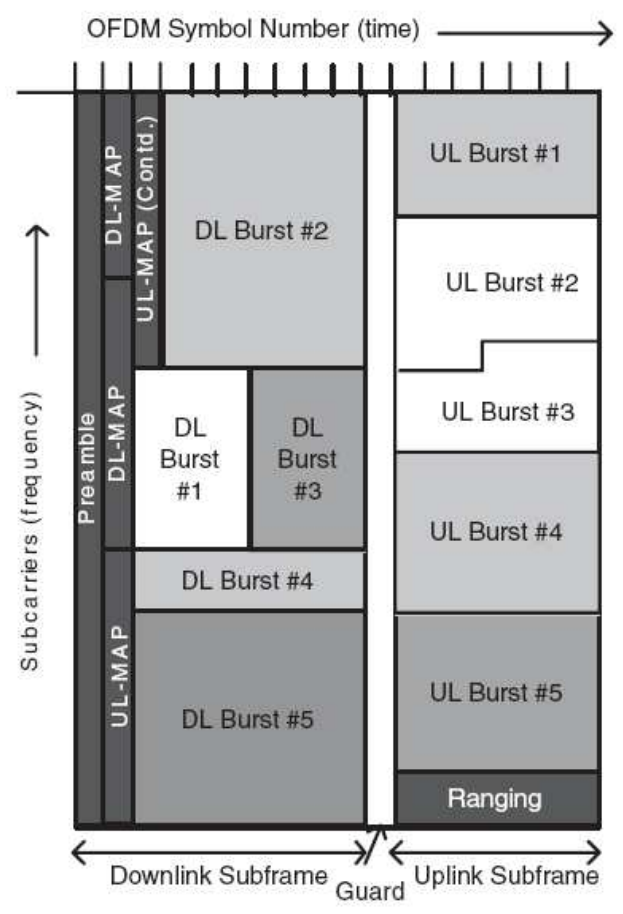

Figura 2.18: Frame WiMAX. Adaptado de [1]

De forma geral, o subframe downlink inicia-se com o preâmbulo, utilizado para procedimentos da camada física, como sincronização e estimação inicial do canal; seguido pelo FCH (Frame Control Header), responsável por prover informações sobre a configuração do frame. São alocadas regiões de dados para múltiplos usuários no frame (DL/UL Burst) e essas alocações são determinadas nos mapas de downlink e uplink (DLMAP e UL-MAP, respectivamente), bem como os esquemas de modulação e codificação utilizados.

O frame WiMAX é bem flexível no que diz respeito à multiplexação de usuários e dados, podendo haver múltiplas rajadas de tamanho e tipo diferentes em um mesmo frame; e também no tocante ao seu tamanho total, que pode variar de $2 \mathrm{~ms}$ a $20 \mathrm{~ms}$.

Com base no que foi apresentado, nota-se que o sistema WiMAX dispõe de ferramentas teóricas e tecnologias eficazes para a obtenção de um bom desempenho em termos de capacidade e cobertura. 


\section{PLANEJAMENTO DE REDE WIMAX}

\subsection{Introdução}

O objetivo principal deste capítulo é apresentar o simulador desenvolvido durante este trabaho de graduação, que efetua o dimensionamento inicial de um sistema WiMAX, baseado no algoritmo de alocação de recursos descrito em [1].

Primeiramente, o capítulo apresenta conceitos que serviram como embasamento para desenvolvimento do software. Em seguida, o algoritmo é apresentado e por fim, mostram-se as respostas das simulações obtidas, após variação de alguns parâmetros de entrada.

\subsection{Aspectos Teóricos do Planejamento}

Planejar uma rede de sistemas de telecomunicações envolve diversas variáveis, sendo seu grau de complexidade e acuidade mais elevado quanto maior for seu detalhamento. O planejamento de uma rede WiMAX é similar ao que vem sendo feito para os sistemas celulares.

Antes de se implantar o sistema é feito um levantamento dos custos e a perspectiva de retorno do investimento, já que a maior motivação é financeira e nenhuma empresa disponibilizará um serviço que trará prejuízo.

Nesta etapa inclui-se um estudo de todos os processos administrativos e burocráticos, tais como aquisição de licença para operar em determinada faixa de frequência, fechamento de contratos para alocação ou compra de terrenos para instalação do equipamento, assim como parcerias com os fabricantes e investidores.

Além disso, é necessário buscar informações sobre a população e região onde se deseja atuar, buscando saber a situação financeira, quais os tipos de serviços existentes, se eles correspondem às expectativas dos usuários, o que poderia ser melhorado, quais serviços a população gostaria de ter, quantas pessoas estariam dispostas a contratá-los, a 
área da região e suas características físicas e morfológicas. A partir dessas informações é possível encontrar a taxa de penetração de mercado e a quantidade de clientes para a dada região, montar um plano de ação e definir os serviços que serão oferecidos, partindo-se então para uma estimativa de cobertura e capacidade do sistema.

O objetivo do estudo de cobertura é estimar o raio da estação base e o comportamento do sinal após este ter sofrido interações com o ambiente. Conhecendo-se o alcance de cada torre, é possível estimar o número de células necessário para cobrir uma dada região, e o número de clientes que seriam atendidos por cada uma destas células. Este número de clientes pode não corresponder a real quantidade, visto que, até agora, não se considerou a taxa exigida por cada cliente nem a capacidade de tráfego de cada célula. Caso a taxa total demandada por estes clientes seja inferior a capacidade máxima da célula, fica caracterizado um caso de limitação por cobertura. Em situação contrária, a célula atende a um número menor de clientes, ocorrendo, portanto, limitação por capacidade.

O raio de alcance pode ser calculado de duas formas. A primeira seria por meio de medições do sinal dada uma certa distância ao redor da BS. Isso seria feito até um ponto limiar, a partir do qual o usuário não receberia um nível mínimo de sinal para usufruir do sistema. Como o WiMAX é um sistema com modulação e codificação adaptativa, é interessante que o procedimento descrito anteriormente seja feito para cada tipo de modulação e taxa de codificação. Contudo, sabe-se que quanto maior for a eficiência espectral menor é o raio de cobertura. A segunda opção seria utilizar algum modelo de predição que se encaixe nas condições do problema e efetuar um balanço de potência, onde a variável de saída seja a distância. Mais uma vez ter-se-ia que realizá-lo para todos os tipos de modulação e codificação. A primeira técnica é mais precisa e dá uma noção do formato real da célula, porém, é trabalhosa e tem um custo elevado. Já a segunda é baseada num valor de perda médio dada uma série de limitações impostas pelo modelo, o qual nem sempre consegue modelar de maneira eficiente a região na qual está sendo aplicado, mas é menos trabalhosa e mais barata. Cabe ao projetista escolher a técnica mais adequada. $\mathrm{O}$ que costuma-se fazer é usar um modelo de predição para confecção de um planejamento inicial e verifcar o comportamento do sistema. Posteriormente, realizam-se estudos de campo para otimização da performance.

A capacidade representa a quantidade de bits por segundo que um sistema pode fornecer. É ela que defini quantos usuários realmente uma estação base pode servir e 
conseqüentemente, quantas BS's serão necessárias para atender todos os clientes de um provedor de serviços.

Seu estudo leva em consideração a taxa requerida por cada cliente, quais tipos de modulação e taxas de codificação estão sendo aplicadas, quanto tempo o usuário está usufruindo do serviço, quantas subportadoras o sistema utiliza e como é feita a alocação de recursos entre os usuários.

Conhecer a taxa requerida por cada cliente é importante, pois dá uma noção de quanto de taxa o sistema deve dispor e colabora na determinação do números de células. Como existem clientes com perfis de utilização do sistema parecidos, é comum aplicar dois conceitos conhecidos por duty cycle e fator de overbooking. Os dois otimizam a utilização da rede e reduzem gastos. $\mathrm{O}$ duty cycle representa a fração do tempo que o usuário está conectado ao sistema que ele realmente está trafegando dados. Já o fator de overbooking representa quantos clientes se alternam na utilização de um mesmo recurso. Por exemplo, se o sistema tiver 100 clientes, e desses, 20 o utilizam ao mesmo tempo, o fator será 5.

Neste ponto cabe uma distinção entre o termo usuário e a expressão cliente. Usuário se refere àquele que está utilizando o serviço, enquanto que cliente é a pessoa que pagou para aquisição do mesmo. A relação entre número de clientes e usuários é:

$$
N_{\text {Clientes }}=N_{\text {Usuários }} \cdot O \cdot \frac{1}{D C}
$$

$N_{\text {Clientes }}$ representa o número de clientes, $N_{\text {Usuários }}$, o número de usuários, $O$, o fator de overbooking e $D C[\%]$, o duty cycle.

O padrão IEEE 802.16 especifica uma série de características, entre as quais destaca-se o fato de a modulação e a taxa de codificação serem adaptativas, ou seja, elas não são fixas e se alteram de acordo com a necessidade. Cada modulação e codificação exige um certo nível de SNR dada uma BER, e esse valor é diretamente proporcional à eficiência espectral. O algoritmo de alocação de recurso definirá que modulação e codificação o usuário receberá. O usuário que receber um sinal ruim terá de utilizar uma combinação (modulação + codificação) mais robusta, porém menos eficiente. Caso o nível de sinal recebido seja alto, será escolhida uma combinação com maior eficiência. Com base na argumentação anterior, é de se esperar que, em um ambiente em que não ocorra 
desvanecimento seletivo em frequiência, regiões mais próximas às BS's terão uma eficiência espectral maior que as mais distantes.

Cada canal possui um fator de amostragem $n$, que determina o espaçamento entre as subportadoras e o tempo simbólico útil. Seu valor varia de acordo com a banda do canal, conforme ilustra a Tabela 3.1:

Tabela 3.7: Fator de Amostragem

\begin{tabular}{|c|c|}
\hline Fator de Amostragem & Condição \\
\hline$n=8 / 7$ & A banda do canal ser múltipla de $1,75 \mathrm{MHz}$ \\
\hline$n=28 / 25$ & A banda do canal ser múltipla de $1,5 \mathrm{MHz}$ \\
\hline$n=28 / 25$ & A banda do canal ser múltipla de $1,25 \mathrm{MHz}$ \\
\hline$n=28 / 25$ & A banda do canal ser múltipla de $2,75 \mathrm{MHz}$ \\
\hline$n=28 / 25$ & A banda do canal ser múltipla de $2,0 \mathrm{MHz}$ \\
\hline$n=8 / 7$ & Para bandas não especificadas \\
\hline
\end{tabular}

Conhecendo o fator de amostragem é possível encontrar a freqüência de amostragem $\left(F_{s}\right)$, pois ela é dada por [4]:

$$
F_{s}=\text { floor }(n \cdot B W / 8000) \cdot 8000
$$

O termo $B W$ da Eq.(3.2) representa a largura de banda do canal, já a expressão floor é uma função que arredonda o conteúdo entre parênteses para o inteiro mais próximo que seja menor ou igual ao que consta dentro dos parênteses.

O espaçamento entre as subportadoras $\Delta f$ é definido como [4]:

$$
\Delta f=F_{s} / N_{F F T}
$$

Onde $F_{s}$ vem da Eq. (3.3) e $N_{F F T}$ representa o total de subportadoras existentes na banda do canal. 
A partir do espaçamento entre as subportadoras, calcula-se o tempo de símbolo útil $\left(T_{b}\right)$. Este parâmetro é necessário para encontrar tanto o tempo de guarda $\left(T_{g}\right)$ como o tempo de duração do símbolo $\operatorname{OFDM}\left(T_{s}\right)$. As expressões que definem estes três parâmetros são [4]:

$$
\begin{gathered}
T_{b}=1 / \Delta f \\
T_{g}=G \cdot T_{b} \\
T_{s}=T_{b}+T_{g}
\end{gathered}
$$

Na Eq. (3.5), $G$ representa o prefixo cíclico o qual é usado diminuir a interferência intersimbólica. Os possíveis valores de $G$ são 1/4, 1/8, 1/16 ou 1/32 [4].

No caso do WiMAX, a taxa é inversamente proporcional ao período do símbolo e diretamente propocional à banda de canal disponível e à eficiência espectral. Sua expressão é dada por :

$$
R=\frac{N_{u s e d} \cdot l \cdot c_{r}}{T_{s}}[\mathrm{bps}]
$$

A expressão acima descreve a taxa máxima obtida, ou seja, representa um valor ideal, pois não considera a possibilidade de o sistema errar na transmissão de algum bit. A taxa real é dada pela diferença entre a taxa transmitida e a quantidade de bits errados.

Na Eq. (3.7), $R$ representa a taxa, $N_{\text {used }}$ o número de subportadoras úteis e $l$ é o ganho de modulação (número de bits por símbolo), sendo igual a 1 (em BPSK), 2 (em QPSK), 4 (em 16-QAM) ou 6 (em 64-QAM). A variável $c_{r}$ indica a taxa de codificação e pode assumir os valores $1 / 2,2 / 3,3 / 4$ ou $5 / 6$. Já $T_{s}$ é o tempo de duração do símbolo e possui valor fixo definido pelo padrão. Só a título de ilustração, $T_{s}$ é igual a $102.8 \mu$ s para canais de $1.25,5,10$ e $20 \mathrm{MHz}, 144 \mu \mathrm{s}$ em canais de 3.5 ou $7 \mathrm{MHz}$ e $115.8 \mu$ s se o canal for de $8.75 \mathrm{MHz}$. Todos esses valores foram calculados para um prefixo cíclico de 1/8.

Para representar a alteração que a taxa sofre após variação dos parâmetros da Eq. (3.7), foram traçados os seguintes gráficos (Figura 3.19 e Figura 3.20). 


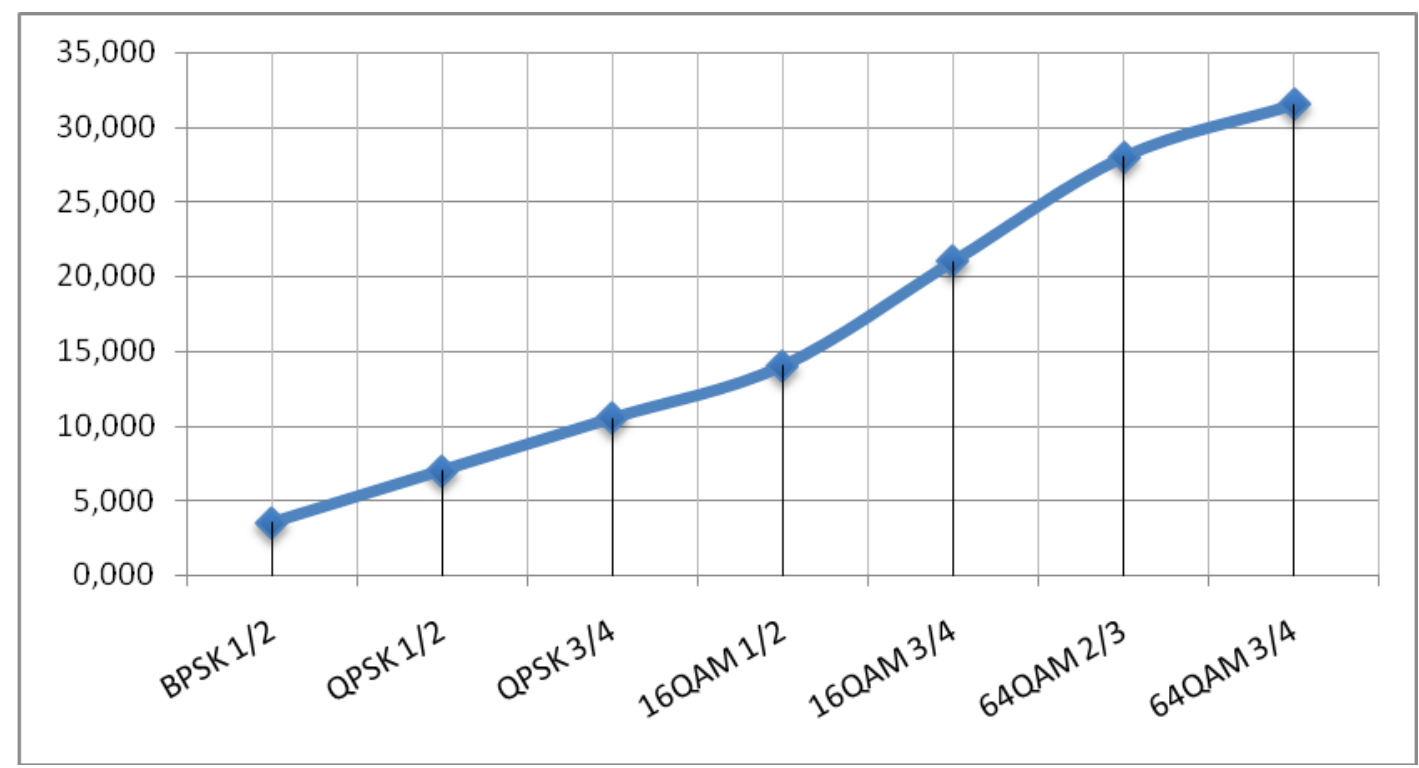

Figura 3.19: Taxa total (Mbps) em função da modulação e codificação

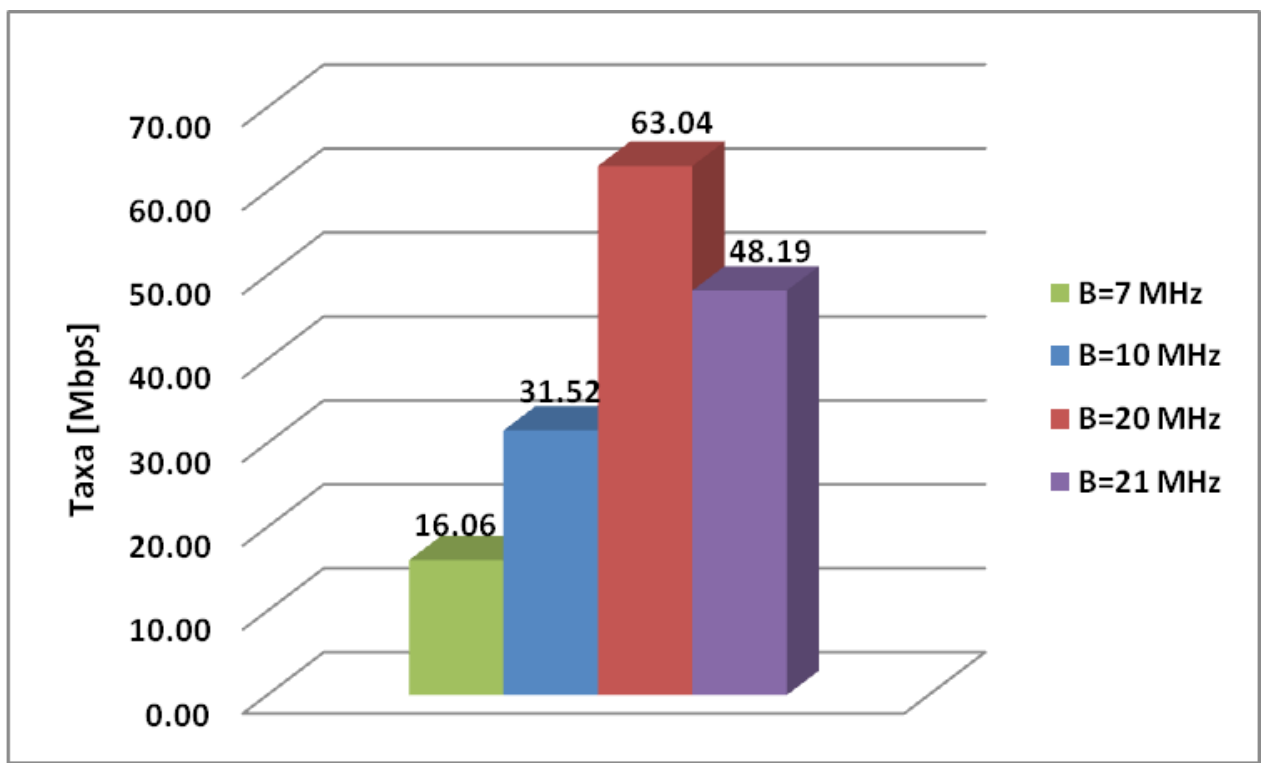

Figura 3.20: Taxa total em função da banda disponível

A Figura 3.1 ilustra o valor da taxa obtido utilizando diferentes técnicas de modulação e codificação para um canal de $10 \mathrm{MHz}$, ou seja, $T_{s}$ e $N_{\text {used }}$ foram mantidos constantes, variando-se apenas $b$ e $c_{r}$.

Na Figura 3.2, os parâmetros alterados são $T_{s}$ e $N_{\text {used }}$ permanecendo constantes $b$ e $c_{r}$. A taxa foi calculada para diferentes valores de bandas, considerando uma modulação de 64-QAM (3/4). As bandas de $10 \mathrm{MHz}$ e $20 \mathrm{MHz}$ possuem um mesmo valor de $T_{s}$, logo, 
a taxa para a banda de $10 \mathrm{MHz}$ é duas vezes menor que a banda de $20 \mathrm{MHz}$. Já as bandas de $7 \mathrm{MHz}$ e $21 \mathrm{MHz}$ apresentam um $T_{s}$ superior ao da banda de $10 \mathrm{MHz}$, o que explica o fato da taxa da banda de $21 \mathrm{MHz}$, ter sido inferior à taxa alcançada em $20 \mathrm{MHz}$ de banda.

A Eq. (3.7) pode tanto ser usada para calcular a taxa total do sistema como a taxa individual de cada usuário. A dificuldade maior é determinar o número de subportadoras que estarão em cada modulação e codificação. A solução deste problema é dada pelos algoritmos de alocação de recursos.

Estes algoritmos não são definidos pelo padrão e fica a cargo da empresa criar seu próprio método de alocação, ou então, utilizar algum já desenvolvido. Em [1], existem alguns exemplos de algoritmos: Maximum Sum Rate, Maximum Fairness e Proportional Rate Constraints.

Definida como será feita a alocação de recursos, consegue-se calcular a taxa máxima que o sistema pode fornecer, delimitar o número de usuários por célula e determinar quantas células serão necessárias para atender todos os clientes.

\subsection{Software de Planejamento}

Neste trabalho foi desenvolvido um programa computacional, no software Matlab, baseado na tecnologia WiMAX. O simulador desenvolvido é estático e tem, como principal objetivo, estimar o número de BSs necessárias para atender uma dada região, a partir do perfil dos clientes.

Para elaboração do simulador, grande parte dos conceitos envolvidos na seção anterior foram considerados, assim como o algoritmo de alocação de recursos proposto em [5]. Este algoritmo busca maximizar a quantidade de usuários atendidos e a taxa que cada um terá. Para isso, propõe uma metodologia que calcula, proporcionalmente, quantas subportadoras cada usuário necessita e, posteriormente, as aloca entre eles.

A seguir serão apresentadas as variáveis do simulador, e para uma melhor compreensão das siglas, utiliza-se o termo BS, para representar a abreviação de Base 
Station (Estação Base) e SS, para representar Subscriber Station (dispositivo utilizado pelo usuário para se conectar ao sistema).

O programa usa como variáveis de entrada: ganho da antena da BS $\left(G_{B S}\right)$, ganho da antena da SS $\left(G_{S S}\right)$, altura da antena da BS $\left(H_{B S}\right)$, altura da antena da SS ( $\left.H_{S S}\right)$, potência de transmissão da BS ( $\left.P_{T X-B S}\right)$, potência de transmissão da SS ( $P_{T X-S S}$ ), figura de ruído da SS $\left(N F_{S S}\right)$, figura de ruído da BS $\left(N F_{B S}\right)$, perdas devido a conexões $\left(P_{\text {conexões }}\right)$ e absorção ( $\left.P_{a b s o r c ̧ a ̃ o}\right)$, freqüêencia de operação, banda do canal ( $\left.B W\right)$, banda de freqüência disponível para a operadora $(B)$, probabilidade de cobertura $\left(P_{\text {cobertura }}\right)$, desvio padrão do desvanecimento lento $(\sigma)$, tipo de terreno, porcentagem de tempo de downlink e uplink (duplexação TDD), população, área da região, penetração de mercado, além de informações sobre os serviços que serão oferecidos (taxa de download, taxa de upload, $D C, O$, percentual de clientes). E apresenta como saídas: o raio máximo de cobertura que cada modulação e taxa de codificação podem alcançar no downlink e no uplink, o raio efetivo de cada célula, a taxa demandada e a obtida por uma BS no downlink e no uplink, quantos usuários podem ser atendidos por torre, quantas células terá o sistema, qual o tipo de limitação (cobertura ou capacidade) e a BER total do sistema para o downlink e o uplink.

Os procedimentos efetuados pelo simulador foram subdivididos em etapas, a fim de melhorar a compreensão do código desenvolvido.

\subsubsection{Primeira Etapa}

O simulador recebe as variáveis de entrada setadas pelo usuário do programa.

\subsubsection{Segunda Etapa}

Após definição das variáveis de entrada, o aplicativo realiza um estudo de cobertura. Este estudo é feito tanto para o downlink como para o uplink, permite encontrar o raio máximo de cobertura de cada técnica de modulação e codificação, e ao término, estima-se o alcance máximo da célula. 
Para realizar o estudo de cobertura, o simulador faz uso do modelo de predição SUI, descrito no Anexo A. Esse modelo estima a perda de percurso (ou path loss), após definição do terreno, da distância entre emissor e receptor, da freqüência e da altura das antenas.

O valor da perda de percurso é considerado na expressão do balanço de potência, onde a única incógnita é o parâmetro distância. Como cada modulação e cada taxa de codificação possuem um valor característico de sensibilidade, é possível calcular o raio máximo que cada técnica terá, por meio da expressão:

$$
\text { Raio }=d_{0} \cdot 10 \frac{-S-P_{\text {conexões }}-P_{\text {absorşa } \tilde{a}}-P_{T X}+G_{B S}+G_{S S}-M D-\left(20 \log \left(\frac{4 \pi d_{0}}{\lambda}\right)+X_{f}+X_{h}\right)}{10 \cdot\left(a-b \cdot H_{B S}+\frac{c}{H_{B S}}\right)}
$$

Em Eq.(3.8), o termo $P_{T X}$ representa a potência de transmissão da antena, $M D$ a margem de sombreamento, $S$ a sensibilidade do receptor, $\lambda$ o comprimento de onda e os parâmetros $\left(X_{f}, X_{h}, d_{0}, a, b, c\right)$ são provenientes do modelo SUI. $M D$ é encontrada a partir das variáveis de entrada $P_{\text {cobertura }}$ e $\sigma$, e a forma como foi calculada, encontra-se presente no Anexo A deste trabalho. Os parâmetros do modelo SUI também encontram-se presentes no Anexo A.

Como o simulador faz uma análise tanto para o downlink como para o uplink, cabe algumas observações antes do uso da Eq.(3.8). Se o cálculo for para o downlink, $P_{T X}$ deve ser substituída por $P_{T X-B S}$ e a sensibilidade será calculada a partir da figura de ruído da SS. No uplink, $P_{T X}$ é substituída por $P_{T X-S S}$ e $S$ é encontrada a partir de $N F_{B S}$.

Quando se efetua as duas análises (downlink e uplink), busca-se um equilíbrio entre os dois links. O critério escolhido para o simulador foi considerar apenas como usuário aqueles indivíduos que conseguiriam fazer download e upload. Como a potência de transmissão muda, no uplink e no downlink, é de se esperar que os raios de cobertura sejam distintos. Portanto, corre-se o risco de um usuário ser capaz de fazer download, mas não upload. Para evitar este problema de desequilíbrio, o raio da célula é definido após 
comparar o maior raio obtido no downlink e no uplink. O menor entre eles é definido como o raio máximo da célula.

No caso do simulador desenvolvido, existem as seguintes técnicas de modulação (taxa de codificação): BPSK (1/2), QPSK (1/2), QPSK (3/4), 16-QAM (1/2), 16-QAM (3/4), 64-QAM (2/3), 64-QAM (3/4), e portanto, o raio máximo de cobertura será igual ao raio alcançado com a modulação BPSK (1/2).

O padrão IEEE 802.16e define os seguintes valores como limiar de SNR para cada esquema de modulação e codificação, para uma BER de $10^{-6}$ (Tabela 3.8).

Tabela 3.8: Límite de SNR por modulação/codificação

\begin{tabular}{|c|c|}
\hline Modulação/Codificação & SNR $_{\text {mín }}(\mathbf{d B})$ \\
\hline BPSK (1/2) & 3 \\
\hline QPSK (1/2) & 6 \\
\hline QPSK (3/4) & 8,5 \\
\hline 16-QAM (1/2) & 11,5 \\
\hline 16-QAM (3/4) & 15 \\
\hline 64-QAM (2/3) & 19 \\
\hline 64-QAM (3/4) & 21 \\
\hline
\end{tabular}

A SNR é dada pela potência do sinal no receptor $\left(P_{R}\right)$ dividida pela potência do ruído $\left(P_{N}\right)$, ou em $\mathrm{dB}$ :

$$
S N R=\left.P_{R}\right|_{d B}-\left.P_{N}\right|_{d B}
$$

Para os valores mínimos de SNR mostrados na Tabela 3.2, a potência de recepção representa a sensiblidade $(S)$. Portanto,

$$
\begin{gathered}
\left.S\right|_{d B}=\left.P_{N}\right|_{d B}+S N R_{\min } \\
\left.P_{N}\right|_{d B m}=10 \log \left(k_{b}\right)+10 \log (\Delta f)+10 \log (T)+N F+30
\end{gathered}
$$

Em Eq.(3.11), $k_{b}$ representa a constante de Boltzmann $\left(1,38 \times 10^{-23} \mathrm{~J} / \mathrm{K}\right), \Delta f$ é a banda de uma subportadora, $T$ é a temperatura do ambiente $(290 \mathrm{~K})$ e $N F$ é a figura de 
ruído. A figura de ruído será a da SS se a análise for para o downlink, e da BS se o cálculo for para o uplink. Portanto,

$$
\left.S\right|_{d B m}=-174+10 \log (\Delta f)+N F+S N R_{\min }
$$

\subsubsection{Terceira Etapa}

O programa calcula quantos clientes o sistema WiMAX pretende atender, e a partir do número de clientes, estima a quantidade de usuários. Nesta etapa do programa, associase a cada usuário, sua taxa requerida no downlink e no uplink.

O WiMAX é um sistema capaz de comportar diferentes tipos de serviço, VoIP, acesso à Internet, vídeo-conferência e etc. Cada um desses serviço possui um valor característico de taxa necessário para garantir seu funcionamento. No programa, são caracterizados 4 tipos de serviço, e permite-se que a taxa de cada um deles seja setada pelo usuário.

O programa calcula a quantidade total de clientes a partir da penetração de mercado e da população total.

$$
N_{\text {Clientes }}=x \cdot N_{\text {População }}
$$

Em Eq. (3.13), $x$ representa o percentual de penetração de mercado e $N_{\text {População }}$ o tamanho da população. Já o número de clientes de cada serviço, é calculado com base no percentual de clientes que cada serviço espera, encontrado da seguinte forma:

$$
\begin{aligned}
& N_{\text {Clientes,Serviço1 }}=x_{1} \cdot N_{\text {Clientes }} \\
& N_{\text {Clientes,Serviço2 }}=x_{2} \cdot N_{\text {Clientes }} \\
& N_{\text {Clientes,Serviço3 }}=x_{3} \cdot N_{\text {Clientes }} \\
& N_{\text {Clientes,Serviço4 }}=x_{4} \cdot N_{\text {Clientes }}
\end{aligned}
$$

Onde $\quad N_{\text {Clientes,Serviço1 }}, \quad N_{\text {Clientes,Serviço2 }}, \quad N_{\text {Clientes,Serviço3 },}, N_{\text {Clientes,Serviço4 }}$ representam a quantidade de clientes de cada serviço e $x_{1}, x_{2}, x_{3}, x_{4}$ o percentual de clientes dos 
serviços 1, 2, 3 e 4, respectivamente. A quantidade de usuários de cada serviço é encontrada por meio da Eq. (3.1) e o total de usuários, pelo somatório de usuários de cada serviço.

\subsubsection{Quarta Etapa}

Calcula-se a densidade de usuários, a qual permite estimar o número inicial de usuários que serão atendidos por célula.

Para se ter uma primeira aproximação de quantos usuários cada BS irá atender, o programa calcula a densidade de usuários, dividindo a totalidade de usuários pela área da região que se deseja cobrir, e depois, multiplica a densidade encontrada pela área máxima de cobertura de uma célula. O número de usuários atendidos por cada BS é denominado $K$ . Cada usuário é representado por um índice inteiro $k$ que varia 1 a $K$.

\subsubsection{Quinta Etapa}

O número de usuários encontrado na quarta etapa é distribuído, de forma proporcional, entre as diferentes técnicas de modulação e codificação. Ao final, cada usuário possui uma distância associada a si.

Conhecendo a área de cobertura de cada esquema de modulação e codificação é possível encontrar quantos usuários estarão presentes em cada combinação, pois estes são distribuídos proporcionalmente de acordo com a área. Dentro das respectivas regiões os usuários são distribuídos aleatoriamente.

\subsubsection{Sexta Etapa}

Cada usuário está a uma certa distância da torre e portanto, presume-se que cada um perceberá um nível de sinal característico à sua localização. Isso implica num valor diferenciado de perda de percurso por usuário. E como no programa, considera-se também a presença do desvanecimento seletivo em freqüência, as subportadoras não apresentarão a mesma relação sinal ruído para um mesmo usuário. 
Nesta etapa, calcula-se a SNR de todas as subportadoras percebida por cada usuário. O valor da SNR de cada subportadora é comparado aos limites presentes no padrão IEEE 802.16e, e por fim, atribui-se uma modulação/codificação à respectiva subportadora. O último procedimento desta etapa é o calculo da SNR média do usuário.

O cálculo da SNR é feito após uma estimativa do comportamento do canal que cada usuário percebe. Para verificar o comportamento do canal, o programa utiliza parâmetros pré-definidos pelo modelo SUI Channels [6] de acordo com o tipo de terreno escolhido e que ajudam a compreender o desvanecimento rápido do canal.

As informações necessárias são potência e delay associados aos 3 tap's que representam cada ambiente. Esses dados quando interpolados geram uma curva com decaimento exponencial que é usada para calcular o ganho de taps igualmente espaçados. A quantidade de taps, igualmente espaçados, necessária para representar o desvanecimento rápido do ambiente, varia de acordo com a banda do canal ( $B W$ ), e a distribuição dos taps é feita dentro do maior delay não negligenciável ( $\left.\tau_{\max }\right)$ de cada terreno. O número de taps $(v)$ é encontrado por :

$$
v=\frac{\tau_{\max }}{1 / B W}
$$

Para encontrar os valores do ganho de cada tap, igualmente espaçados, é feita uma interpolação dentro do comportamento exponencial e é feita a normalização desses ganhos. São geradas $v$ amostras complexas com distribuição gaussianas, e estas são multiplicadas pela distribuição encontrada anteriormente, obtendo assim, a resposta impulsional do canal. Aplicando a FFT sobre a resposta impulsional tem-se o ganho do canal no domínio da freqüência.

O desvanecimento rápido sofrido por cada subportadora é somado ao valor de SNR (decorrente do pathloss e shadowing) característico de cada usuário. Como resultado desta soma, obtém-se a SNR de cada subportadora.

A rotina elaborada para estimar o canal é rodada para cada usuário. Assim, esperase um comportamento distinto para cada usuário, ou seja, uma subportadora que é ruim para um pode ser boa para outro. Ao término desta rotina, o algoritmo gera uma matriz 
$N_{\text {uteis }} \times K$, que é verificada antes de alocar as subportadoras aos usuários. A SNR média de cada usuário é dada pela média aritmética da SNR de cada subportadora.

É importante observar que as subportadoras destinadas a um mesmo usuário podem assumir modulações distintas. Durante o desenvolvimento do algoritmo, optou-se por sempre atribuir a combinação (modulação/codificação) que proporciona a melhor eficiência espectral, entre as disponíveis.

\subsubsection{Sétima Etapa}

O objetivo desta etapa é calcular o número de subportadoras que será destinado a cada usuário e quantas subportadoras livres. Para encontrar a quantidade de subportadoras que o usuário necessita, o simulador precisa conhecer a taxa requerida e a SNR média de cada usuário, além do valor $K$.

A partir da SNR média, define-se a modulação que será considerada para encontrar o número de subportadoras de cada usuário $\left(N_{k}\right)$. Antes de calcular $N_{k}$, o algoritmo determina o fator de modulação $\left(f m_{k}\right)$, o fator de serviço $\left(f s_{k}\right)$ e o fator de proporção $\left(\phi_{k}\right.$ ) .

O fator de modulação define quantas subportadoras a mais uma técnica de modulação e codificação necessita para atingir um mesmo valor de taxa, se comparada a 64-QAM (3/4). Seu valor é definido de acordo com a Tabela (3.3):

Tabela 3.9: Valores para o fator de modulação

\begin{tabular}{|c|c|c|c|c|c|c|c|}
\hline & BPSK & QPSK & QPSK & 16-QAM & 16-QAM & 64-QAM & 64-QAM \\
$(\mathbf{1} / \mathbf{2})$ & $(\mathbf{1 / 2})$ & $(\mathbf{3 / 4})$ & $(\mathbf{1 / 2})$ & $(\mathbf{3 / 4})$ & $(\mathbf{2 / 3})$ & $(\mathbf{3 / 4})$ \\
\hline$f m_{k}$ & 9 & 4.5 & 3 & 2.25 & 1.5 & 1.125 & 1 \\
\hline
\end{tabular}

O fator de serviço é diretamente proporcional ao valor da taxa requerida. O serviço com menor taxa tem fator igual a 1. Para os demais serviços, o fator é dado pela razão entre o valor de sua taxa e a taxa do menor serviço, ou seja, se o menor serviço possuir uma taxa de $100 \mathrm{kbps}$, um serviço de 200 kbps terá um fator de serviço igual a 2.

O fator de proporção de cada usuário é calculado a partir das expressões: 


$$
\begin{gathered}
\delta_{k}=f s_{k} \cdot f m_{k} \\
\phi_{k}=\frac{\delta_{k}}{\delta} \\
\delta=\sum_{k=1}^{K} \delta_{k}
\end{gathered}
$$

Por fim, define-se $N_{k}$ que é dado por :

$$
N_{k}=\operatorname{fix}\left(N_{\text {uteis }} \cdot \phi_{k}\right)
$$

Na Eq. (3.19), $N_{\text {uteis }}$ representa o total de subportadoras úteis presentes na banda de canal escolhida. Ao término desse cálculo, o somatório dos $N_{k}$ 's poderá ser um valor menor ou igual a $N_{\text {uteis }}$. Se for igual, significa que se o número de subportadoras requisitado por cada usuário foi atendido, não restarão subportadoras livres. Caso o somatório seja inferior, existirão subportadoras disponíveis mesmo após os usuários terem recebido a quantidade exigida. A quantidade de subportadoras livres $\left(N^{*}\right)$ é definida por :

$$
N^{*}=N_{u t e i s}-\sum_{k=1}^{K} N_{k}
$$

Todo o procedimento descrito anteriormente para determinar $N_{k}$ e $N^{*}$ deve ser feito tanto no cálculo do downlink, como no do uplink porque as taxas desses serviços costumam ser diferentes.

\subsubsection{Oitava Etapa}

Nesta etapa o algoritmo define qual subportadora, entre as $N_{\text {uteis }}$ possíveis, será alocada para cada usuário. Inicialmente, o programa atribui zero de taxa a todos os usuários e considera que todas as subportadoras estão livres.

$$
R_{k}=0, \quad \forall k \in\{1,2, \ldots, K\}
$$

$\mathrm{Na}$ Eq.(3.21), $R_{k}$ representa a taxa do usuário representado pelo índice $k$. 
Então, o algoritmo calcula para o primeiro usuário, qual subportadora entre as disponíveis lhe oferece uma maior SNR. Após encontrá-la, a subportadora é alocada para o usuário e não pertence mais ao grupo das disponíveis. A atribuição da subportadora deve, também, reduzir em uma unidade o valor de $N_{1}$. Esse procedimento é feito para cada usuário uma única vez, e após a alocação, incrementa-se $R_{k}$.

Para o cálculo da taxa de cada usuário $\left(R_{k}\right)$ necessita-se conhecer a probabilidade de erro de símbolo ( $B L E R)$, a eficiência espectral máxima $\left(C_{\max }\right)$ de cada técnica de modulação/codificação e o período de um símbolo $\left(T_{s}\right)$, já que a taxa é definida por: \

$$
R_{k}=R_{k}+\frac{C_{\max }(1-B L E R)}{T_{s}}
$$

A eficiência espectral máxima é encontrada a partir do produto da taxa de codificação com a quantidade de bits que formam um símbolo $(l)$. No algoritmo utilizamse os seguintes valores:

Tabela 3.10: Valores de Cmax e $l$ para cada esquema modulação/codificação

\begin{tabular}{|c|c|c|c|}
\hline Modulação & $\begin{array}{c}\text { Taxa de } \\
\text { Codificação }\end{array}$ & $l$ & $C_{\max }$ \\
\hline BPSK & $1 / 2$ & 1 & 0.5 \\
\hline \multirow{2}{*}{ QPSK } & $1 / 2$ & 2 & 1.0 \\
\cline { 2 - 4 } & $3 / 4$ & 2 & 1.5 \\
\hline \multirow{2}{*}{ 16-QAM } & $1 / 2$ & 4 & 2.0 \\
\cline { 2 - 4 } & $3 / 4$ & 4 & 3.0 \\
\hline \multirow{2}{*}{ 64-QAM } & $2 / 3$ & 6 & 4.0 \\
\cline { 2 - 4 } & $3 / 4$ & 6 & 4.5 \\
\hline
\end{tabular}

O período do símbolo é calculado para um prefixo cíclico de $1 / 8$, enquanto que a probabilidade de erro de símbolo é dada por [1]:

$$
B L E R=l \cdot B E R
$$


A probabilidade de erro de bit ( $B E R$ ) é encontrada a partir da SNR e da eficiência espectral máxima. Em [7] é proposta uma aproximação genérica para se calcular a BER de sistemas M-QAM e M-PSK, onde esta é dada por:

$$
B E R \approx c_{1} \exp \left(\frac{-1.6 \cdot S N R}{2^{C_{M A X}}-1}\right)
$$

$\mathrm{Na}$ Eq.(3.24) $c_{1}$ é uma constante que varia de acordo com o sistema. Para cada esquema de modulação/codificação calculou-se o valor de $c_{l}$ respectivo, considerando seu $\mathrm{SNR}_{\min }$ e o seu valor de eficiência espectral máxima $\left(\mathrm{C}_{\text {máx }}\right)$, para uma BER de $10^{-6}$. Os valores calculados são mostrados na Tabela 3.5.

Tabela 3.11: Valores da constante $c_{1}$ para o cálculo da BER

\begin{tabular}{|c|c|}
\hline Modulação/Codificação & $\boldsymbol{c}_{\boldsymbol{1}}$ \\
\hline BPSK (1/2) & $2.22427 \mathrm{e}-3$ \\
\hline QPSK (1/2) & $5.8389 \mathrm{e}-4$ \\
\hline QPSK (3/4) & $4.903 \mathrm{e}-4$ \\
\hline 16-QAM (1/2) & $1.8697 \mathrm{e}-3$ \\
\hline 16-QAM (3/4) & $1.377552 \mathrm{e}-3$ \\
\hline 64-QAM (2/3) & $4.783 \mathrm{e}-3$ \\
\hline 64-QAM (3/4) & 0.011087 \\
\hline
\end{tabular}

\subsubsection{Nona Etapa}

Depois que cada usuário já recebeu uma subportadora, o algoritmo inicia um processo diferente de alocação, o programa verifica entre todos os usuários qual possui a menor razão $\frac{R_{k}}{\phi_{k}}$ e, então, atribui uma subportadora para ele. Essa subportadora será aquela entre as disponíveis que possui a melhor SNR. Mais uma vez, a subportadora alocada é retirada do grupo das disponíveis e diminui-se em uma unidade o $N_{k}$ do usuário que recebeu a subportadora. Esse processo é repetido várias vezes até que o $N_{k}$ de todos os usuários seja zero. Porém, não há necessariamente um intercalamento de usuários na 
hora de receber a subportadora. Tem preferência aquele com menor $\frac{R_{k}}{\phi_{k}}$ a cada nova verificação. A taxa de cada usuário se altera após este ter recebido uma nova subportadora, e é calculada a partir da Eq. (3.22).

\subsubsection{Décima Etapa}

Até o momento, não houve a alocação das $N^{*}$ subportadoras. Para alocá-las, o algoritmo escolhe uma das $N^{*}$ subportadoras. O usuário que apresentar a melhor relação sinal ruído receberá a tal subportadora e não poderá receber nenhuma das subportadoras restantes, ou seja, no máximo cada usuário recebe uma do conjunto das $N^{*}$ subportadoras. Novamente, calcula-se a nova taxa para este usuário por meio da Eq.(3.22).

\subsubsection{Décima Primeira Etapa}

O objetivo desta etapa é verificar se os $K$ usuários poderão ou não ser atendidos por uma única BS. Se a resposta for negativa, o algoritmo calcula um novo valor de $K$.

Ao término da alocação de todas as $N_{\text {uteis }}$ subportadoras, o algoritmo encontra a taxa total obtida pelo sistema ( $R_{\text {Total-Obtida }}$ ), somando a taxa de cada usuário.

$$
R_{\text {Total-Obtida }}=\sum_{k=1}^{K} R_{k}
$$

Calcula-se também a taxa requerida pelo sistema $\left(R_{\text {Total-Requerida }}\right)$, dada pelo somatório das taxas dos serviços demandadas por cada usuário.

O valor de $R_{\text {Total-Obtida }}$ é comparado ao de $R_{\text {Total-Requerida. }}$ Se $\frac{R_{\text {Total-Obtida }}}{R_{\text {Total-Requerida }}} \geq 1$ o programa encerra os cálculos e classifica o caso como limitação por cobertura. Já se a razão der $\frac{R_{\text {Total-Obtida }}}{R_{\text {Total-Requerida }}}<1$, a classificação atribuída é limitação por capacidade, e o programa refaz todos os cálculos anteriores, após reduzir o valor de $K$. Esse processo 
iterativo ocorre até que a razão $\frac{R_{\text {Total-Obtida }}}{R_{\text {Total-Requerida }}}$ permaneça no intervalo de erro permitido pelo código do programa, o que evita de se cair em loop's infinitos. Como o simulador efetua tanto um cálculo para o downlink como para o uplink, o comparativo das taxas é efetuado de maneira paralela nos dois casos e só se encerra quando as duas restrições forem satisfeitas.

Para saber quantos usuários serão eliminados, o algoritmo multiplica $K$ pela razão $\frac{R_{\text {Total-Obtida }}}{R_{\text {Total-Requerida }}}$, e como esta é menor que 1 , ocorre uma redução no número de usuários. O comando para tal ação é dado por:

$$
K=\operatorname{round}\left(K \cdot \frac{R_{\text {Total-Obtida }}}{R_{\text {Total-Re querida }}}\right)
$$

O comando round da Eq.(3.26) arredonda o valor entre parênteses para o inteiro superior mais próximo, e é usado para que $K$ seja sempre um número inteiro. Conhecendo o valor do novo $K$ e do anterior, encontra-se a quantidade de usuários que deve ser eliminada. O código opta sempre por retirar aqueles usuários que estão mais distantes da BS. Vale ressaltar, que a distância, a modulação, a codificação e a taxa requerida por cada usuário não se alteram a cada definição de um novo $K$.

\subsubsection{Décima Segunda Etapa}

O simulador encontra as variáveis de saída e as amostra na interface gráfica desenvolvida no ambiente Guide do Matlab.

O número máximo de usuários que cada $\mathrm{BS}$ pode atender é definido como o valor de $K$ para qual a condição das taxas é alcançada.

A determinação de quantas células serão necessárias para atender a região é feita com base no número máximo de usuários atendidos por uma única torre.

$$
\text { Número de Células }=\frac{\text { Total de Usuários }}{K}
$$


Depois de calcular o número de células, o programa calcula o raio máximo de cada célula ( $\left.R_{\text {célula }}\right)$ da seguinte forma.

$$
\text { Área }_{\text {célula }}=\frac{\text { Área Total }}{\text { Número de Células }}
$$

Considerando células hexagonais, o raio da célula pode ser calculado pela Eq. (3.29).

$$
R_{\text {célula }}=\sqrt{\frac{\text {Área }_{\text {célula }}}{2,6}}
$$

O simulador também devolve como saída a taxa de erro de bit total do uplink e do downlink.

$$
\begin{gathered}
B E R_{\text {downlink }}=\frac{\text { bits errados }_{\text {dowlink }}}{\text { bits enviados }_{\text {downlink }}} \\
B E R_{\text {uplink }}=\frac{\text { bits errados }_{\text {uplink }}}{\text { bits enviados }_{\text {uplink }}}
\end{gathered}
$$

\subsection{Fluxograma do Algoritmo do Software de Planejamento}

Para uma melhor visualização do algoritmo desenvolvido, a seguir, apresenta-se um fluxograma do simulador (Figura 3.21). 


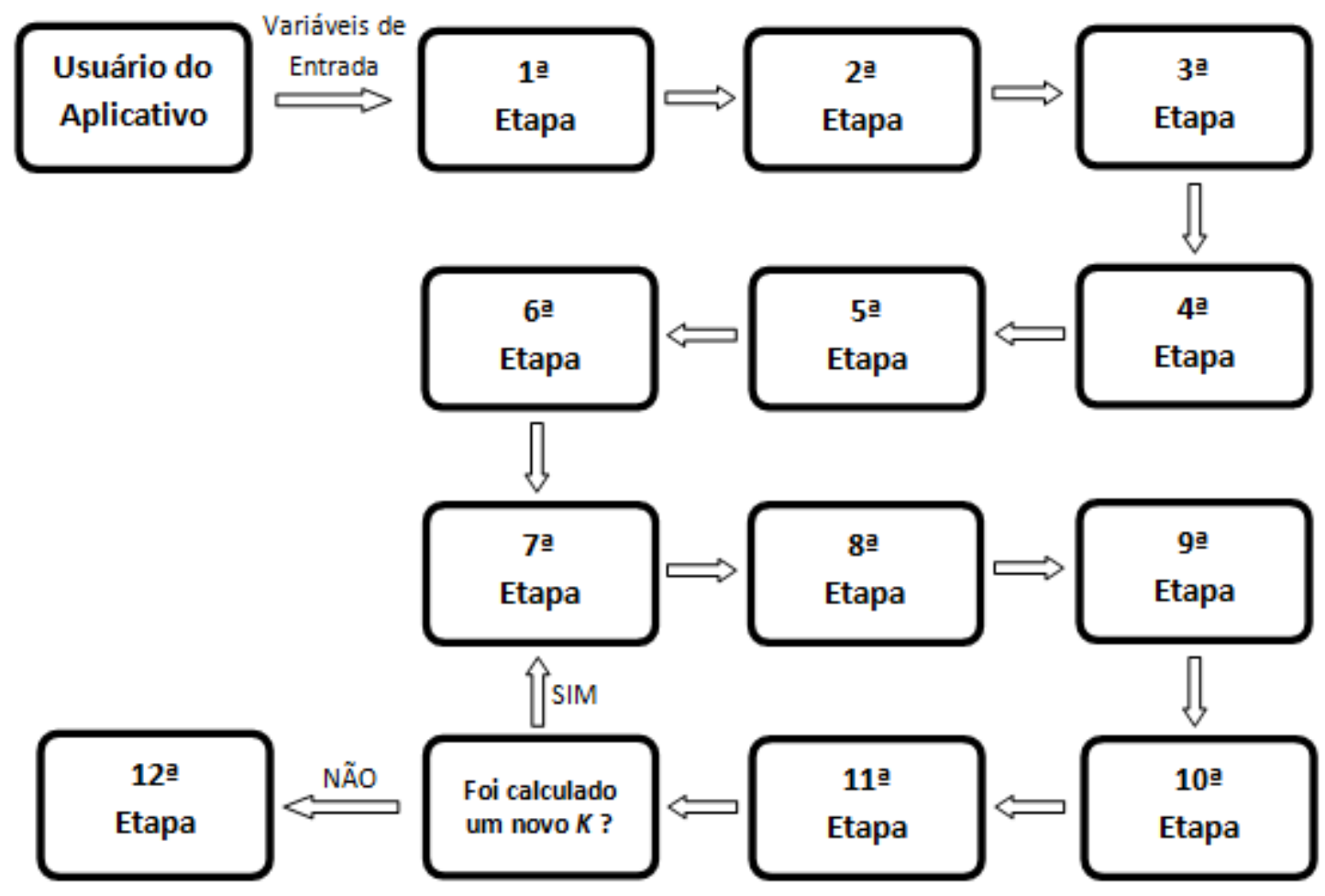

Figura 3.21: Fluxograma do algorítimo

\subsection{Resultados de Simulações}

Foram executadas simulações para diferentes configurações de ambiente, população e parâmetros do sistema.

Em todos os testes, foram comuns os parâmetros mostrados nas Tabelas 3.6 e 3.7 abaixo:

Tabela 3.12: Parâmetros de entrada 1

\begin{tabular}{|c|c|}
\hline Parâmetro & Valor \\
\hline Potência de Transmissão da BS & $10 \mathrm{~W}$ \\
\hline Potência da Transmissão da SS & $1 \mathrm{~W}$ \\
\hline Ganho da Antena da BS & $25 \mathrm{dBi}$ \\
\hline Ganho da Antena da SS & $0 \mathrm{dBi}$ \\
\hline Altura da Antena da BS & $60 \mathrm{~m}$ \\
\hline Altura da Antena da SS & $1.8 \mathrm{~m}$ \\
\hline Perda de Conexões & $3 \mathrm{~dB}$ \\
\hline
\end{tabular}

Continuação da Tabela 3.6

\begin{tabular}{|c|c|}
\hline Parâmetro & Valor \\
\hline Perda de Absorção & $4 \mathrm{~dB}$ \\
\hline Figura de Ruído da BS & $3 \mathrm{~dB}$ \\
\hline
\end{tabular}


Tabela 3.13: Parâmetros de entrada 2

\begin{tabular}{|c|c|c|c|c|c|}
\hline Serviço & $\begin{array}{c}\text { Taxa de } \\
\text { Downlink } \\
{[\boldsymbol{k b p s}]}\end{array}$ & $\begin{array}{c}\text { Taxa de } \\
\text { Uplink } \\
{[\text { kbps }]}\end{array}$ & $\begin{array}{c}\text { Duty Cycle } \\
{[\%]}\end{array}$ & $\begin{array}{c}\text { Fator de } \\
\text { Overbookin }\end{array}$ & $\begin{array}{c}\text { Percentual } \\
\text { de Usuários } \\
{[\%]}\end{array}$ \\
\hline 1 & 640 & 110 & 25 & 5 & 50 \\
\hline 2 & 480 & 80 & 25 & 7 & 35 \\
\hline 3 & 240 & 40 & 25 & 20 & 15 \\
\hline
\end{tabular}

Os valores da Tabela 3.6 são característicos de equipamentos que vêm sendo utilizados em sistemas WiMAX. Já a Tabela 3.7 utiliza os serviços especificados em [8].

Para cada teste foram feitas 100 iterações e calculada a média e o desvio padrão dos resultados obtidos.

Comparou-se, nas freqüências de 2,5 GHz e 3,5 GHz, para os diferentes tipos de terreno especificado pelo modelo SUI, a quantidade de células necessária para cobrir a região especificada, o número de usuários atendidos e a taxa obtida em cada célula. $\mathrm{Na}$ freqüência de 3,5 GHz e terreno do tipo B, variou-se a banda total disponível no sistema para medir o impacto desta.

\subsubsection{Comparação entre Freqüências}

A Tabela 3.8 apresenta os resultados médios e os desvios-padrão calculados para os parâmetros citados anteriormente, bem como a população, a penetração de mercado e a área para cada tipo de terreno. Estas simulações foram feitas com uma banda disponível de $10 \mathrm{MHz}$ e com uma banda do canal de $10 \mathrm{MHz}$.

Tabela 3.14: Resultados da comparação entre freqüências

\begin{tabular}{|c|c|c|c|}
\hline & Situação 1 & Situação 2 & Situação 3 \\
\hline Tipo de Terreno & Terreno A & Terreno B & Terreno C \\
\hline População & 800000 & 300000 & 53500 \\
\hline Penetração (\%) & 10 & 10 & 10 \\
\hline Área $\left(\mathrm{km}^{2}\right)$ & 200 & 500 & 500 \\
\hline Freqüência $(\mathrm{GHz})$ & 2,5 & 2,5 & 2,5 \\
\hline
\end{tabular}




\begin{tabular}{|c|c|c|c|c|c|c|}
\hline Número de células & 93 & 93 & 42 & 48 & 12 & 14 \\
\hline Desvio Padrão & 0,00 & 0,00 & 1,85 & 2,62 & 1,00 & 1,29 \\
\hline $\begin{array}{c}\text { Quantidade de } \\
\text { usuários por célula }\end{array}$ & 34 & 34 & 29 & 25 & 19 & 16 \\
\hline Desvio Padrão & 0,00 & 0,00 & 1,34 & 1,33 & 1,66 & 1,29 \\
\hline $\begin{array}{c}\text { Taxa por célula } \\
\text { (Mbps) }\end{array}$ & 22,06 & 22,04 & 19,11 & 16,64 & 12,67 & 9,49 \\
\hline Desvio Padrão & 0,00 & 0,05 & 0,56 & 0,69 & 0,95 & 0,45 \\
\hline
\end{tabular}

A Figura 3.22 apresenta a variação da quantidade de células em função da frequiência de operação necessárias para cobrir adequadamente cada uma das regiões. Sabe-se que para freqüências mais elevadas a perda de percurso é maior, levando a um menor raio de cobertura para cada esquema de modulação/codificação.

$\mathrm{Na}$ situação 1, não houve diferença no número de células entre as bandas de 2,5 e 3,5 GHz. Esta região apresenta uma grande densidade populacional, o que representa uma grande quantidade de usuários perto da torre e, como o raio de cobertura que é limitado por capacidade não é grande (já que quanto maior a densidade de usuários maior será a densidade de tráfego requerida e menor será o raio de cobertura), existe uma tendência de que todos os usuários atendidos pela BS estejam utilizando 64QAM como modulação, independentemente da freqüência.

Nas situações 2 e 3, a densidade da população já não é tão intensa, levando a uma maior separação entre os usuários, e, portanto, há um aumento do raio de cobertura. Isso leva a uma diferenciação entre as modulações utilizadas pelos usuários entre cada uma das faixas de freqüências utilizadas, o que justifica uma maior exigência no número de células para a freqüência de $3,5 \mathrm{GHz}$. 


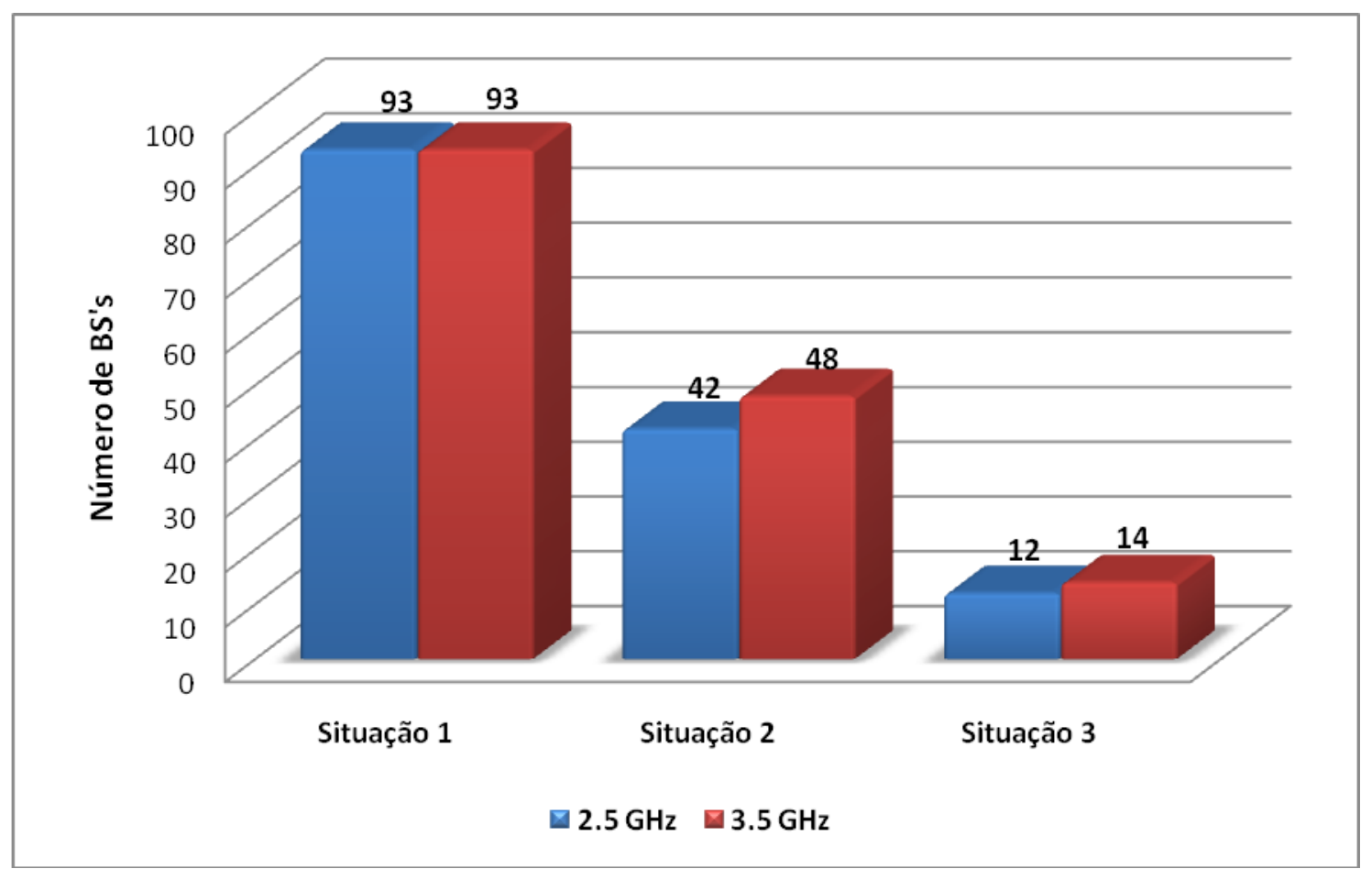

Figura 3.22: Número de células na comparação entre freqüências

A análise da Figura 3.23 é semelhante a da Figura 3.22, visto que os parâmetros população, penetração e área não foram alterados. Na situação 1, o número de usuários é o mesmo tanto na freqüência de $2,5 \mathrm{GHz}$ como em $3,5 \mathrm{GHz}$, pois há limitação por capacidade e todos os usuários estão utilizando a mesma técnica de modulação, logo, a taxa total obtida tende a ser a mesma. Como cada BS é capaz de fornecer uma taxa máxima, dividindo-se esse valor pela taxa obtida por cada usuário, encontra-se a quantidade de usuários atendidos por uma célula. Tendo em vista que a taxa total obtida pelos usuários não se alterou mesmo com a mudança da freqüência é de se esperar que o número de usuários permaneça o mesmo nas duas situações. 


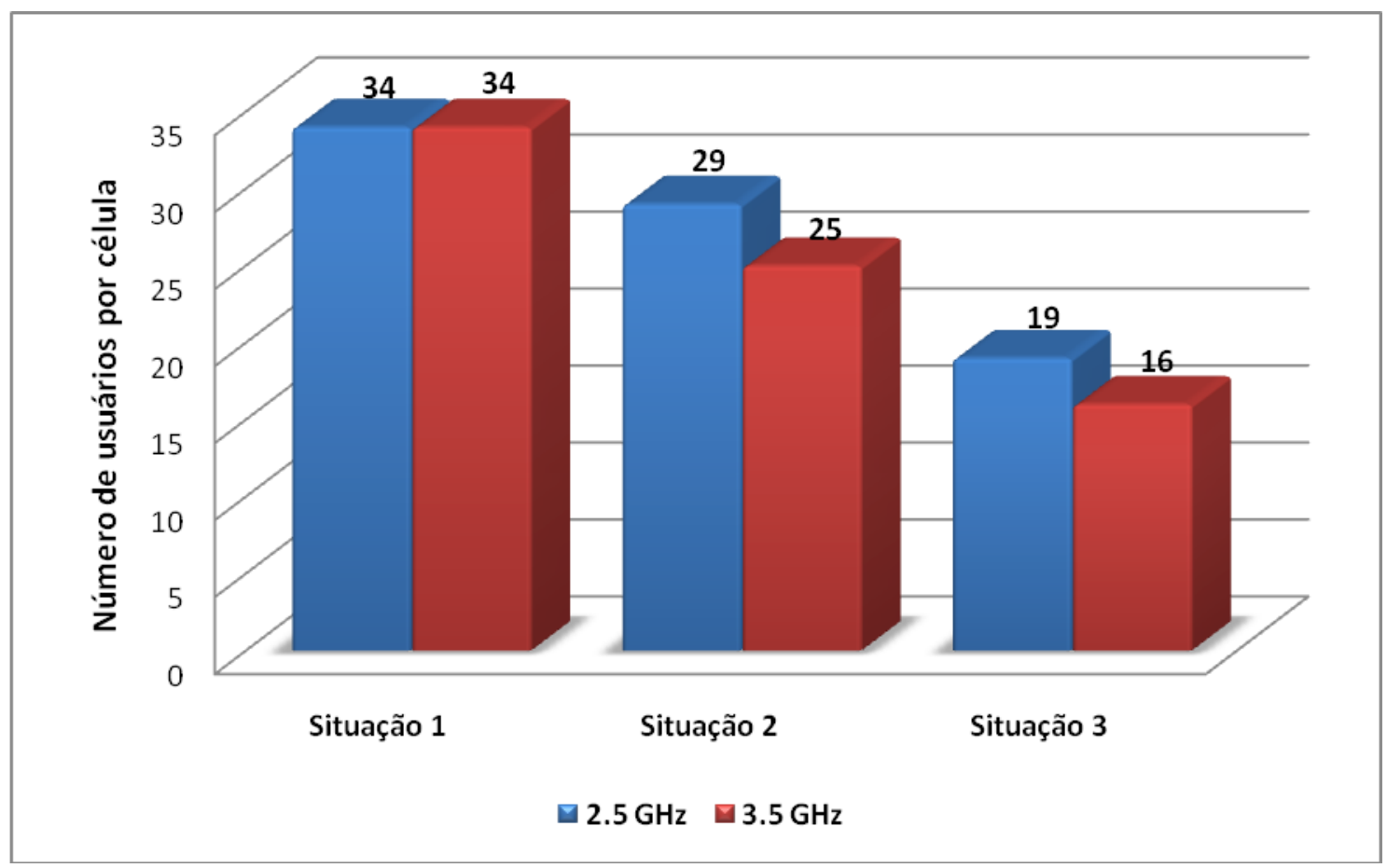

Figura 3.23: Número usuários por célula na comparação entre freqüências

Já nas situações 2 e 3, com a mudança da freqüência, alguns usuários alteraram suas técnicas de modulação/codificação. Houve um melhor aproveitamento da banda do canal, quando a freqüência foi setada em $2,5 \mathrm{GHz}$, ou seja, alguns usuários passaram a ter modulação menos robusta, porém com maior eficiência espectral. Isso traz como conseqüência, uma célula capaz de comportar um maior número de usuários. É também por este motivo, que a taxa obtida na freqüência de $2,5 \mathrm{GHz}$ é superior a taxa na frequiência de 3,5 GHz, conforme ilustra a Figura 3.24.

Já a taxa total obtida por célula, na situação 1 (Figura 3.6), é quase a mesma para ambas as faixas de frequiência. Porém, para a faixa de $2,5 \mathrm{GHz}$, o sistema se mostra um pouco mais eficiente, mesmo estando todos os usuários operando na modulação 64QAM 3/4. Isso se deve ao fato de a faixa de $3,5 \mathrm{GHz}$ apresentar maiores perdas de percurso, o que leva a um menor valor de SNR para uma certa distância. Diminuir a SNR acarreta em uma maior taxa de erro de bit (BER) - Eq. (3.24), e conseqüentemente, em uma maior BLER - Eq. (3.23). Assim, conforme mostrado na Eq. (3.22), a taxa total é diminuída. Entretanto, essa pequena diferença de taxa entre as duas faixas de freqüência estudadas não justifica um aumento no número de células utilizadas na cobertura desta região. 


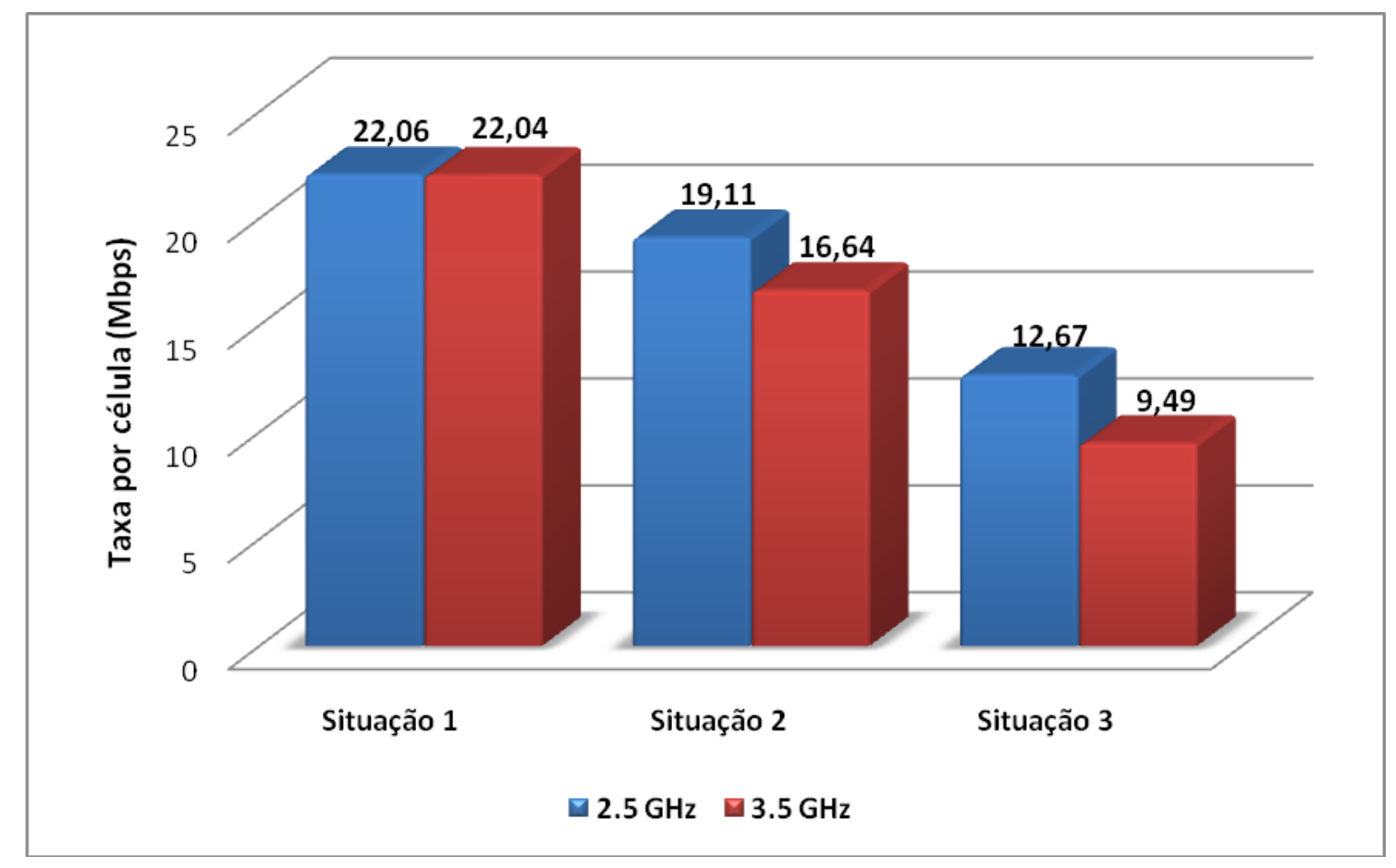

Figura 3.24: Taxa por célula na comparação entre freqüências

\subsubsection{Comparação em relação à banda do canal}

Para este teste optou-se por avaliar apenas o terreno tipo B, já que apresenta uma densidade de usuários intermediária. Como o objetivo era verificar a resposta do simulador sob diferentes tamanhos de canais e bandas, os demais parâmetros não foram alterados . As variáveis de saída analisadas são as mesmas do estudo de comparação em freqüência, ou seja, número de células, taxa e número de usuários atendidos por BS. Este teste foi realizado numa freqüência de $3,5 \mathrm{GHz}$, e com as mesmas características populacionais utilizadas na simulação da situação 2 anterior. A Tabela 3.9 apresenta os resultados obtidos para esta simulação. 
Tabela 3.15: Resultados para a comparação entre bandas

\begin{tabular}{|c|c|c|c|c|c|}
\hline$B(\mathrm{MHz})$ & $\mathbf{1 0}$ & $\mathbf{1 5}$ & $\mathbf{2 0}$ & $\mathbf{2 1}$ & $\mathbf{3 0}$ \\
\hline$B W(\mathrm{MHz})$ & $\mathbf{1 0}$ & $\mathbf{5}$ & $\mathbf{1 0}$ & $\mathbf{7}$ & $\mathbf{1 0}$ \\
\hline Número de células & 48 & 40 & 35 & 36 & 28 \\
\hline Desvio Padrão & 2,62 & 4,33 & 2,3 & 2,18 & 1,54 \\
\hline Quantidade de usuários & 25 & 30 & 33 & 32 & 43 \\
\hline Desvio Padrão & 1,33 & 2,93 & 2,06 & 1,99 & 2,58 \\
\hline Taxa por célula (Mbps) & 16,64 & 21,29 & 24,82 & 22,55 & 28,05 \\
\hline Desvio Padrão & 0,69 & 1,98 & 1,51 & 1,17 & 2,84 \\
\hline
\end{tabular}

Aumentar a banda proporciona um aumento na capacidade de tráfego oferecida pela célula, conforme mostrado na Figura 3.25. A primeira vista, pode parecer que com uma banda de $21 \mathrm{MHz}$ e um canal de $7 \mathrm{MHz}$, o sistema teria um desempenho melhor do que a configuração com banda de $20 \mathrm{MHz}$ e canal de $10 \mathrm{MHz}$, pois a banda é $1 \mathrm{MHz}$ maior. Todavia, observa-se que isso não ocorreu. Isso se deve ao fato de que o canal de 7 MHz possui o símbolo com duração maior do que o símbolo do canal de $10 \mathrm{MHz}$. Como a taxa é inversamente proporcional ao período do símbolo, o comportamento encontrado é justificado.

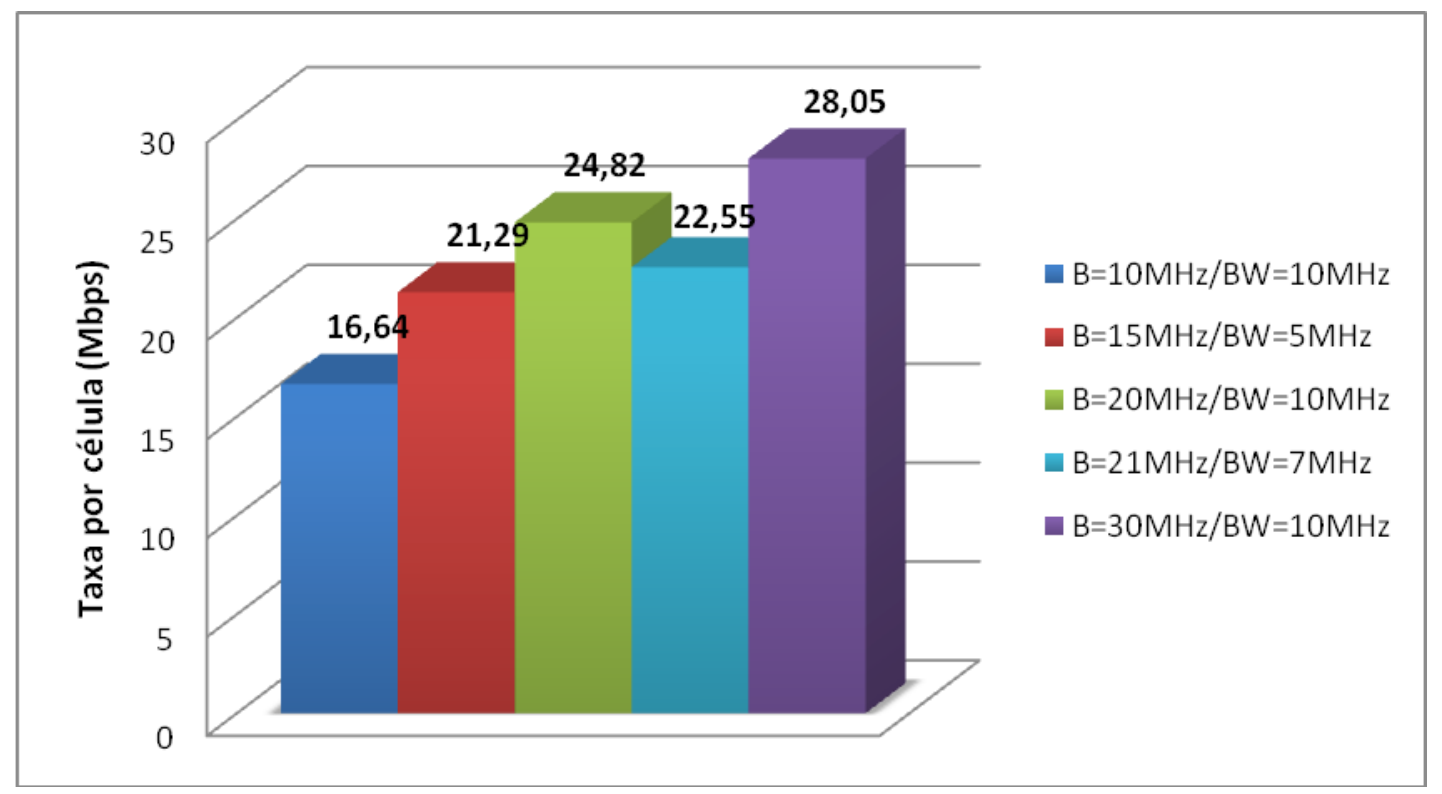

Figura 3.25: Taxa por célula na comparação entre banda

A Figura 3.26 mostra que, conforme esperado, quanto maior a banda disponível menor é o número de células necessárias para cobrir a região, com exceção do caso de 21 
MHz de banda, que conforme explicado apresenta uma menor taxa por célula, e portando um maior número de células, quando comparado à banda de $20 \mathrm{MHz}$.

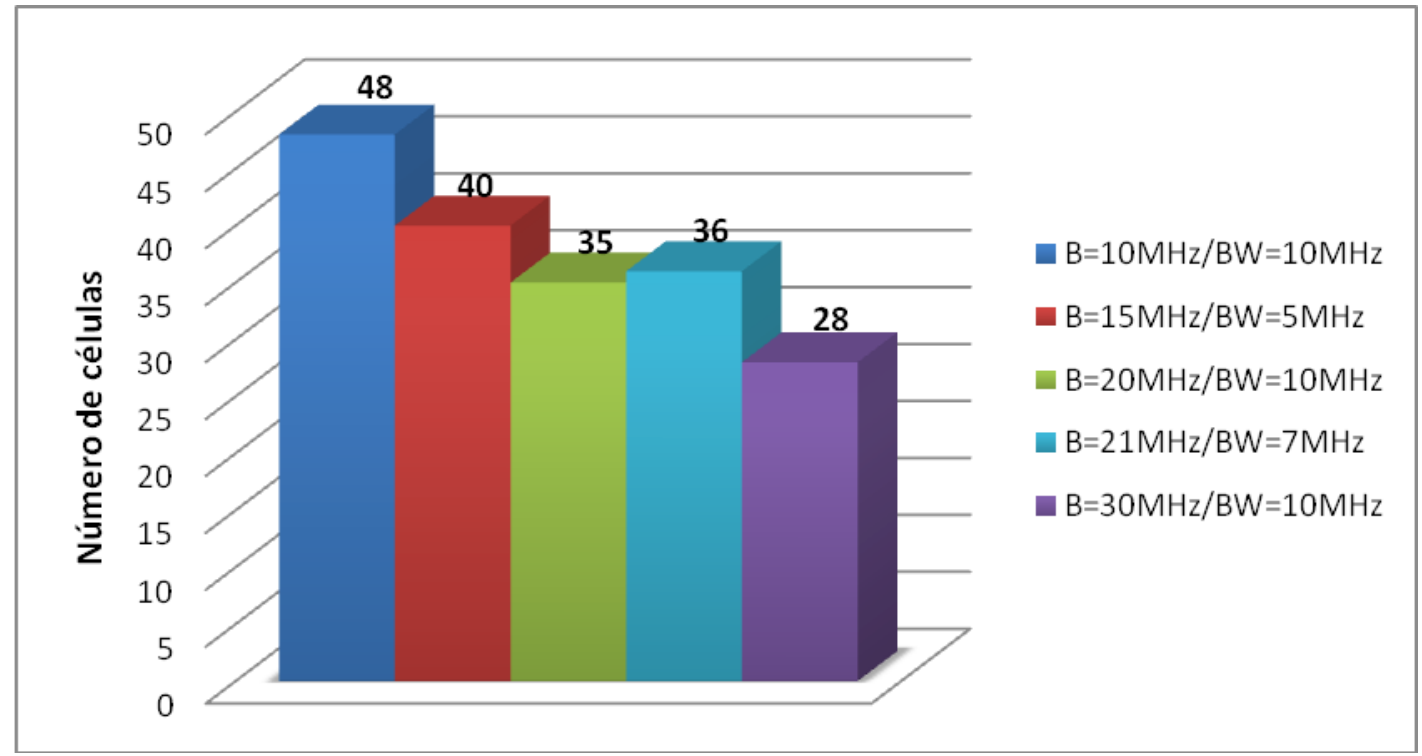

Figura 3.26: Número de células na comparação entre freqüências

A quantidade de usuários por célula segue um comportamento inverso ao do número de células, conforme mostrado na Figura 3.27.

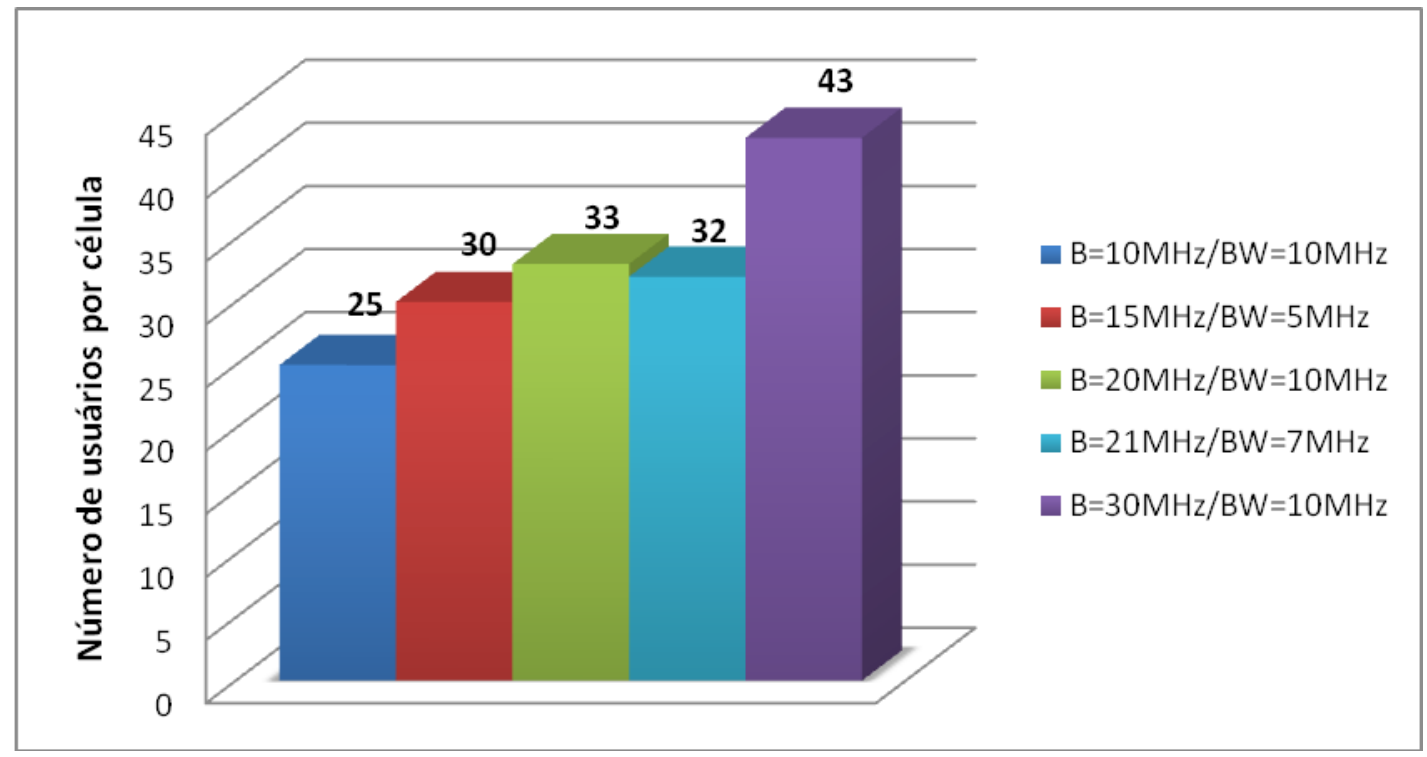

Figura 3.27: Número de usuários por célula na comparação entre freqüências 


\subsection{Conclusão}

Este capítulo apresentou uma metodologia para dimensionamento de redes WiMAX, que permite determinar o número de células em uma dada região, a partir de parâmetros que caracterizam o ambiente, os tipos de serviços oferecidos e o sistema.

A metodologia foi avaliada utilizando um aplicativo desenvolvido em Matlab, para diferentes condições de ambiente e do sistema. Os dados obtidos em cada configuração foram avaliados e comparados entre si, a fim de verificar o impacto causado pela variação de alguns dos parâmetros de entrada.

O próximo capítulo é dedicado a avaliação de drive tests realizados por duas operadoras de telecomunicações, que estão estudando a implementação do sistema WiMAX. 


\section{ANÁLISE DE DRIVE TESTS DE SISTEMAS WIMAX}

\subsection{Introdução}

Este capítulo tem a finalidade de analisar o desempenho de sistemas WiMAX, em implantação, de duas grandes operadoras de telefonia móvel. Para a implantação de um sistema de comunicação, é necessário que sejam realizados testes para que se possa verificar o funcionamento da rede. O objetivo é atender a diversos perfis de usuário e ajustar as ferramentas a serem utilizadas no planejamento e na manutenção da rede.

As medidas são desenvolvidas com o objetivo de verificar parâmetros que sejam, de alguma forma, importantes para avaliação do desempenho do sistema. Parâmetros de relevância, para o caso em questão, são: o RSSI (Received Signal Strenght Indicator), o CINR (Carrier to interference-plus-Noise Ratio), a potência transmitida (Uplink), MCS (Modulation and Coding Scheme) e a taxa de dados recebida (Throughput).

A seguir, serão apresentados os resultados das operadoras A e B.

\subsection{Operadora A}

Em uma rede WiMAX existem vários parâmetros a serem configurados de forma a caracterizá-la. Nos testes realizados pela operadora A as configurações do sistema são as seguintes:

- $\quad$ Banda do canal $(B W) 5 \mathrm{MHz}$;

- Tamanho da FFT igual a 512;

- Prefixo cíclico $(G)$ igual a $1 / 8$;

- $\mathrm{RTG}=\mathrm{TTG}=60 \mu \mathrm{s}$

- Razão de TDD igual a 2:1, sendo 30 símbolos para download e 15 símbolos para upload.

A operadora A realizou os testes de estabilidade e cobertura. Os mesmo serão retratados nos tópicos a seguir. 


\subsubsection{Teste de Estabilidade}

O sistema WiMAX permite a utilização de diversos serviços, cada um com suas necessidades e limitações. Com isso, o padrão IEEE 802.16d definiu classes de serviços a partir da QoS (Quality of Service) requerida por cada um deles, o que facilitou a distribuição da banda entre os diferentes usuários e a análise dos parâmetros necessários para sua aplicação.

As quatro classes de serviços definidas pelo padrão IEEE 802.16d são:

- Unsolicited Grant Service (UGS)

- real-time Polling Service (rtPS)

- $\quad$ non-real-time Polling Service (nrtPS)

- Best-Effort (BE)

Uma quinta classe de serviço foi adicionada no padrão IEEE 802.16e:

- $\quad$ extended real-time Polling Service (ertPS)

A Tabela 4.1 a seguir mostra as especificações de QoS para cada classe definida:

Tabela 4.16: Aplicações de WiMAX móvel e QoS [9]

\begin{tabular}{|c|c|c|}
\hline Categoria de QoS & Aplicação & Especificações de QoS \\
\hline UGS & VoIP & $\begin{array}{l}\text { - Máxima taxa de transmissão sustentada } \\
\text { - Tolerância de latência máxima } \\
\text { - Tolerância de jitter }\end{array}$ \\
\hline $\mathrm{rtPS}$ & $\begin{array}{c}\text { Streaming de áudio } \\
\text { ou vídeo }\end{array}$ & $\begin{array}{l}\text { - Máxima taxa de transmissão sustentada } \\
\text { - Prioridade de tráfego } \\
\text { - Mínima taxa de transmissão sustentada } \\
\text { - Tolerância de latência máxima }\end{array}$ \\
\hline ertPS & $\begin{array}{c}\text { VoIP com detecção } \\
\text { ativa }\end{array}$ & $\begin{array}{l}\text { - Máxima taxa de transmissão sustentada } \\
\text { - Prioridade de tráfego } \\
\text { - Mínima taxa de transmissão sustentada } \\
\text { - Tolerância de latência máxima } \\
\text { - Tolerância de jitter }\end{array}$ \\
\hline nrtPS & $\begin{array}{c}\text { FTP } \\
\text { (File Transfer } \\
\text { Protocol) }\end{array}$ & $\begin{array}{l}\text { - Máxima taxa de transmissão sustentada } \\
\text { - Prioridade de tráfego } \\
\text { - Mínima taxa de transmissão sustentada }\end{array}$ \\
\hline
\end{tabular}


Continuação da Tabela 4.1

\begin{tabular}{|c|c|l|}
\hline Categoria de QoS & Aplicação & Especificações de QoS \\
\hline BE & $\begin{array}{c}\text { Transferência de dados, } \\
\text { navegação na internet, } \\
\text { etc. }\end{array}$ & $\begin{array}{c}\text { Máxima taxa de transmissão sustentada } \\
\text { Prioridade de tráfego }\end{array}$ \\
\hline
\end{tabular}

Especificações de QoS:

- Máxima taxa de transmissão sustentada:

Parâmetro que define o pico da taxa de transferência do serviço. Este não limita a taxa instantânea. Entretanto, para a interface da rede de destino, o serviço deve ser controlado para atender a este parâmetro, na média, sobre o tempo.

- Prioridade de tráfego:

Este parâmetro seta um bit para indicar à BS (Base Station) que a SS (Subscriber Station) em questão deve continuar trafegando informação quando estiver em sleep mode.

- Mínima taxa de transmissão reservada

Especifica a taxa mínima de transmissão que deve ser reservada para o serviço pela BS.

- Tolerância de latência máxima

Especifica o máximo período tolerável entre a saída da mensagem da SS e sua recepção na BS.

- Tolerância de jitter

Especifica o jitter (variação da latência no envio de pacotes subsequientes) tolerável para funcionamento normal de determinados serviços.

A partir da Tabela 4.1, nota-se que, para algumas aplicações do sistema WiMAX, parâmetros como o tempo máximo de latência e jitter são importantes. Assim, a empresa A achou necessária a realização de testes de estabilidade para medição desses parâmetros. 
O WiMAX Forum identificou diversas aplicações para sistemas baseados em [4]. Estas foram divididas em grupos e sumarizadas na Tabela 4.2. Foram definidos, também, limiares de latência, jitter e banda alocada:

Tabela 4.17: Limites aplicados aos serviço do sistema WiMAX [9]

\begin{tabular}{|c|c|c|c|c|c|c|c|}
\hline Grupo & Aplicação & \multicolumn{2}{|c|}{ Limite de banda alocada } & \multicolumn{2}{|c|}{ Limite de latência } & \multicolumn{2}{|c|}{ Limite de jitter } \\
\hline 1 & $\begin{array}{l}\text { interativos } \\
\text { multiplayer }\end{array}$ & Baixo & $50 \mathrm{kbps}$ & Baixo & $<25 \mathrm{~ms}$ & & N/A \\
\hline 2 & $\begin{array}{l}\text { VoIP e Video } \\
\text { Conferência }\end{array}$ & Baixo & 32 a $64 \mathrm{kbps}$ & Baixo & $<160 \mathrm{~ms}$ & Baixo & $<50 \mathrm{~ms}$ \\
\hline 3 & $\begin{array}{c}\text { Streaming de } \\
\text { Mídia } \\
\end{array}$ & $\begin{array}{c}\text { Baixo para } \\
\text { Alto } \\
\end{array}$ & $\begin{array}{c}5 \mathrm{kbps} \\
\text { a } 2 \mathrm{Mbps}\end{array}$ & & N/A & Baixo & $<100 \mathrm{~ms}$ \\
\hline 4 & $\begin{array}{c}\text { Navegação na } \\
\text { Web e } \\
\text { mensagens } \\
\text { instantâneas }\end{array}$ & Moderado & $\begin{array}{l}10 \mathrm{kbps} \\
\text { a } 2 \mathrm{Mbps}\end{array}$ & & N/A & & N/A \\
\hline 5 & $\begin{array}{l}\text { Conteúdos } \\
\text { Multimídia e } \\
\text { Download }\end{array}$ & Alto & $>2 \mathrm{Mbps}$ & & N/A & & N/A \\
\hline
\end{tabular}

Os testes de estabilidade têm como objetivo a verificação do comportamento do sistema implantado. Por este motivo, todo o canal foi alocado para o usuário de teste, para averiguar se os elementos em questão apresentavam comportamento igual ou próximo ao esperado, em termos de latência, jitter e taxa de transmissão, para diferentes situações.

Foram aplicados os seguintes testes aos elementos do sistema:

\subsubsection{Teste de ping}

Inicialmente, foram realizados testes de ping para aferir a latência média do sistema em questão. Para isso, foram aplicados os seguintes critérios:

- Usuário com perfil denominado user5Mb (usuário que demanda taxa média de $5 \mathrm{Mbps})$;

- Serviços Best-Effort;

- Utilização de placa PCMCIA ZyXEL Max-110 Rev. 2;

- Condição LOS (Line-of-Sight) estático; 
$\mathrm{O}$ primeiro teste, realizado no setor 1 do site $\mathrm{BBB}$, durou uma hora. $\mathrm{O}$ usuário procurou acessar o servidor WAC (Windows Access), que estava ligado a um setor diferente. Com isso, pôde-se avaliar a estabilidade do sistema quando um usuário tenta acessar um servidor que não está no seu setor. Para os testes subseqüentes, servidor WAC e usuário se encontravam no mesmo setor.

Escolheu-se o setor 1 da BS BBB, que possui antena do tipo AAS, e o ping médio obtido foi de 159 ms. Como esse parâmetro é a medida do período entre a mensagem enviada pela SS e a resposta recebida pela mesma, pode-se afirmar que o período médio de latência entre a mensagem enviada da SS e o recebimento desta pela BS (Base Station) é menor que 79,5 ms, dado que existe o tempo de processamento da mensagem pela BS.

O segundo teste foi realizado no setor 3 do site AAA e teve duração de 30 minutos. Este setor utiliza antena de polarização cruzada e é não-segmentada. $\mathrm{O}$ ping médio obtido foi de $158 \mathrm{~ms}$ e, portanto, a latência média é considerada menor que $79 \mathrm{~ms}$.

O terceiro ocorreu no setor 4 do site AAA e também teve duração de 30 minutos. Este setor possui antena AAS e utiliza segmentação PUSC. A latência média obtida foi inferior a 79,5 ms, já que o ping médio foi de 159 ms.

$\mathrm{O}$ quarto teste, realizado novamente no setor 1 do site $\mathrm{BBB}$, mas mantendo o usuário em apenas umas estação, obteve latência média menor que 76,5 ms. Sua duração foi de 30 minutos.

O quinto e último teste de ping realizado, foi aplicado sobre setor 2 do site BBB (antena com polarização cruzada e segmentação PUSC). Sua latência média foi a menor dentre os testes até então realizados, atingindo valor menor que 75,5 ms.

Em todos os testes realizados obteve-se $0 \%$ de perdas de pacotes.

Os testes foram realizados com alguns usuários de teste na rede. Entretanto, a quantidade de usuários ativos não permite uma visualização de funcionamento da mesma sobre máxima capacidade, visto que se trata de um número pequeno de usuários.

A Tabela 4.3 mostra o resultado dos testes: 
Tabela 4.18: Resultado de testes de ping para setores dos sites BBB e AAA (drive test realizado pela empresa A)

\begin{tabular}{|c|c|c|c|c|c|c|c|c|}
\hline \multirow[b]{2}{*}{ BS/Setor } & \multirow{2}{*}{$\begin{array}{c}\text { Freqüência Central } \\
\text { de Downlink } \\
(\mathrm{kHz})\end{array}$} & \multirow[b]{2}{*}{ Permut. } & \multirow[b]{2}{*}{$\begin{array}{l}\text { Tipo de } \\
\text { Antena }\end{array}$} & \multicolumn{4}{|c|}{ ping } & \multirow{2}{*}{$\begin{array}{l}\text { Duração } \\
\text { do Teste } \\
\text { (min) }\end{array}$} \\
\hline & & & & Médio (ms) & $\begin{array}{c}\text { Máximo } \\
\text { (ms) }\end{array}$ & Mínimo (ms) & Perdas $(\%)$ & \\
\hline $\mathrm{BBB} / 1$ & 3571250 & Normal & AAS & 159 & 791 & 40 & 0 & 60 \\
\hline AAA/3 & 3571250 & Normal & Cruzada & 158 & 741 & 70 & 0 & 30 \\
\hline AAA/4 & 3471250 & PUSC 1 & AAS & 159 & 882 & 60 & 0 & 30 \\
\hline $\mathrm{BBB} / 1$ & 3571250 & Normal & AAS & 153 & 851 & 70 & 0 & 30 \\
\hline $\mathrm{BBB} / 2$ & 3471250 & PUSC 1 & Cruzada & 151 & 681 & 40 & 0 & 30 \\
\hline
\end{tabular}

Serviços como os do grupo 1 da Tabela 4.2 necessitam de latência menor que $25 \mathrm{~ms}$ para seu correto funcionamento. Nos testes de ping acima descritos, foram obtidas latências médias da ordem de $70 \mathrm{~ms}$. Considerando-se que, ao operar em sua capacidade máxima, o período médio de latência do sistema deve aumentar consideravelmente, e que latências com valor maior que os estipulados podem gerar eco e degradar a qualidade da aplicação, pode-se afirmar que alguns serviços não poderão ser implementados até a otimização da rede.

Como estes estavam sendo realizados utilizando o perfil de usuário Best-Effort, serviços que não possuem limitações de QoS quanto à latência e jitter, os resultados se mostraram demasiadamente altos em termos de latência. Utilizando-se serviços de UGS (VoIP e vídeo conferência) a latência caía para 20ms, já que features de QoS eram utilizadas para se estabelecer a aplicação. Entretanto, os serviços do tipo Best-Effort - o foco das aplicações desta operadora - degradaram-se, devido às instabilidades encontradas na versão de software utilizada, tornando-se impraticáveis. Foi possível confirmar a inviabilidade na prestação de alguns serviços.

\subsubsection{Testes de jitter e perdas}

As BS's são limitas em termos de roteamento de pacotes de forma imediata. Caso o número de pacotes recebidos seja maior que esta capacidade da BS de roteá-los, a mesma terá que guardá-los em uma fila, gerando congestionamento no sistema.

Em caso de severo congestionamento, a BS pode simplesmente descartar os pacotes em excesso, não os reencaminhando. O jitter é a medida utilizada para avaliar o trânsito de pacotes pela BS. Para jitters acima do valor definido, as perdas de pacotes podem ser tão 
elevadas que certos serviços degradam-se drasticamente. Chamadas VoIP podem se apresentar mudas nestas condições.

Os seguintes critérios foram aplicados para os testes de jitter:

- Utilização de setor não-segmentado e com antena omnidirecional;

- Serviços Best-Effort;

- $\mathrm{CPE}$ indoor;

- Linha de visada (LOS).

Os testes foram realizados para diferentes perfis de usuários e para diferentes alocações de banda. Um software específico para este tipo de teste foi utilizado. Todos os testes usaram o protocolo UDP, pois este tipo de tráfego não é sujeito a retransmissões, o que criaria situações de congestionamento com maior facilidade. Além disso, serviços de VoIP não utilizam retransmissão, já que os pacotes perdidos deixam de ser necessários após um curto limite de tempo. Caso isto acontecesse, a chamada tornar-se-ia inviável. Nesses casos, a perda de pacotes na comunicação é preferível.

Novamente, deve-se considerar que o jitter pode piorar com a entrada de mais usuários na rede.

Os resultados destes testes são resumidos na Tabela 4.4.

Tabela 4.19: Resultado de testes de jitter e perdas para diferentes perfis de usuários. (drive test realizado pela empresa $\mathrm{A}$ )

\begin{tabular}{|c|c|c|c|c|}
\hline Usuário & Tipo de Protocolo & Taxa (kbps) & Jitter $(\mathbf{m s})$ & Perdas (\%) \\
\hline \multirow{4}{*}{ User5Mb } & UDP & 1000 & 6,02 & 0,00 \\
\cline { 2 - 5 } & UDP & 2000 & 7,25 & 0,00 \\
\cline { 2 - 5 } & UDP & 3000 & 5,87 & 0,00 \\
\cline { 2 - 5 } & UDP & 4000 & 4,95 & 0,00 \\
\cline { 2 - 5 } & UDP & 4100 & 4,94 & 0,00 \\
\cline { 2 - 5 } & UDP & 4200 & 4,20 & 0,03 \\
\hline \multirow{3}{*}{ User2Mb } & UDP & 512 & 7,82 & 0,00 \\
\cline { 2 - 5 } & UDP & 1000 & 6,13 & 0,00 \\
\cline { 2 - 5 } & UDP & 2000 & 7,26 & 0,00 \\
\hline
\end{tabular}

Continuação da Tabela 4.4

\begin{tabular}{|c|c|c|c|c|}
\hline Usuário & Tipo de Protocolo & Taxa (kbps) & Jitter $(\mathbf{m s})$ & Perdas (\%) \\
\hline \multirow{2}{*}{ User1Mb } & UDP & 512 & 7,83 & 0,00 \\
\cline { 2 - 5 } & UDP & 1000 & 5,77 & 0,00 \\
\hline
\end{tabular}




\begin{tabular}{|l|l|l|l|l|}
\hline \multirow{2}{*}{ User512 } & UDP & 256 & 3,53 & 0,00 \\
\cline { 2 - 5 } & UDP & 512 & 7,84 & 0,00 \\
\hline
\end{tabular}

Os testes de jitter confirmaram que o sistema mostra-se promissor quanto a sua utilização para serviços com limitação de jitter. Segundo o fornecedor do serviço, o jitter apresentou valores ainda menores quando se utilizou serviços UGS. Entretanto, como citado anteriormente, ao se utilizarem estes serviços, ocorreu grande degradação dos demais serviços, como o Best-Effort por exemplo.

\subsubsection{Testes de FTP}

Testes de FTP foram executados para averiguar a estabilidade do sistema em termos da taxa de transmissão. Disponibilizando-se toda a banda disponível da BS, afere-se uma medida da máxima taxa oferecida pela mesma. Para a realização dos testes foi utilizado:

- Placa PCMCIA ZyXEL Max-110;

- Perfil de usuário user5Mb.

Um software específico para realização deste tipo de teste foi utilizado. Com este software, executa-se o download de um arquivo pré-definido no servidor FTP próprio do sistema (livre de interferências externas) e, em seguida, o upload do mesmo arquivo do usuário para o servidor. Desta forma, medidas de download e upload podem ser realizadas.

Foram obtidas medidas dos setores 3 e 4 do site AAA e setores 1 e 2 do site BBB, em situações LOS e NLOS.

A Tabela 4.5 mostra os resultados dos testes de FTP realizados para os diversos setores e situações:

Tabela 4.20: Resultado de testes de FTP para diversos setores e situações. [drive test realizado pela empresa A)

\begin{tabular}{|c|c|c|c|c|c|c|c|c|c|c|}
\hline \multirow[b]{2}{*}{ BS/Setor } & \multirow{2}{*}{$\begin{array}{c}\text { Freqüência } \\
\text { Central de } \\
\text { Downlink }(\mathbf{k H z})\end{array}$} & \multirow[b]{2}{*}{ Permutação } & \multirow{2}{*}{$\begin{array}{l}\text { Tipo de } \\
\text { Antena }\end{array}$} & \multicolumn{3}{|c|}{ FTP } & \multirow{2}{*}{$\begin{array}{l}\text { CINR } \\
\text { médio } \\
\text { (dB) }\end{array}$} & \multirow{2}{*}{$\begin{array}{c}\text { Condições } \\
\text { de RF }\end{array}$} & \multirow{2}{*}{$\begin{array}{c}\text { Distância da } \\
\text { BS (m) }\end{array}$} & \multirow{2}{*}{$\begin{array}{l}\text { Duração do } \\
\text { Teste (min) }\end{array}$} \\
\hline & & & & Tipo & $\begin{array}{l}\text { Médio } \\
\text { (kbps) }\end{array}$ & $\begin{array}{c}\text { Máximo } \\
\text { (kpbs) }\end{array}$ & & & & \\
\hline $\mathrm{BBB} / 1$ & 3471250 & Normal & AAS & Download & 921 & 3763 & 28,5 & LOS & 350 & 60 \\
\hline $\mathrm{AAA} / 3$ & 3471250 & Normal & Cruzada & Download & 917 & 2186 & 31,0 & LOS & 190 & 6 \\
\hline $\mathrm{AAA} / 3$ & 3471250 & Normal & Cruzada & Upload & 862 & 1373 & 31,0 & LOS & 190 & 6 \\
\hline AAA/3 & 3471250 & Normal & Cruzada & Download & 772 & 2028 & 23,0 & NLOS & 520 & 6 \\
\hline
\end{tabular}




\begin{tabular}{|c|c|c|c|c|c|c|c|c|c|c|}
\hline $\mathrm{AAA} / 3$ & 3471250 & Normal & Cruzada & Upload & 702 & 1373 & 21,0 & NLOS & 520 & 6 \\
\hline $\mathrm{AAA} / 4^{1}$ & 3571250 & PUSC 1 & AAS & Download & 901 & 1041 & 31,0 & LOS & 100 & 6 \\
\hline $\mathrm{AAA} / 4^{1}$ & 3571250 & PUSC 1 & AAS & Upload & 363 & 438 & 27,5 & LOS & 100 & $\overline{6}$ \\
\hline $\mathrm{AAA} / 4^{1}$ & 3571250 & PUSC 1 & AAS & Download & 552 & 1040 & 15,0 & NLOS & 300 & 6 \\
\hline$\overline{\mathrm{AAA} / 4^{1}}$ & 3571250 & $\begin{array}{l}\text { PUSC } 1 \\
\end{array}$ & AAS & Upload & 333 & 439 & 13,5 & NLOS & 300 & 6 \\
\hline $\mathrm{BBB} / 1$ & 3471250 & Normal & AAS & Download & 856 & 2396 & 29,5 & LOS & 1170 & 6 \\
\hline $\mathrm{BBB} / 1$ & 3471250 & Normal & AAS & Upload & 748 & 1373 & 29,5 & LOS & 1170 & $\overline{6}$ \\
\hline $\mathrm{BBB} / 1$ & 3471250 & Normal & AAS & Download & 2600 & 5140 & 24,0 & NLOS & 920 & 6 \\
\hline $\mathrm{BBB} / 1$ & 3471250 & Normal & AAS & Upload & 241 & 644 & 20,0 & NLOS & 920 & 6 \\
\hline $\mathrm{BBB} / 2$ & 3571250 & PUSC 1 & Cruzada & Download & 1174 & 1576 & 31,5 & LOS & 450 & 6 \\
\hline $\mathrm{BBB} / 2$ & 3571250 & PUSC 1 & Cruzada & Upload & 330 & 437 & 31,5 & LOS & 450 & 6 \\
\hline $\mathrm{BBB} / 2$ & 3571250 & PUSC 1 & Cruzada & Download & 639 & 1545 & 24,0 & NLOS & 750 & 6 \\
\hline $\mathrm{BBB} / 2$ & 3571250 & PUSC 1 & Cruzada & Upload & 162 & 199 & 22,0 & NLOS & 750 & 6 \\
\hline
\end{tabular}

A partir dos resultados dos testes de FTP, conclui-se que taxas muito inferiores ao esperado foram alcançadas, mesmo para situações onde a CINR permitia modulações de alta eficiência espectral. Em uma primeira análise, considerou-se que a versão de software utilizada também apresentou instabilidade quanto ao throughput.

A Tabela 4.6 mostra as taxas de transmissão sustentadas, aferidas nos testes da operadora A, e proporciona uma comparação com dados do software de predição:

Tabela 4.21: Taxas sustentadas pela operadora A e simuladas pelo software de planejamento

\begin{tabular}{|c|c|c|c|}
\hline \multicolumn{4}{|c|}{ Canal de $5 \mathrm{MHz}$} \\
\hline \multicolumn{2}{|c|}{ Throughput [Mbps] } & \multicolumn{2}{|c|}{ Modulação (Taxa de Codificação) } \\
\hline \multicolumn{2}{|c|}{ Operadora A } & \multicolumn{2}{|c|}{ Simulador [Mbps] } \\
\hline \multirow{2}{*}{ Minimo } & \multirow{2}{*}{0,552} & $\mathrm{BPSK}(1 / 2)$ & 1,17 \\
\hline & & $\mathrm{QPSK}(1 / 2)$ & 2,33 \\
\hline \multirow{2}{*}{ Médio } & \multirow{2}{*}{0,917} & $\mathrm{QPSK}(3 / 4)$ & 3,5 \\
\hline & & 16-OAM (1/2) & 4,67 \\
\hline \multirow{2}{*}{ Móximo } & \multirow{2}{*}{2,6} & $16-0 A M(3 / 4)$ & 7,01 \\
\hline & & 64-OAW (1/2) & 7,01 \\
\hline
\end{tabular}

A partir da Tabela 4.6 pode-se perceber que a máxima taxa de transmissão sustentada nos testes da operadora A foi de 2,6 Mbps (resultado conseguido no setor 1 do site $\mathrm{BBB}$, cujos resultados foram mais favoráveis devido às condições deste setor). Nesta situação, o setor se encontrava com CINR de $24 \mathrm{~dB}$, o que lhe permitia a utilização da modulação 64-QAM 1/2. Valendo-se dos parâmetros utilizados pela operadora A, os dados simulados também foram expressos na Tabela 4.6 e uma taxa de transmissão de 7,01Mbps foi alcançada para a modulação citada anteriormente. Percebe-se que, mesmo para o ${ }^{1} \mathrm{O}$ setor AAA/4 apresentou problemas de hardware e estava com a modulação 64-QAM bloqueada. 
melhor caso, a taxa de transmissão alcançada estava aquém do simulado. Desta forma, percebe-se o grau de instabilidade da versão do software utilizado pela operadora A.

\subsubsection{Teste de cobertura}

Para que a BS tome decisões apropriadas sobre o gerenciamento de recursos de transmissão (controle de potência, modulação e codificação, etc.), em [3] definiram-se duas famílias de indicadores de qualidade do canal:

- RSSI (Received Signal Strength Indicator): Informação do nível de potência recebida.

- CINR (Carrier-to-Interference-and-Noise Ratio): Informação sobre o nível da razão entre a potência e o somatório da interferência e ruído na banda de uma portadora.

\subsubsection{RSSI}

A medida do RSSI, como definido por [4], não requer que o receptor demodule o sinal, reduzindo a potência de processamento demandada. Após um requerimento da BS, a SS faz medidas instantâneas de RSSI. O conjunto de medidas de RSSI instantâneas é utilizado para se calcular RSSI médio e seu desvio padrão. A média $\mu_{R S S I}[k]$ e o desvio

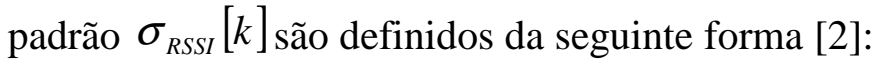

$$
\begin{gathered}
\mu_{R S S I}[k]=\left\{\begin{array}{l}
R[0] \\
\left(1-\alpha_{\text {avg }}\right) \cdot \mu_{R S S I}[k-1]+\alpha_{\text {avg }} \cdot R[k] \quad \text { se } k=0 \\
x_{\text {RSSI }}^{2}[k]=\left\{\begin{array}{l}
\left|R[0]^{2}\right| \\
\text { se } k>0
\end{array} \quad(m W)\right. \\
\left(1-\alpha_{\text {avg }}\right) \cdot x_{\text {RSSI }}^{2}[k-1]+\alpha_{\text {avg }} \cdot \mid R[k]^{2} \quad \text { se } k>0 \quad\left(m W^{2}\right)
\end{array}\right. \\
\mu_{R S S I_{d B m}}[k]=10 \log \left(\mu_{\text {RSSI }}[k]\right) \quad(d B m) \\
\sigma_{R S S I_{d B m}[k]=5 \log \left(\left|x_{R S S I}^{2}[k]-\left(\mu_{R S S I}[k]\right)^{2}\right|\right) \quad(d B)}
\end{gathered}
$$


Onde R[k] é a k-ésima medida de RSSI instantânea, $\alpha_{R S S I}$ é o fator de média e $x_{R S S L}^{2}[k]$ é a expectativa estatística quadrática. O índice da amostra $\mathrm{k}$ é incrementado a cada frame. E a potência é medida sobre o preâmbulo do frame.

O método para se aferir a RSSI deve ser especificado pelo fornecedor do sistema, entretanto, as medidas devem se apresentar dentro de uma faixa de erro absoluto de $\pm 4 d B$ $[2]$.

\subsubsection{CINR}

As medidas de CINR requerem demodulação do sinal e, normalmente, são melhores indicadores da qualidade do canal.

A CINR média e seu desvio padrão são calculadas da mesma forma que o RSSI.

Alguns relatórios de CINR podem ser demandados, entre eles:

- CINR no preâmbulo: Em casos de redes com sistemas de reuso 3, a CINR é medida sobre as subportadoras moduladas do preâmbulo. Se a rede apresentar reuso de freqüência 1 , a CINR é medida sobre todas as subportadoras (moduladas ou não, excluindo a banda de guarda e subportadora DC).

- CINR em uma zona de permutação: Neste caso, amostras da CINR são retiradas a partir das subportadoras piloto da zona de permutação.

Os testes de cobertura realizados pela operadora A visam a obtenção da área de cobertura das células implantadas por meio dos valores de CINR (em dB) e RSSI (em $\mathrm{dBm}$ ) mensurados. Medidas sobre as subportadoras do preâmbulo foram utilizadas com intuito de se aferir a interferência de co-canal sem a necessidade de usuários adicionais na rede. Isto se deve ao fato de todas as subportadoras do preâmbulo serem transmitidas em todos os setores. Realizaram-se testes na cidade A (nome suprimido por solicitação da própria operadora), escolhida de acordo com interesses estratégicos da empresa. Considerando a localização das antenas na cidade A, a mesma foi determinada como suburbana (densidade populacional média). 
Para uma melhor visualização das áreas de cobertura, foram traçadas a circunferência de raio máximo, que levam em consideração CINRs maiores ou iguais a $8 \mathrm{~dB}$ e circunferências intermediárias, com raios progredindo a cada 500 metros.

Desta forma, para o sistema em questão, segundo informações do fornecedor do equipamento e de acordo com [4], a técnica de modulação de menor eficiência espectral considerada foi QPSK 1/2.

São apresentados testes realizados em dois momentos distintos: no primeiro deles, os setores não possuíam tipo algum de segmentação e as antenas implantadas eram antenas de polarização cruzada, somente; no segundo momento, alguns setores contaram com a segmentação PUSC e utilizaram antenas do tipo AAS (com beamforming estático, mas sem MIMO), além de algumas correções de tilt e azimute, que representam a posição angular vertical e horizontal da antena, respectivamente. A segmentação PUSC permite a utilização da mesma freqüência central para os setores em que ela foi adotada, visto que grupos diferentes de subportadoras serão alocados para cada setor do mesmo site. No caso em questão, cada um desses setores utiliza um terço da banda total de $5 \mathrm{MHz}$ e o setor do site que não adotou esquema de segmentação utilizou outra freqüência central e toda a banda de $5 \mathrm{MHz}$.

\section{Testes realizados na cidade $\mathrm{A}$}

A Tabela 4.7 contém as informações dos setores de cada site instalado do segundo momento.

Tabela 4.22: Informações de cada setor dos sites implantados na cidade A (drive test realizado pela empresa A)

\begin{tabular}{|c|c|c|c|c|c|c|c|c|c|}
\hline \multirow{2}{*}{ BS/Setor } & \multicolumn{2}{|c|}{ Coordenadas } & \multirow{2}{*}{$\begin{array}{c}\text { Freqüência } \\
\text { Central de } \\
\text { Downlink } \\
(\mathrm{kHz}) \\
\end{array}$} & \multirow{2}{*}{ Permutação } & \multirow{2}{*}{$\begin{array}{l}\text { Tipo de } \\
\text { Antena }\end{array}$} & \multirow{2}{*}{$\begin{array}{c}\text { Potência de } \\
\text { Transmissão } \\
\text { (dBm) }\end{array}$} & \multirow{2}{*}{$\begin{array}{c}\text { Altura } \\
\text { da } \\
\text { Antena } \\
\text { (m) } \\
\end{array}$} & \multirow{2}{*}{$\begin{array}{c}\text { Tilt } \\
\text { (graus) }\end{array}$} & \multirow{2}{*}{$\begin{array}{c}\text { Azimute } \\
(\mathbf{N V})\end{array}$} \\
\hline & Lat.(S) & Long.(W) & & & & & & & \\
\hline AAA/1 & $-25,3903$ & $-49,2381$ & 3571250 & PUSC 3 & Normal & 33,0 & 25 & 6 & 45 \\
\hline $\mathrm{AAA} / 2$ & $-25,3903$ & $-49,2381$ & 3571250 & PUSC 2 & Normal & 30,0 & 28 & 4 & 150 \\
\hline AAA/3 & $-25,3903$ & $-49,2381$ & 3471250 & Normal & Normal & 34,0 & 28 & 0 & 230 \\
\hline $\mathrm{AAA} / 4$ & $-25,3903$ & $-49,2381$ & 3571250 & PUSC 1 & AAS & 34,0 & 25 & 4 & 315 \\
\hline $\mathrm{BBB} / 1$ & $-25,3834$ & $-49,2316$ & 3471250 & Normal & AAS & 34,0 & 50 & 7 & 35 \\
\hline $\mathrm{BBB} / 2$ & $-25,3834$ & $-49,2316$ & 3571250 & PUSC 1 & Normal & 33,0 & 50 & 6 & 125 \\
\hline $\mathrm{BBB} / 3$ & $-25,3834$ & $-49,2316$ & 3571250 & PUSC 2 & Normal & 30,0 & 50 & 10 & 215 \\
\hline $\mathrm{BBB} / 4$ & $-25,3834$ & $-49,2316$ & 3571250 & PUSC 3 & Normal & 33,0 & 50 & 5 & 305 \\
\hline
\end{tabular}


A partir dos dados colhidos nas medidas, utilizou-se o software Mapinfo para gerar o mapa de cobertura (Figura 4.1):

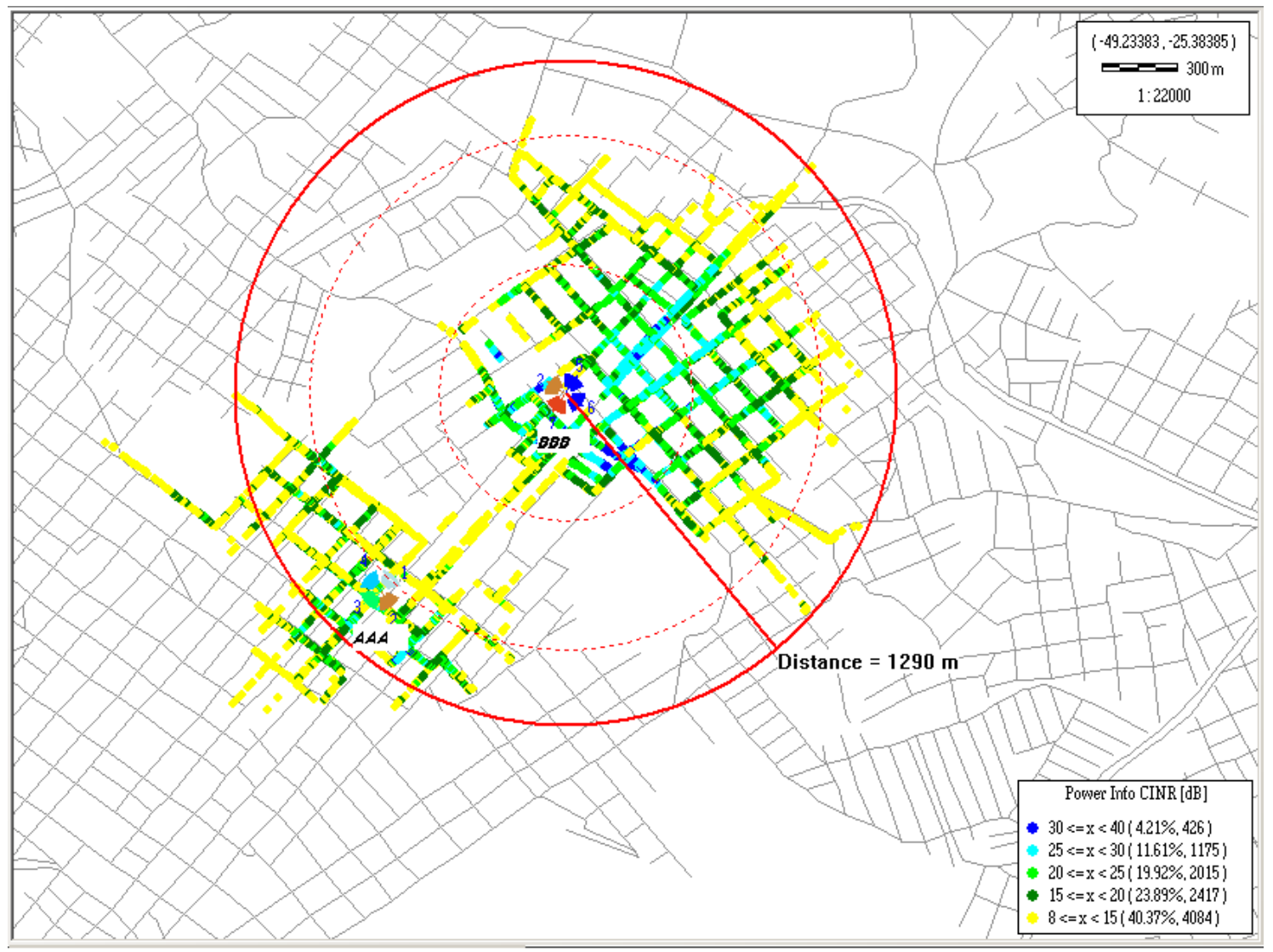

Figura 4.28: Mapa de Cobertura da Cidade A - Momento 1 


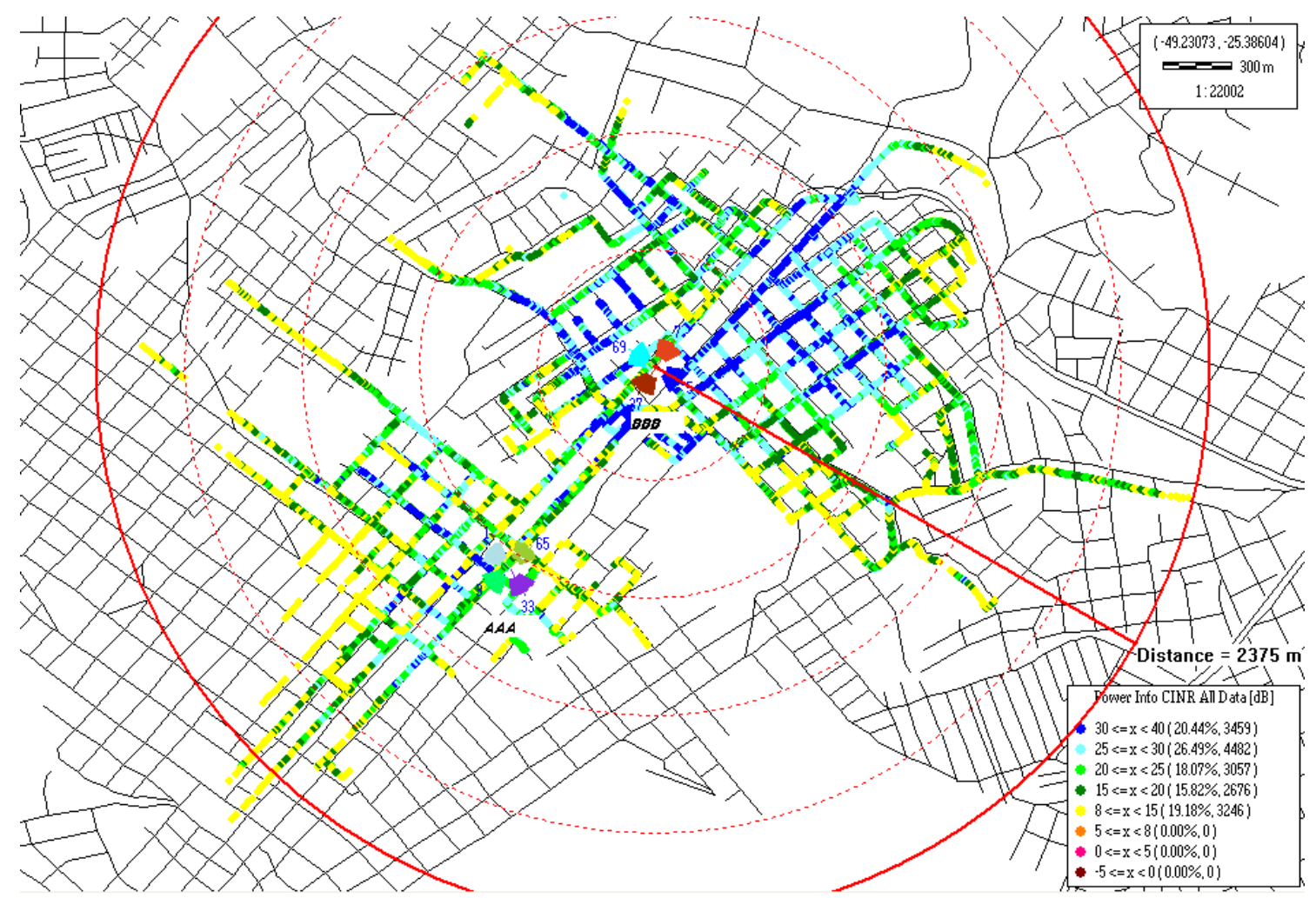

Figura 4.29: Mapa de Cobertura da Cidade A - Momento 2

Para uma avaliação quantitativa dos resultados obtidos em cada configuração, foram traçados gráficos da PDF (Probability Density Function) dos valores de CINR obtidos em cada uma delas (Figura 4.3). 


\section{Figura T3 : Comrat}

Considerando a Figura 4.1, obteve-se, para a primeira situação de teste, raio máximo de cobertura igual a 1290 metros. Já na segunda situação, a máxima distância de cobertura alcançada foi de 2375 metros, como pode ser visualizado pela Figura 4.2.

Analisando a Figura 4.3, percebe-se uma melhora na distribuição das CINRs obtidas do momento 1 para o momento 2, visto que uma quantidade superior de amostras apresentaram valores mais elevados de CINR para a segunda situação. Isto se deve ao fato de o modo de permutação PUSC ter por objetivo evitar que subportadoras adjacentes sejam oferecidas ao mesmo subcanal (diminuindo interferências de subportadoras adjacentes) e setores adjacentes possuírem grupos diferentes de subportadoras (diminuindo interferência de co-canal em setores adjacentes). Outro fator que influencia o aumento da área de cobertura é o fato de se usar beamforming estático. Com a focalização do lóbulo principal das posições determinadas para esta implementação, ocorrerá um aumento de alcance do setor. 
Com o objetivo de comparar os resultados obtidos na prática e os previstos pelo software de planejamento, escolheu-se o setor 1 do site BBB. Como o simulador não implementa antenas adaptativas, utilizou-se o primeiro momento de testes, já que nesta situação ainda não se havia implantado a antena AAS no setor em questão. O resultado dos testes é mostrado na Figura 4.4:

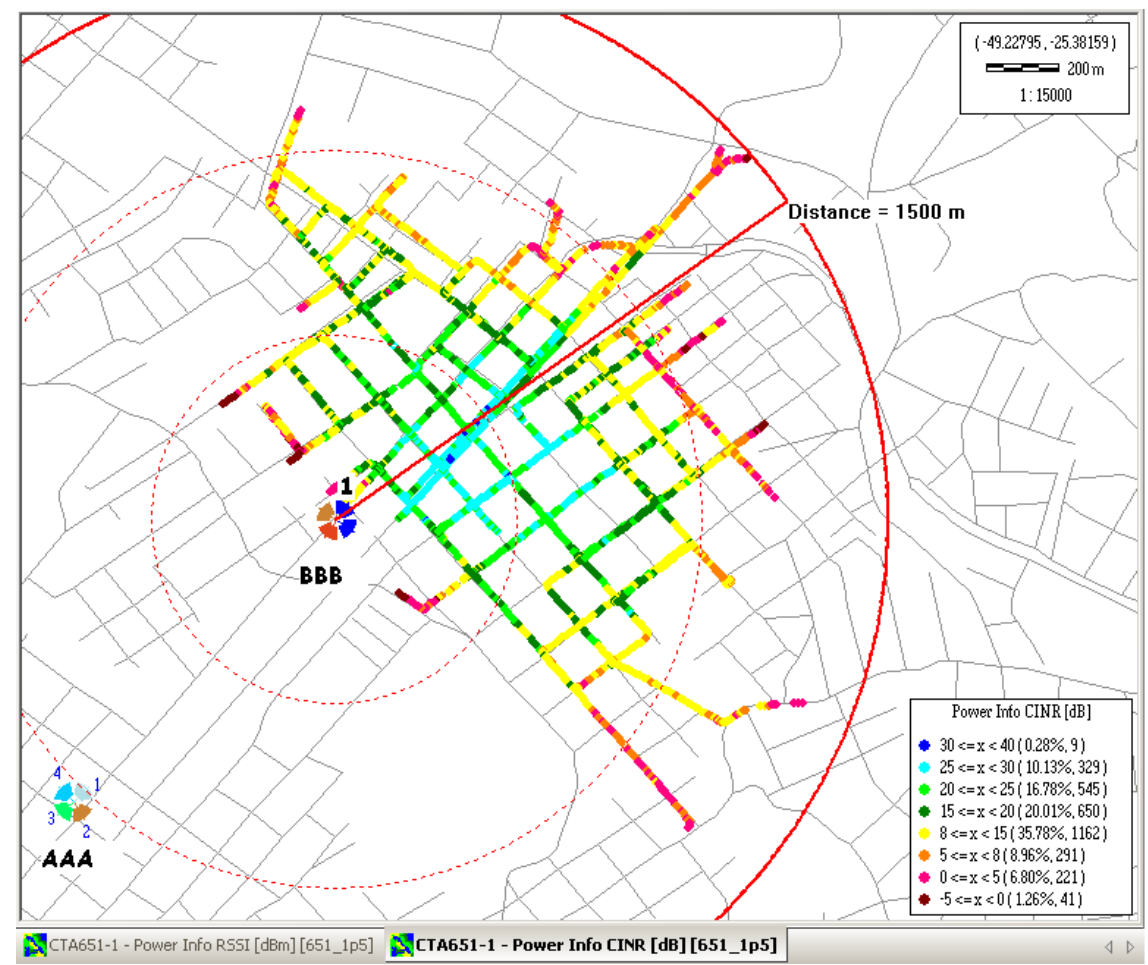

Figura 4.31: Cobertura obtida em testes do setor 1 do site BBB (primeiro momento)

A partir da Figura 4.4, percebe-se que um raio de cobertura de $1500 \mathrm{~m}$ foi obtido para as condições mínimas de atuação do sistema. Simulando a situação em questão foram obtidos $1723,45 \mathrm{~m}$ para cobertura da célula. Apesar da pequena diferença encontrada entre o valor simulado e o alcançado - que pode ser explicado por diversos fatores como a não utilização da configuração ótima de tilt e azimute - pode-se considerar que o software de planejamento é eficaz para a predição de cobertura dos sites a serem implantados pelo sistema WiMAX.

\subsection{Operadora B}

$\mathrm{O}$ drive test da operadora B foi dividido em 4 partes: verificação da qualidade do VoIP para o WiMAX fixo, verificação da qualidade do VoIP para o WiMAX móvel, 
medida do throughput e medida de cobertura do sistema. Além de testar o desempenho de possíveis serviços a serem disponibilizados, foram calibradas as ferramentas de predição e simulação a serem utilizadas no planejamento do sistema.

A rede utilizada possui as seguintes características:

- $\quad$ Banda do canal $(B W)$ de $5 \mathrm{MHz}$

- Tamanho da FFT igual a 512;

- Prefixo cíclico $(G)$ igual a $1 / 8$;

- Razão de TDD igual a 2:1;

- 6 BSs tri-setorizadas;

- 4 canais de $5 \mathrm{MHz}$;

- Fator de reuso 4.

A topologia da rede é mostrada na Figura 4.5 abaixo:

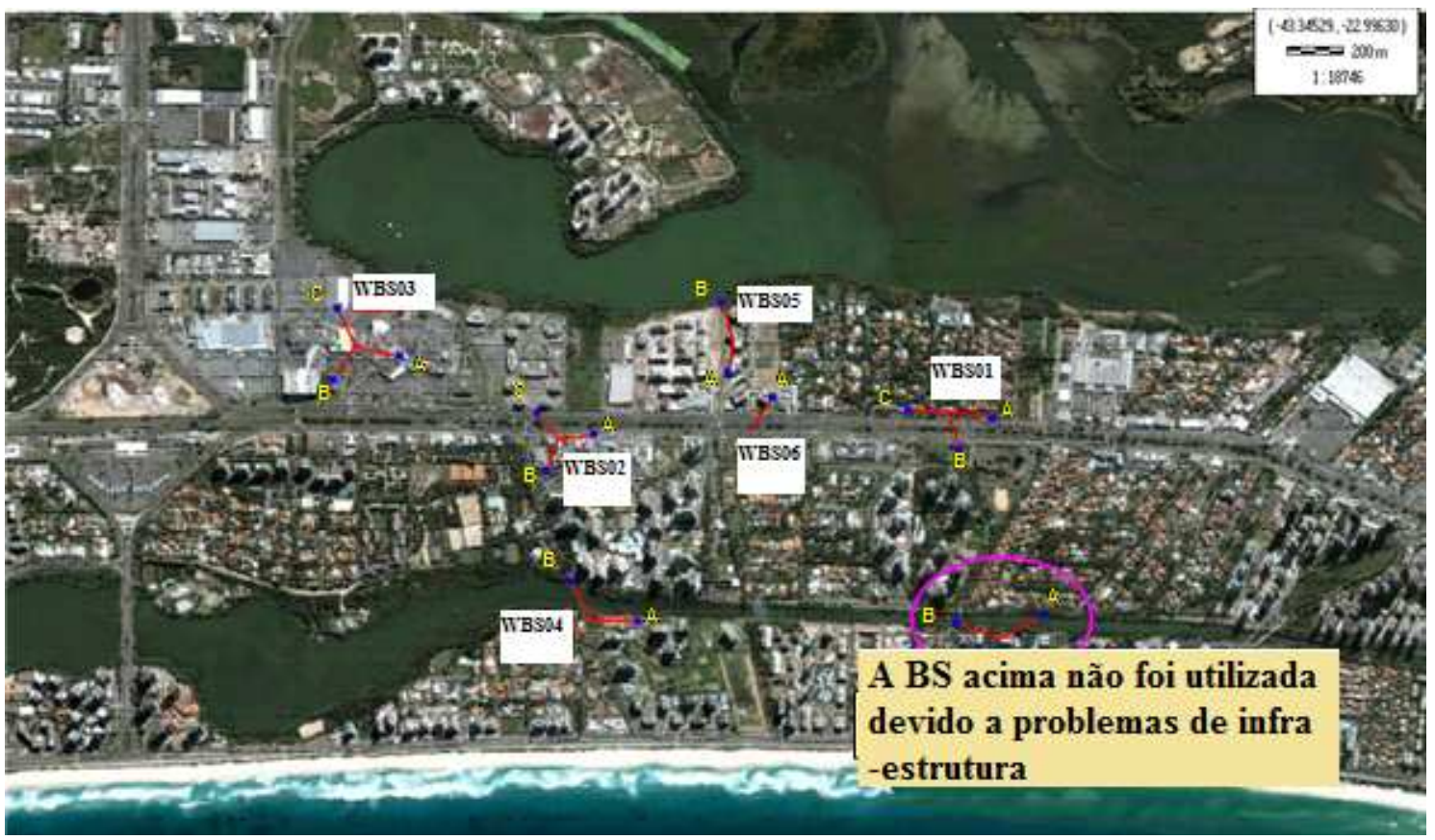

Figura 4.32: Topologia da rede WiMAX utilizada. 


\subsubsection{Testes de QoS}

\subsubsection{Usuário Estático}

Primeiramente, verificou-se a QoS (Quality of Service) das chamadas VoIP (Voice over IP ) para um usuário estático. O parâmetro de medida utilizado na avaliação foi o MOS (Mean Opinion Score) [10], que quantifica o esforço necessário para perceber a comunicação em vigor, levando em conta a qualidade do áudio de uma chamada de voz ou de uma vídeo conferência. Para isso uma escala que varia de 1 a 5 foi determinada. $O$ valor 5 não foi considerado, dado que as redes atuais utilizam Codecs, que impossibilitam a transmissão fiel dos dados [10].

Segue abaixo a Tabela 4.8 com os valores de MOS e suas classificações:

Tabela 4.23: Escala MOS [10]

\begin{tabular}{|c|c|}
\hline MOS & Classificação \\
\hline 1 & Péssimo \\
\hline 2 & Ruim \\
\hline 3 & Aceitável \\
\hline 4 & Boa \\
\hline 5 & Excelente \\
\hline
\end{tabular}

No teste, simularam-se vários casos de realização e recebimento de chamadas VoIP, com e sem tráfego de dados, para um usuário estático, em um meio de propagação urbano. Essas medidas também tinham como objetivo comparar o MOS dos perfis UGS e ertVR (ou ertPS) e as condições de propagação do meio, de acordo com o nível de RSSI, a potência de transmissão e o CINR. Para a realização tanto deste teste (usuário estático) quanto do próximo (usuário móvel), utilizou-se um usuário nas proximidades da torre e na outra ponta conectou-se um equipamento que simula uma chamada de voz real.

Utilizou-se um analisador de chamadas Hammer, um CPE Beceem, software XCAL, software XCAP e o setor 1 da estação base WBS02, ou WBS02A (a topologia das BS pode ser observada na Figura 4.5). O analisador de chamadas Hammer mensura a latência do sinal, o jitter e a perda de pacote. Com esses valores, um algoritmo realiza o cálculo do valor de MOS para uma determinada conexão [11]. O CPE Beceem é utilizado para realizar chamadas VoIP, downloads e uploads na rede WiMAX em questão. Para determinar parâmetros de RSSI, potência de transmissão do CPE e CINR, foi utilizado o 
software XCAL da Couei. Para realizar o pós-processamento dos dados medidos com o XCAL, foi utilizado outro software da Couei, o XCAP. A partir do mesmo, são produzidos arquivos de texto contendo os parâmetros citados, além da posição (latitude e longitude) e do instante relativos a cada medida.

Calculou-se, então, os valores mínimo, máximo, médio, desvio padrão e mediana das medidas para análise dos dados, apresentados nas Tabelas 4.9 e 4.10.

Tabela 4.24: Resultados da medida utilizando o serviço ertVR

\begin{tabular}{|l|c|c|c|c|c|c|c|c|}
\hline $\begin{array}{c}\text { Chamada } \\
\text { VoIP }\end{array}$ & $\begin{array}{c}\text { Seção de } \\
\text { dados }\end{array}$ & $\begin{array}{c}\text { Primeiro } \\
\text { evento }\end{array}$ & $\begin{array}{c}\text { RSSI médio } \\
(\mathbf{d B m})\end{array}$ & $\begin{array}{c}\text { Potência de } \\
\text { Tx média } \\
(\mathbf{d B m})\end{array}$ & $\begin{array}{c}\text { CINR } \\
\text { médio (dB) }\end{array}$ & $\begin{array}{c}\text { Throughput } \\
\text { (kbps) }\end{array}$ & $\begin{array}{c}\text { MOS do } \\
\text { remetente }\end{array}$ & $\begin{array}{c}\text { MOS do } \\
\text { destinatário }\end{array}$ \\
\hline Realizada & $\begin{array}{c}\text { Sem tráfego } \\
\text { de dados }\end{array}$ & VoIP & $-75,014$ & 17,329 & 21,26 & 14,767 & 3,332 \\
\hline Recebida & $\begin{array}{c}\text { Sem tráfego } \\
\text { de dados }\end{array}$ & VoIP & $-76,127$ & 17,1 & 20,664 & 11,072 & 3,332 \\
\hline Realizada & Download & Download & $-75,866$ & 15,622 & 20,463 & 1912,455 & 3,266 \\
\hline Recebida & Download & Download & $-75,304$ & 16,728 & 21,228 & 2050,802 & 2,859 \\
\hline Realizada & Download & VoIP & $-75,731$ & 16,763 & 20,978 & 874,213 & 3,199 \\
\hline Recebida & Download & VoIP & $-76,291$ & 16,86 & 20,081 & 564,299 & 3,359 \\
\hline Realizada & Upload & Upload & $-76,488$ & 22,679 & 20,417 & 111,381 & 3,059 \\
\hline Recebida & Upload & Upload & $-76,767$ & 22,617 & 20,267 & 116,967 & 3,234 \\
\hline Realizada & Upload & VoIP & $-76,063$ & 20,188 & 20,388 & 64,425 & 3,266 & 3,059 \\
\hline Recebida & Upload & VoIP & $-75,903$ & 18,835 & 20,544 & 34,388 & 3,359 & 3,133 \\
\hline
\end{tabular}

Tabela 4.25: Resultados da medida utilizando o serviço UGS

\begin{tabular}{|c|c|c|c|c|c|c|c|c|}
\hline $\begin{array}{l}\text { Chamada } \\
\text { VoIP }\end{array}$ & $\begin{array}{l}\text { Seção de } \\
\text { dados }\end{array}$ & $\begin{array}{l}\text { Primeiro } \\
\text { evento }\end{array}$ & $\begin{array}{l}\text { RSSI médio } \\
\text { (dBm) }\end{array}$ & $\begin{array}{c}\text { Potência de } \\
\text { Tx média } \\
(\mathbf{d B m})\end{array}$ & $\begin{array}{c}\text { CINR } \\
\text { médio (dB) }\end{array}$ & $\begin{array}{l}\text { Throughput } \\
\text { (kbps) }\end{array}$ & $\begin{array}{l}\text { MOS do } \\
\text { remetente }\end{array}$ & $\begin{array}{c}\text { MOS do } \\
\text { destinatário }\end{array}$ \\
\hline Recebida & $\begin{array}{l}\text { Sem tráfego } \\
\text { de dados }\end{array}$ & VoIP & $-44,709$ & $-9,091$ & 30,136 & 22,727 & 3,234 & 3,377 \\
\hline Recebida & Download & Download & $-47,878$ & $-0,634$ & 30,244 & 2098,317 & 3,133 & 3,367 \\
\hline Realizada & Download & VoIP & $-48,25$ & $-6,922$ & 29,992 & 690,516 & 3,301 & 3,444 \\
\hline Recebida & Download & VoIP & $-44,619$ & $-4,102$ & 30,398 & 700,831 & 3,301 & 3,444 \\
\hline Recebida & Upload & VoIP & $-45,935$ & 5,145 & 30,355 & 854,274 & 3,445 & 3,533 \\
\hline
\end{tabular}

\footnotetext{
${ }^{2}$ Os dados foram corrompidos, dessa forma os mesmo foram representados como NA nas tabelas 4.8, 4.9, 4.10 e 4.11.
} 
Os resultados se mostraram satisfatórios, apesar de condições desfavoráveis de propagação e certa instabilidade do sistema impossibilitarem a conexão e, conseqüentemente, a coleta de dados em certos lugares.

Dos valores de MOS mostrados nas Tabelas 4.9 e 4.10, pode-se notar uma superioridade de QoS para chamadas VoIP na classe de serviços UGS em relação ao serviço ertVR. Esses valores variaram de 3,359 a 2,859 no segundo serviço; e de 3,533 a 3,133, no primeiro. Este resultado é justificado pela natureza do serviço testado (VoIP), pois o ertVR utiliza a "supressão do silêncio" [1], ou seja, enquanto o usuário de uma chamada VoIP estiver mudo, o sistema suspende a transmissão de pacotes, economizando recursos do terminal do SS (carga da bateria e vida útil do aparelho), porém na retransmissão dos pacotes, há um atraso na reativação da transmissão. Outro fator que podemos observar é que os valores do MOS do destinatário são geralmente inferiores em relação ao MOS do remetente, devido as condições de propagação do downlink serem mais favoráveis do que a do uplink, tornando a qualidade da chamada superior na recepção do remetente.

\subsubsection{Usuário Móvel}

O mesmo procedimento foi realizado para um usuário a $40 \mathrm{~km} / \mathrm{h}$. Para essa nova situação, foram utilizados: um carro, um analisador de chamadas Hammer, um CPE ZyXEL, software XCAL, software XCAP e o setor 1 da WBS02.

Nessa nova configuração, são acrescentados dois aspectos que não estavam presentes na condição estática: efeito Doppler e variação de ambiente. Para este teste, o handover foi desativado, ou seja, o CPE ficou conectado somente a um setor de uma BS, a WBS02A.

Foram coletados os dados, tanto do analisador de chamadas Hammer (MOS), como do software XCAL da Couei (RSSI, potência de transmissão e o CINR).

As Tabelas 4.11 e 4.12 resumem os resultados obtidos: Resultados da medida utilizando o serviço ertVR 
Tabela 4.26: Resultados da medida utilizando o serviço ertVR

\begin{tabular}{|c|c|c|c|c|c|c|c|}
\hline $\begin{array}{c}\text { Chamada } \\
\text { VoIP }\end{array}$ & $\begin{array}{c}\text { Seção de } \\
\text { dados }\end{array}$ & $\begin{array}{c}\text { Primeiro } \\
\text { evento }\end{array}$ & $\begin{array}{c}\text { RSSI médio } \\
\mathbf{( d B m})\end{array}$ & $\begin{array}{c}\text { Potência de } \\
\text { Tx média } \\
\mathbf{( d B m})\end{array}$ & $\begin{array}{c}\text { CINR } \\
\text { médio } \\
(\mathbf{d B})\end{array}$ & $\begin{array}{c}\text { MOS do } \\
\text { remetente }\end{array}$ & $\begin{array}{c}\text { MOS do } \\
\text { destinatário }\end{array}$ \\
\hline Realizada & Upload & Upload & $-61,383$ & $-5,427$ & 20,833 & 4,156 & 4,137 \\
\hline Recebida & Upload & Upload & $-56,828$ & $-8,164$ & 23,209 & 4,18 & 1,055 \\
\hline Realizada & Upload & VoIP & $-60,394$ & $-5,496$ & 20,144 & 4,178 & 1,07 \\
\hline Recebida & Upload & VoIP & $-60,367$ & $-0,289$ & 21,746 & 4,18 & 1,113 \\
\hline Realizada & Download & Download & $-64,212$ & $-2,649$ & 19,246 & 4,18 & $1.793^{3}$ \\
\hline Recebida & Download & Download & $-59,483$ & 0,405 & 22,215 & 4,18 & 3,395 \\
\hline Realizada & Download & VoIP & $-60,593$ & $-4,558$ & 20,421 & NA & NA \\
\hline Recebida & Download & VoIP & $-56,797$ & $-2,302$ & 23,49 & NA & NA \\
\hline
\end{tabular}

Tabela 4.27: Resultados da medida utilizando o serviço UGS

\begin{tabular}{|c|c|c|c|c|c|c|c|}
\hline $\begin{array}{c}\text { Chamada } \\
\text { VoIP }\end{array}$ & $\begin{array}{c}\text { Seção de } \\
\text { dados }\end{array}$ & $\begin{array}{c}\text { Primeiro } \\
\text { evento }\end{array}$ & $\begin{array}{c}\text { RSSI médio } \\
(\mathbf{d B m})\end{array}$ & $\begin{array}{c}\text { Potência de } \\
\text { Tx média } \\
(\mathbf{d B m})\end{array}$ & $\begin{array}{c}\text { CINR } \\
\text { médio } \\
(\mathbf{d B})\end{array}$ & $\begin{array}{c}\text { MOS do } \\
\text { remetente }\end{array}$ & $\begin{array}{c}\text { MOS do } \\
\text { destinatário }\end{array}$ \\
\hline Realizada & Upload & Upload & $-58,249$ & $-5,958$ & 20,916 & NA & NA \\
\hline Recebida & Upload & Upload & $-32,59$ & -10 & 33 & 4,156 & 4,113 \\
\hline Realizada & Upload & VoIP & $-68,316$ & 1,168 & 16,802 & NA & NA \\
\hline Recebida & Upload & VoIP & $-56,29$ & $-2,75$ & 22,507 & 4,156 & 3,016 \\
\hline Realizada & Download & $\begin{array}{c}\text { Downloa } \\
d\end{array}$ & $-60,128$ & $-1,355$ & 20,988 & 3,875 & 3,109 \\
\hline Recebida & Download & $\begin{array}{c}\text { Downloa } \\
d\end{array}$ & $-57,935$ & $-6,435$ & 21,143 & 4,156 & 3,301 \\
\hline Realizada & Download & VoIP & $-59,885$ & $-5,901$ & 21,126 & 3,844 & 3,395 \\
\hline Recebida & Download & VoIP & $-55,998$ & $-4,723$ & 20,869 & 4,156 & 3,109 \\
\hline
\end{tabular}

Os testes para o perfil UGS foram satisfatórios. Já os relativos ao ertVR tiveram um desempenho inferior ao desejado, pois foram registrados baixos valores de MOS (inferiores a 2) na maioria dos casos, devido a mesma justificativa feita no teste para usuários estáticos.

\subsubsection{Cobertura e Calibragem do Software de Predição}

O teste em questão consistiu em realizar uma conexão com um setor de uma BS e sustentá-la o quanto fosse possível, para obtenção dos parâmetros de CINR, RSSI e potência de transmissão. As BSs analisadas foram WBS01, WBS02, WBS03, WBS04, WBS05 e WBS06 (Figura 4.5). Para desenvolvimento do teste, utilizou-se uma placa PCMCIA ZyXEL como equipamento de acesso, um carro, software XCAL, software

\footnotetext{
${ }^{3}$ Segundo informações da operadora, o valor de 1,793 para o MOS (Tabela 4.10) não retratou a realidade do teste, pois o mesmo mostrou-se bom ou satisfatório no decorrer da conexão.
} 
XCAP e uma antena posicionada fora do carro, para melhorar a recepção do sinal. Como esses testes foram realizados para diferentes BS, os trajetos realizados não foram iguais. Os resultados obtidos podem ser utilizados para o desenvolvimento e calibração de softwares de predição.

Os parâmetros foram extraídos pelo software XCAL e traçados pelo software XCAP nas Figuras 4.6, 4.7 e 4.8:

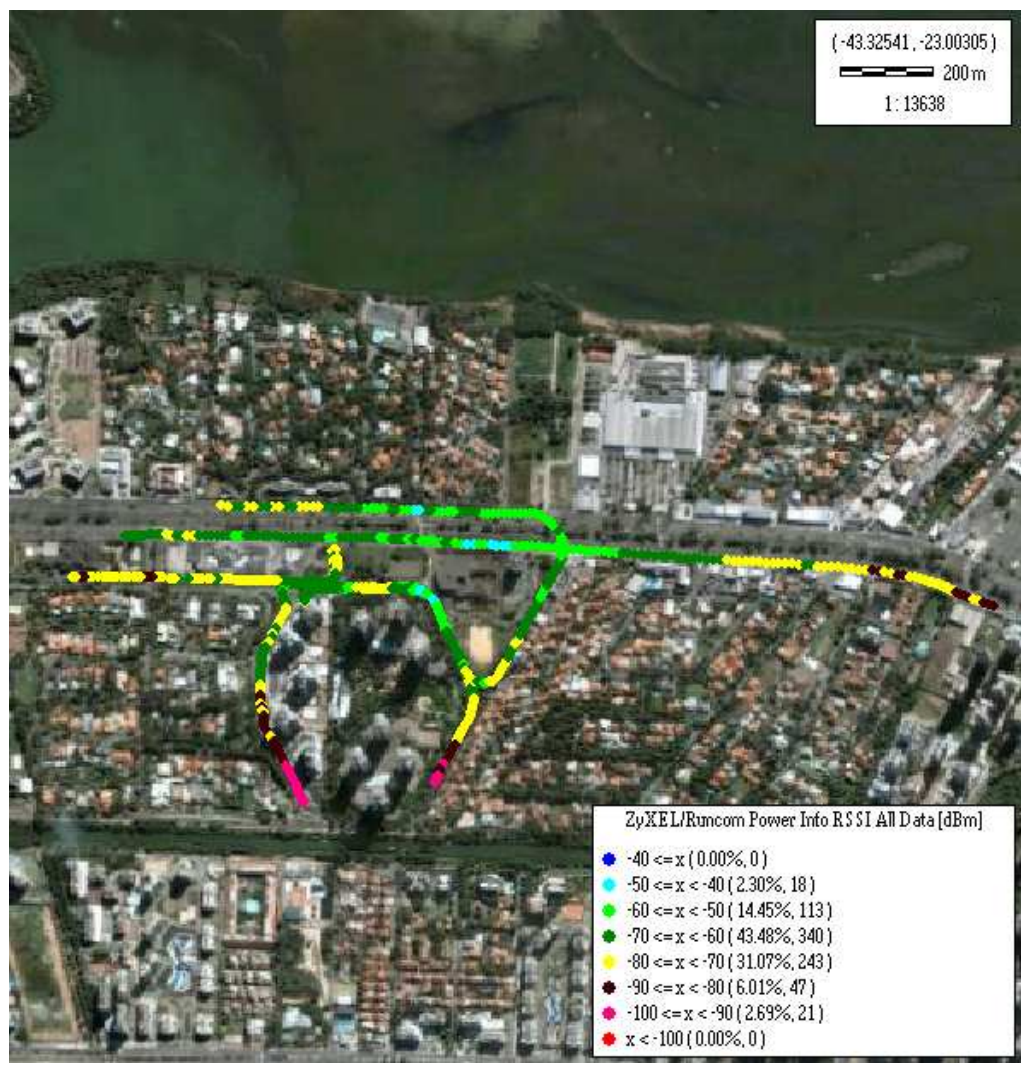

Figura 4.33: Ilustração das medidas de RSSI em dBm para o WBS01B 


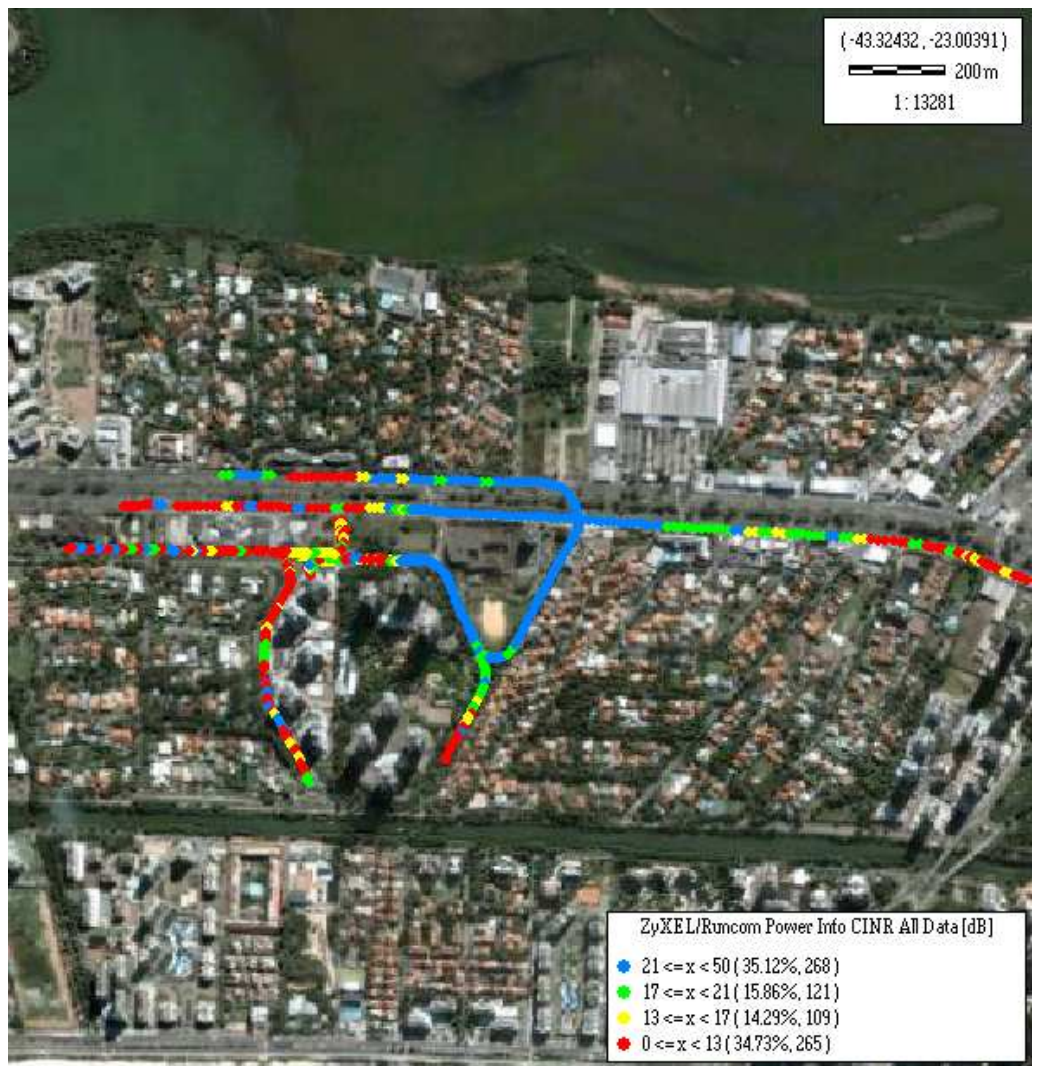

Figura 4.34: Ilustração das medidas de CNIR em dB para o WBS01B

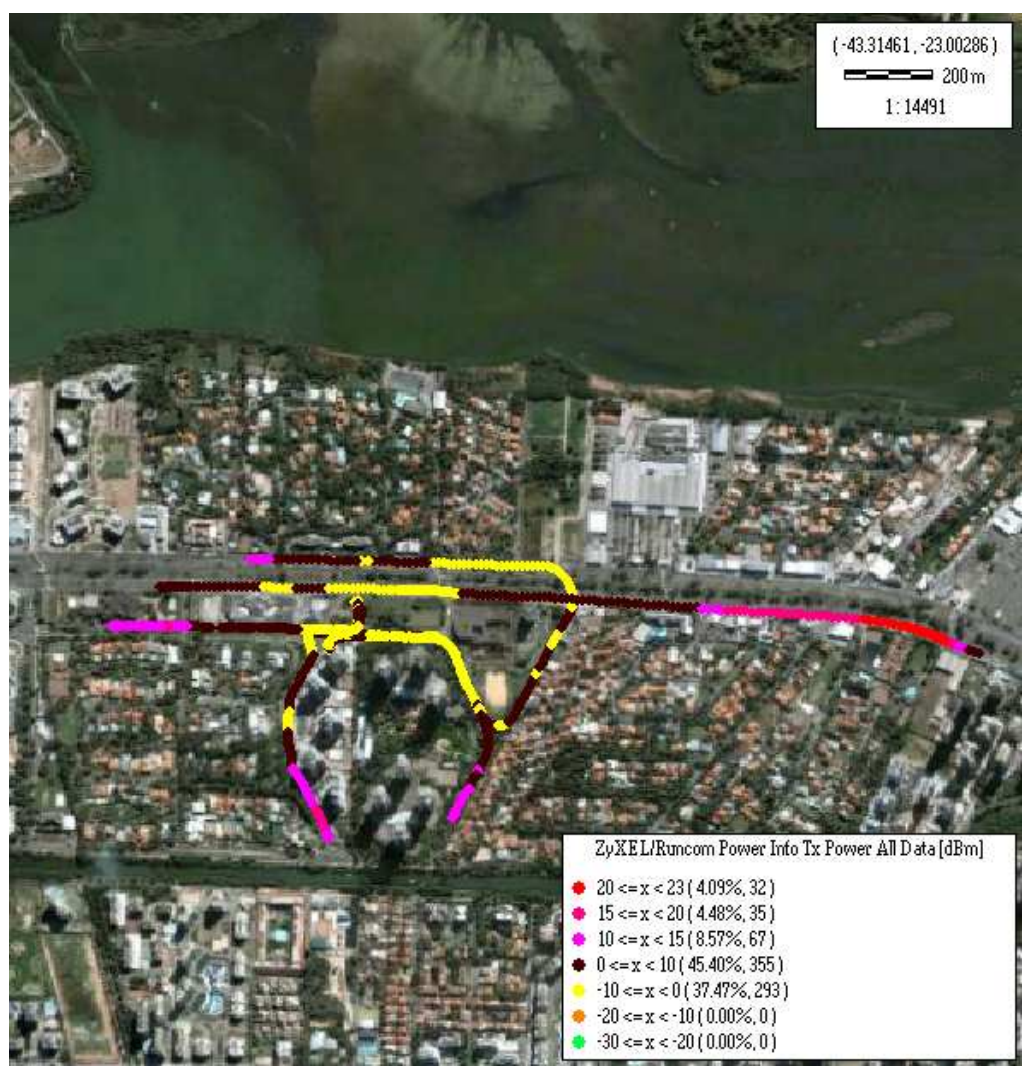

Figura 4.35: Ilustração das medidas da potência de transmissão em dBm para o WBS01B 
Os valores mínimos, máximos, médias aritméticas, desvios padrão e a mediana das CINRs estão resumidos na Tabela 4.13.

Tabela 4.28: Valores de CINR para cada BS

\begin{tabular}{|c|c|c|c|c|}
\hline BS & $\begin{array}{c}\text { Valor Máximo } \\
(\mathbf{d B})\end{array}$ & $\begin{array}{c}\text { Valor mínimo } \\
(\mathbf{d B})\end{array}$ & $\begin{array}{c}\text { Média } \\
(\mathbf{d B})\end{array}$ & $\begin{array}{c}\text { Desvio Padrão } \\
(\mathbf{d B})\end{array}$ \\
\hline WBS01 & 33 & -12 & 15,651 & 8,244 \\
\hline WBS02 & 33 & -12 & 16,426 & 9,862 \\
\hline WBS03 & 33 & -12 & 14,682 & 9,294 \\
\hline WBS04 & 33 & -12 & 18,447 & 10,765 \\
\hline WBS05 & 33 & -12 & 14,208 & 9,758 \\
\hline WBS06 & 33 & -4 & 24,809 & 7,185 \\
\hline
\end{tabular}

O raio de cobertura máximo alcançado pelo WBS01B foi de 1205 metros, conforme ilustra a Figura 4.9.

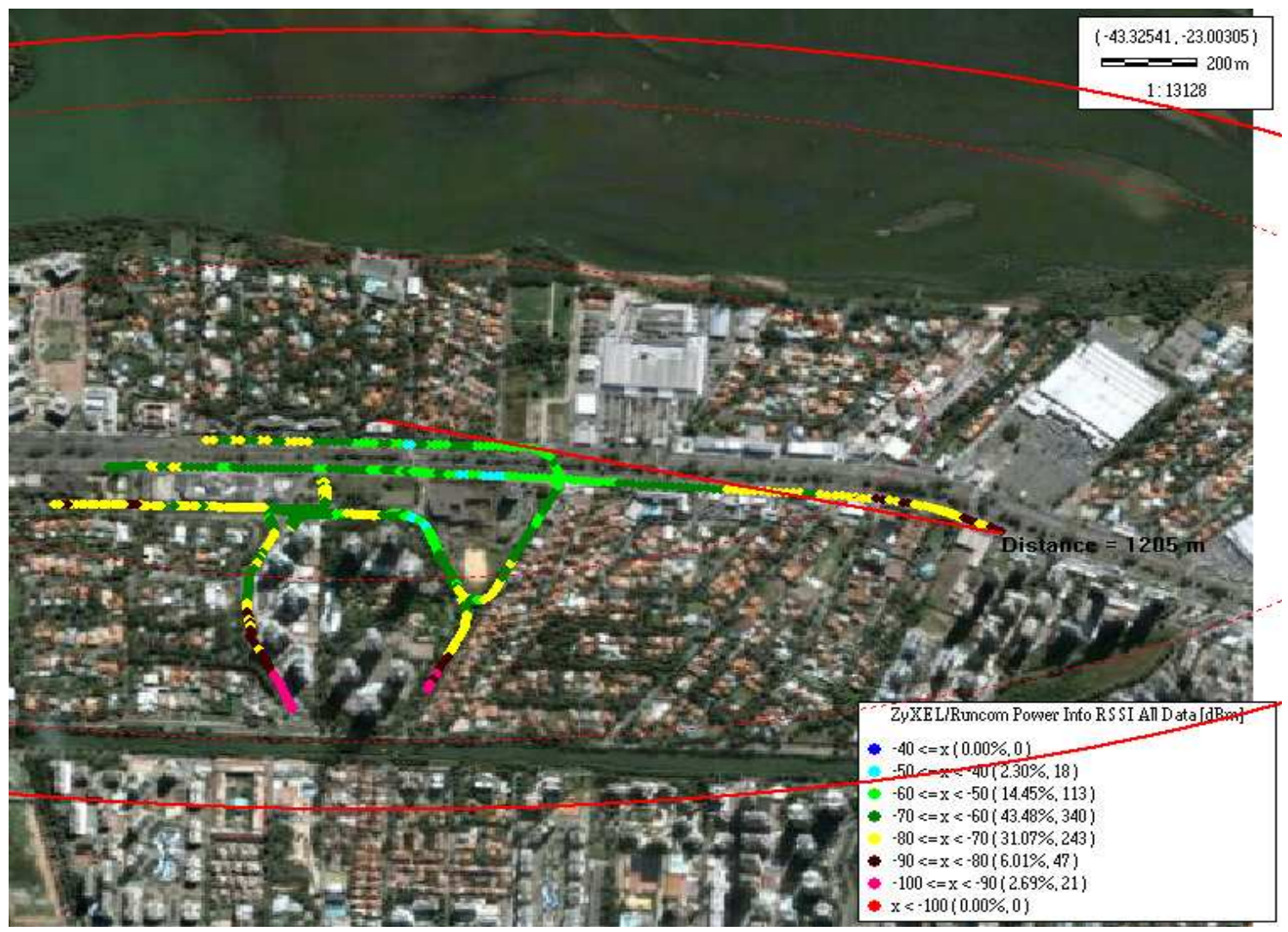

Figura 4.36: Ilustração da distância máxima alcançada para o WBS01B

Para se ter uma melhor percepção sobre os resultados apresentados pela operadora B, foi feita uma comparação com os valores teóricos, obtidos a partir do programa apresentado no capítulo anterior. Para isso, foram utilizados no simulador os mesmos 
parâmetros que caracterizaram o sistema da operadora, obtendo, para o WBS01B, um raio máximo de cobertura de 927,49 metros.

Os resultados demonstram que o programa desenvolvido neste trabalho necessita de alguns ajustes para ser utilizado na cidade $B$, já que o raio de cobertura obtido na prática foi maior que o raio simulado. Essa diferença pode ser explicada pelo fato de o modelo SUI ter sido desenvolvido em cidades típicas dos Estados Unidos, ou seja, para utilizá-lo em outras localidades é necessário um ajuste, já que cada lugar possui as suas peculiaridades que diferenciam a propagação das ondas eletromagnéticas. Além disso, no teste realizado foi utilizada uma antena externa, que proporciona um ganho adicional, que não foi considerado na simulação.

\subsubsection{Throughput}

O teste de throughput foi realizado também em movimento com o handover desabilitado, de modo a verificar o desempenho do sistema para utilização da classe de serviço de Best-Effort, em meios de propagação e velocidades distintas para o SS - 20 $\mathrm{km} / \mathrm{h}, 40 \mathrm{~km} / \mathrm{h}$ e $60 \mathrm{~km} / \mathrm{h}$ - para cada setor da BS. Foram utilizadas duas versões de software, V1 e V2, sendo V2 uma versão otimizada de V1.

A realização do teste para as duas versões de software serviu para verificar a evolução de desempenho entre elas. A primeira estabelecia um perfil de usuário com taxas de 2 Mbps no downlink e $512 \mathrm{kbps}$ no uplink, enquanto o V2 almejava taxas de 6 Mbps e 2 Mbps, respectivamente. Um aspecto importante a ser mencionado é que os dados relacionados ao software V1 foram coletados anteriormente ao teste com o V2.

De modo a simplificar a análise dos meios de propagação, foram definidos três tipos de meios (bom, médio e ruim) de acordo com as faixas de CINR proporcionadas no downlink (Tabela 4.14):

Tabela 4.29:Parâmetros de definição dos ambientes de propagação

\begin{tabular}{|l|l|}
\hline Ruim & DL CINR $<12 \mathrm{~dB}$ \\
\hline Médio & $12 \mathrm{~dB}<$ DL CINR $<25 \mathrm{~dB}$ \\
\hline
\end{tabular}




\begin{tabular}{|l|l|}
\hline Bom & DL CINR $>25 \mathrm{~dB}$ \\
\hline
\end{tabular}

Para a realização deste teste na versão V1, foi utilizada a WBS02A e toda a banda disponível, $5 \mathrm{MHz}$, de modo a testar a capacidade total do sistema para a transmissão de dados. O percurso foi definido de forma a obter linha de visada em sua totalidade, sendo coletadas informações de CINR, RSSI e potência de transmissão, apresentadas nas Tabelas $4.15,4.16,4.17,4.18,4.19$ e 4.20 .

Tabela 4.30: Valores encontrados para o ensaio no downlink a uma velocidade de $20 \mathrm{~km} / \mathrm{h}$

\begin{tabular}{|c|c|c|c|}
\hline Parâmetros & Valores & V2 & V1 \\
\hline \multirow{4}{*}{ RSSI [dBm] } & Mínimo & $-79,45$ & $-86,17$ \\
\cline { 2 - 4 } & Máximo & $-38,28$ & $-34,98$ \\
\cline { 2 - 4 } & Média aritmética & $-63,61$ & $-66,36$ \\
\cline { 2 - 4 } & Desvio Padrão & 11,26 & 13,39 \\
\hline \multirow{4}{*}{ CINR [dB] } & Mínimo & -11 & 10 \\
\cline { 2 - 4 } & Máximo & 32 & 30 \\
\cline { 2 - 4 } & Média aritmética & 16,89 & 21,56 \\
\cline { 2 - 4 } & Desvio Padrão & 11,62 & 4,51 \\
\hline \multirow{4}{*}{ Pransmissão [dBm] } & Mínimo & -13 & -9 \\
\cline { 2 - 4 } & Máximo & 9 & 21 \\
\cline { 2 - 4 } & Média aritmética & $-3,25$ & 7,33 \\
\cline { 2 - 4 } & Desvio Padrão & 8,86 & 6,88 \\
\hline \multirow{4}{*}{ Throughput $[\mathrm{kbps}]$} & Mínimo & 0 & 0 \\
\cline { 2 - 4 } & Máximo & 5348,16 & 4370,3 \\
\cline { 2 - 4 } & Média aritmética & 3690,41 & 701,36 \\
\cline { 2 - 4 } & Desvio Padrão & 1997,11 & 964,67 \\
\hline
\end{tabular}

Tabela 4.31: Valores encontrados para o ensaio no downlink a uma velocidade de $40 \mathrm{~km} / \mathrm{h}$

\begin{tabular}{|c|c|c|c|}
\hline Parâmetros & Valores & V2 & V1 \\
\hline \multirow{4}{*}{ RSSI $[\mathrm{dBm}]$} & Mínimo & $-77,51$ & $-89,42$ \\
\cline { 2 - 4 } & Máximo & $-33,44$ & $-41,23$ \\
\cline { 2 - 4 } & Média aritmética & $-59,62$ & $-68,76$ \\
\cline { 2 - 4 } & Desvio Padrão & 12,82 & 10,69 \\
\hline CINR $[\mathrm{dB}]$ & Mínimo & -11 & 7 \\
\hline
\end{tabular}




\begin{tabular}{|c|c|c|c|}
\hline \multirow{4}{*}{$\begin{array}{c}\text { Potência de } \\
\text { Transmissão [dBm] }\end{array}$} & Máximo & 32 & 30 \\
\cline { 2 - 4 } & Média aritmética & 19,64 & 21,41 \\
\cline { 2 - 4 } & Desvio Padrão & 10,59 & 4,21 \\
\cline { 2 - 4 } & Mínimo & -21 & -12 \\
\cline { 2 - 4 } & Média aritmética & $-6,8$ & 21 \\
\hline \multirow{4}{*}{ Throughput [kbps] } & Desvio Padrão & 11,16 & 7,73 \\
\cline { 2 - 4 } & Mínimo & 0 & 8,4 \\
\cline { 2 - 4 } & Média aritmética & 3970,58 & 0 \\
\cline { 2 - 4 } & Desvio Padrão & 1796,58 & 8933,7 \\
\cline { 2 - 4 } & & 5358,38 & 960,49 \\
\hline
\end{tabular}

Tabela 4.32: Valores encontrados para o ensaio no downlink a uma velocidade de $60 \mathrm{~km} / \mathrm{h}$

\begin{tabular}{|c|c|c|c|}
\hline Parâmetros & Valores & $\mathbf{V 2}$ & V1 \\
\hline \multirow{4}{*}{ RSSI [dBm] } & Mínimo & $-77,48$ & $-87,55$ \\
\hline & Máximo & $-35,73$ & $-40,28$ \\
\hline & Média aritmética & $-59,38$ & $-62,36$ \\
\hline & Desvio Padrão & 12,92 & 13,67 \\
\hline \multirow{4}{*}{ CINR [dB] } & Mínimo & 0 & 8 \\
\hline & Máximo & 32 & 30 \\
\hline & Média aritmética & 19,8 & 22,62 \\
\hline & Desvio Padrão & 9,8 & 5,68 \\
\hline \multirow{4}{*}{$\begin{array}{c}\text { Potência de } \\
\text { Transmissão }[\mathrm{dBm}]\end{array}$} & Mínimo & -14 & -14 \\
\hline & Máximo & 9 & 20 \\
\hline & Média aritmética & $-5,79$ & 2,95 \\
\hline & Desvio Padrão & 8,22 & 10,51 \\
\hline \multirow{4}{*}{ Throughput [kbps] } & Mínimo & 26,21 & 0 \\
\hline & Máximo & 5356,08 & 3942,42 \\
\hline & Média aritmética & 4068,98 & 965,96 \\
\hline & Desvio Padrão & 1738,57 & 1039,51 \\
\hline
\end{tabular}

Tabela 4.33: Valores encontrados para o ensaio no uplink a uma velocidade de $20 \mathrm{~km} / \mathrm{h}$

\begin{tabular}{|c|c|c|c|}
\hline Parâmetros & Valores & V2 & V1 \\
\hline \multirow{4}{*}{ RSSI $[\mathrm{dBm}]$} & Mínimo & $-78,69$ & NA \\
\cline { 2 - 4 } & Máximo & $-32,04$ & NA \\
\cline { 2 - 4 } & Média aritmética & $-62,85$ & NA \\
\cline { 2 - 4 } & Desvio Padrão & 11,57 & NA \\
\hline CINR $[\mathrm{dB}]$ & Mínimo & -4 & 12 \\
\cline { 2 - 4 } & Máximo & 32 & 30 \\
\cline { 2 - 4 } & Média aritmética & 18,04 & 23,34 \\
\hline
\end{tabular}




\begin{tabular}{|c|c|c|c|}
\hline & Desvio Padrão & 10,31 & 3,5 \\
\hline \multirow{4}{*}{$\begin{array}{c}\text { Potência de } \\
\text { Transmissão [dBm] }\end{array}$} & Mínimo & -15 & -12 \\
\cline { 2 - 4 } & Máximo & 9 & 20 \\
\cline { 2 - 4 } & Média aritmética & $-3,02$ & 14,37 \\
\cline { 2 - 4 } & Desvio Padrão & 8,46 & 5,54 \\
\hline \multirow{3}{*}{ Throughput $[\mathrm{kbps}]$} & Mínimo & 11,17 & $\mathrm{NA}$ \\
\cline { 2 - 4 } & Máximo & 1898,94 & 20 \\
\cline { 2 - 4 } & Média aritmética & 1059,24 & 14 \\
\cline { 2 - 4 } & Desvio Padrão & 825,67 & 6 \\
\hline
\end{tabular}

Tabela 4.34: Valores encontrados para o ensaio no uplink a uma velocidade de $40 \mathrm{~km} / \mathrm{h}$

\begin{tabular}{|c|c|c|c|}
\hline Parâmetros & Valores & $\mathbf{V 2}$ & V1 \\
\hline \multirow{4}{*}{ RSSI [dBm] } & Mínimo & $-76,6$ & $-90,84$ \\
\hline & Máximo & $-29,14$ & $-37,22$ \\
\hline & Média aritmética & $-60,26$ & $-65,41$ \\
\hline & Desvio Padrão & 12,04 & 13,06 \\
\hline \multirow{4}{*}{ CINR $[\mathrm{dB}]$} & Mínimo & -2 & 3 \\
\hline & Máximo & 32 & 30 \\
\hline & Média aritmética & 18,8 & 22,01 \\
\hline & Desvio Padrão & 10,74 & 5,51 \\
\hline \multirow{4}{*}{$\begin{array}{c}\text { Potência de } \\
\text { Transmissão }[\mathrm{dBm}]\end{array}$} & Mínimo & -12 & -13 \\
\hline & Máximo & 8 & 23 \\
\hline & Média aritmética & $-0,56$ & 11,6 \\
\hline & Desvio Padrão & 5,14 & 8,13 \\
\hline \multirow{4}{*}{ Throughput [kbps] } & Mínimo & 0 & 0 \\
\hline & Máximo & 1968,86 & 1974,56 \\
\hline & Média aritmética & 998,98 & 808,25 \\
\hline & Desvio Padrão & 703,38 & 801,62 \\
\hline
\end{tabular}

Tabela 4.35: Valores encontrados para o ensaio no uplink a uma velocidade de $60 \mathrm{~km} / \mathrm{h}$

\begin{tabular}{|c|c|c|c|}
\hline Parâmetros & Valores & V2 & V1 \\
\hline \multirow{4}{*}{ RSSI $[\mathrm{dBm}]$} & Mínimo & $-78,29$ & $-90,26$ \\
\cline { 2 - 4 } & Máximo & $-36,87$ & $-42,26$ \\
\cline { 2 - 4 } & Média aritmética & $-60,49$ & $-60,39$ \\
\cline { 2 - 4 } & Desvio Padrão & 12,3 & 11,9 \\
\hline \multirow{4}{*}{ CINR $[\mathrm{dB}]$} & Mínimo & -9 & 4 \\
\cline { 2 - 4 } & Máximo & 32 & 31 \\
\cline { 2 - 4 } & Média aritmética & 18,68 & 25,23 \\
\cline { 2 - 4 } & Desvio Padrão & 11,79 & 5,33 \\
\hline Potência de & Mínimo & -17 & -12 \\
\hline
\end{tabular}




\begin{tabular}{|c|c|c|c|}
\hline \multirow{4}{*}{ Transmissão [dBm] } & Máximo & 8 & 20 \\
\cline { 2 - 4 } & Média aritmética & $-5,48$ & 11,17 \\
\cline { 2 - 4 } & Desvio Padrão & 9,75 & 6,16 \\
\hline \multirow{3}{*}{ Throughput [kbps] } & Mínimo & 0 & 0 \\
\cline { 2 - 4 } & Máximo & 1899,78 & 1967,14 \\
\cline { 2 - 4 } & Média aritmética & 1157,95 & 1161,55 \\
\cline { 2 - 4 } & Desvio Padrão & 824,86 & 838,5 \\
\hline
\end{tabular}

Os resultados obtidos, repetindo-se o teste para o software V2, são apresentados nas Figuras 4.10, 4.11, 4.12, 4.13, 4.14 e 4.15:

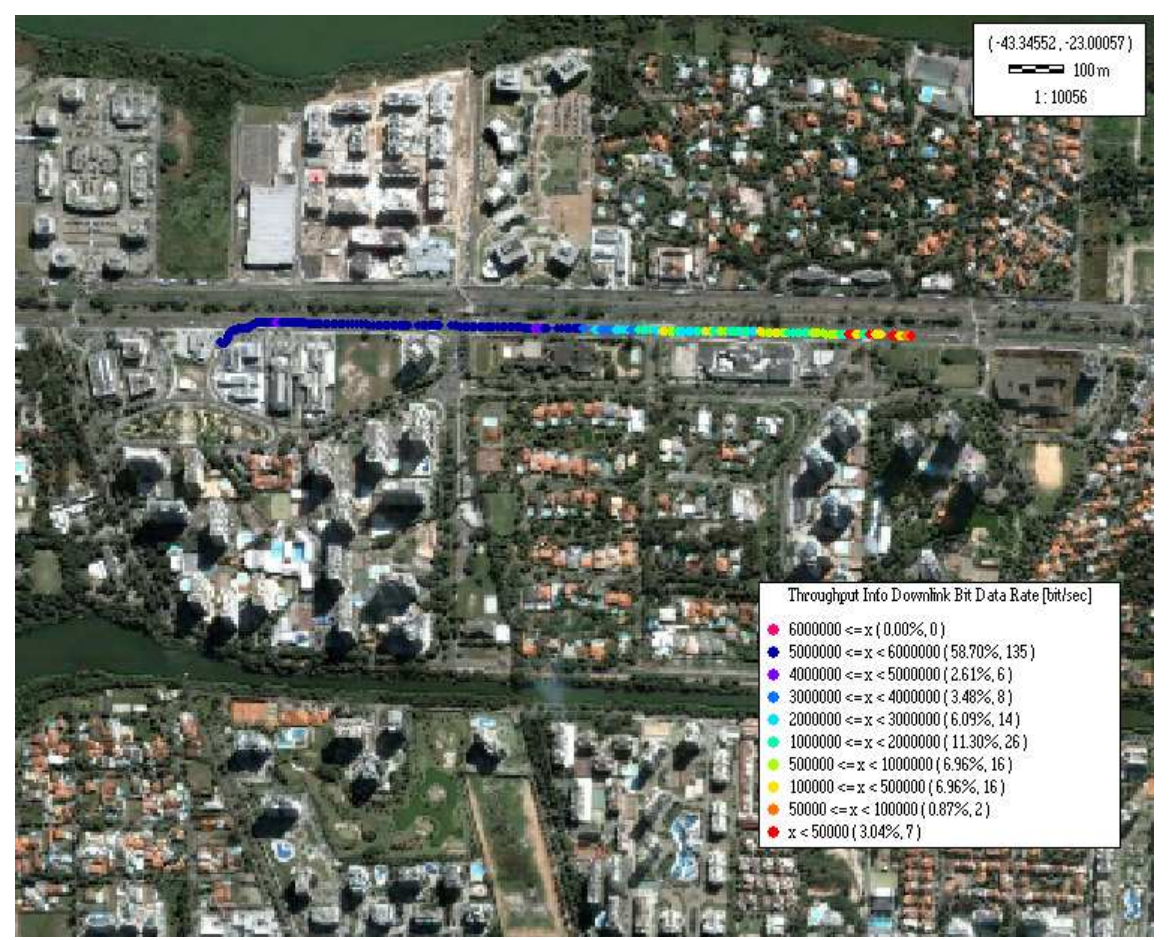

Figura 4.37: Ilustração dos resultados de throughput no downlink para uma velocidade de $20 \mathrm{~km} / \mathrm{h}$ 


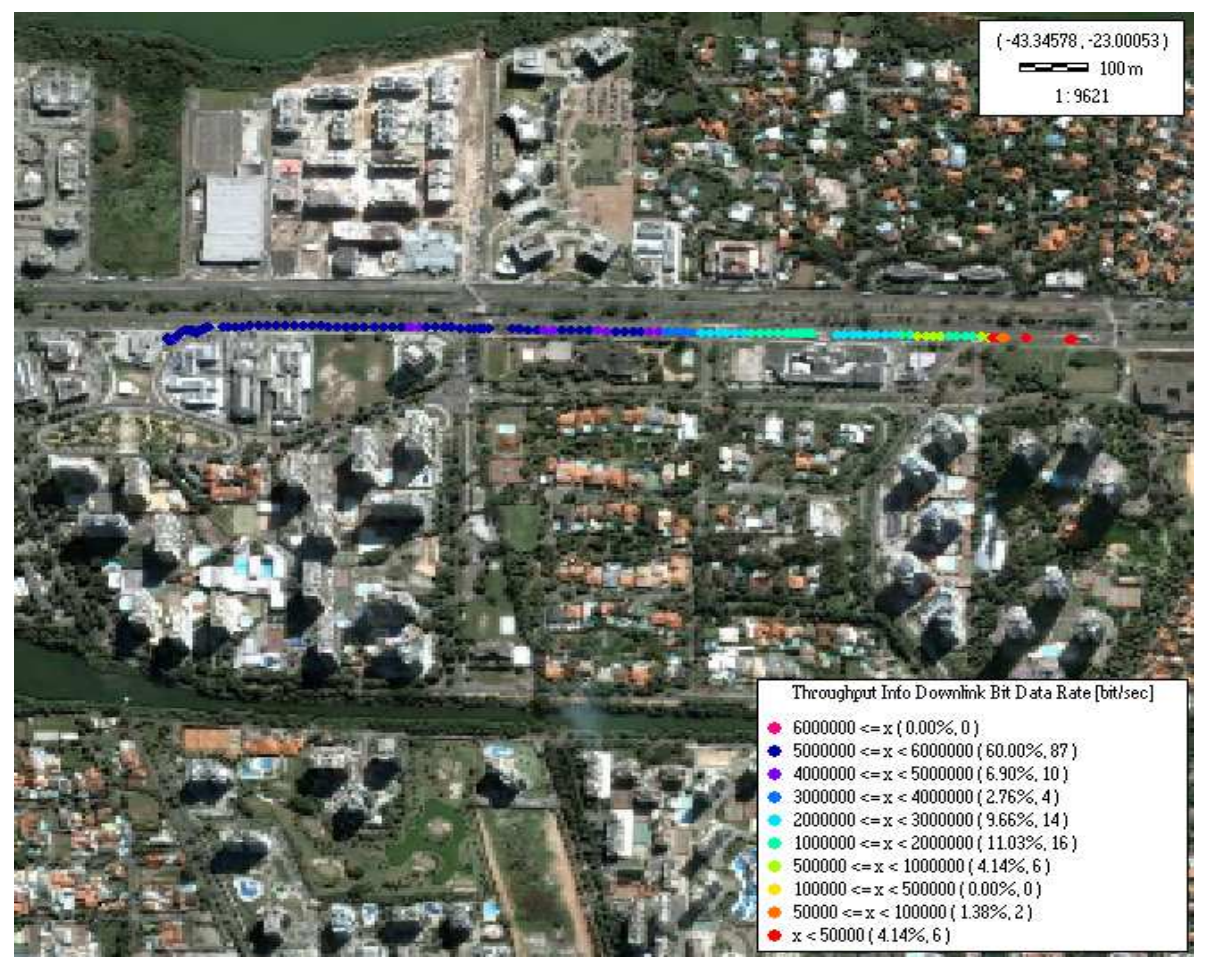

Figura 4.38: Ilustração dos resultados de throughput no downlink para uma velocidade de $40 \mathrm{~km} / \mathrm{h}$

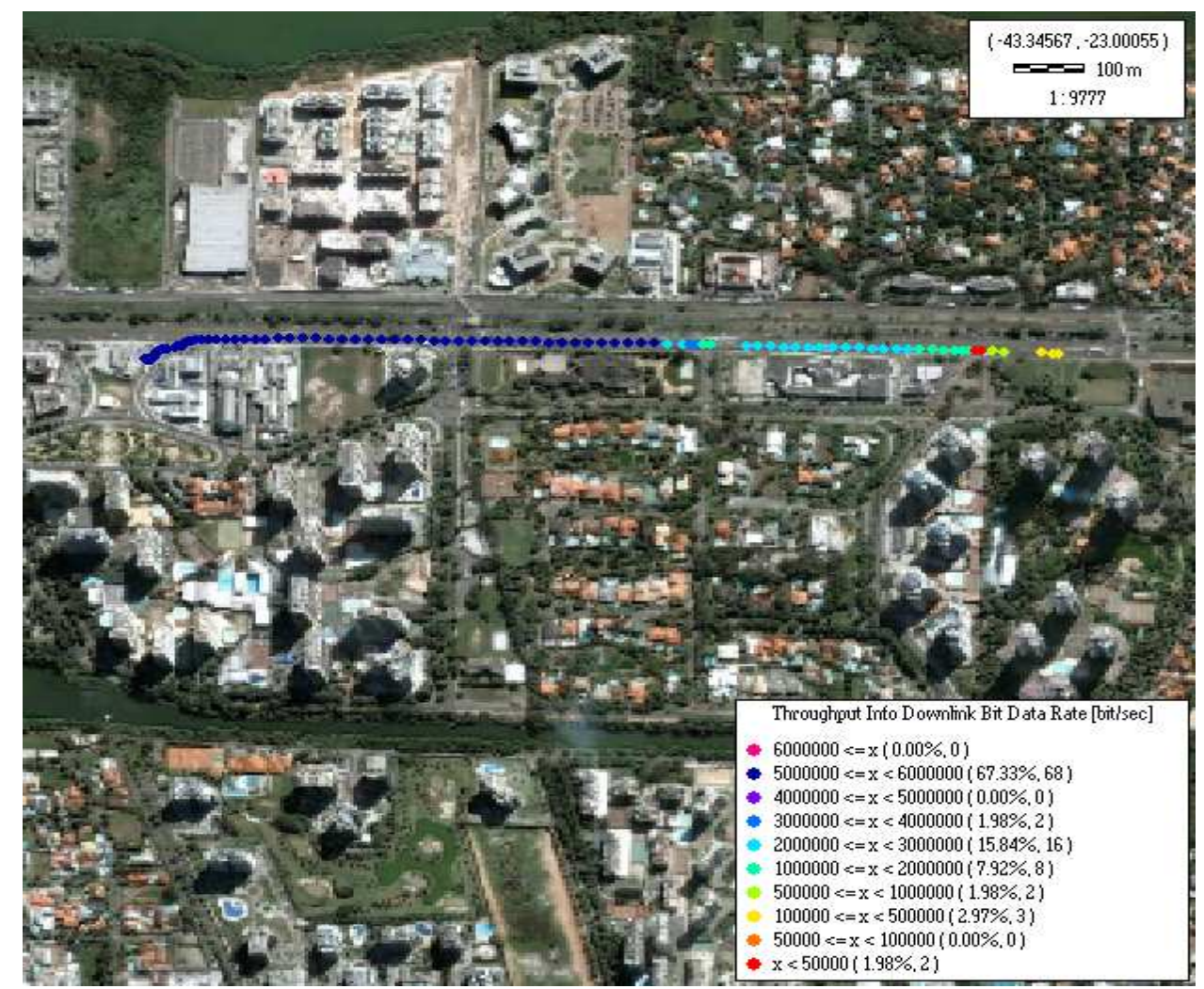

Figura 4.39: Ilustração dos resultados de throughput no downlink para uma velocidade de $60 \mathrm{~km} / \mathrm{h}$ 


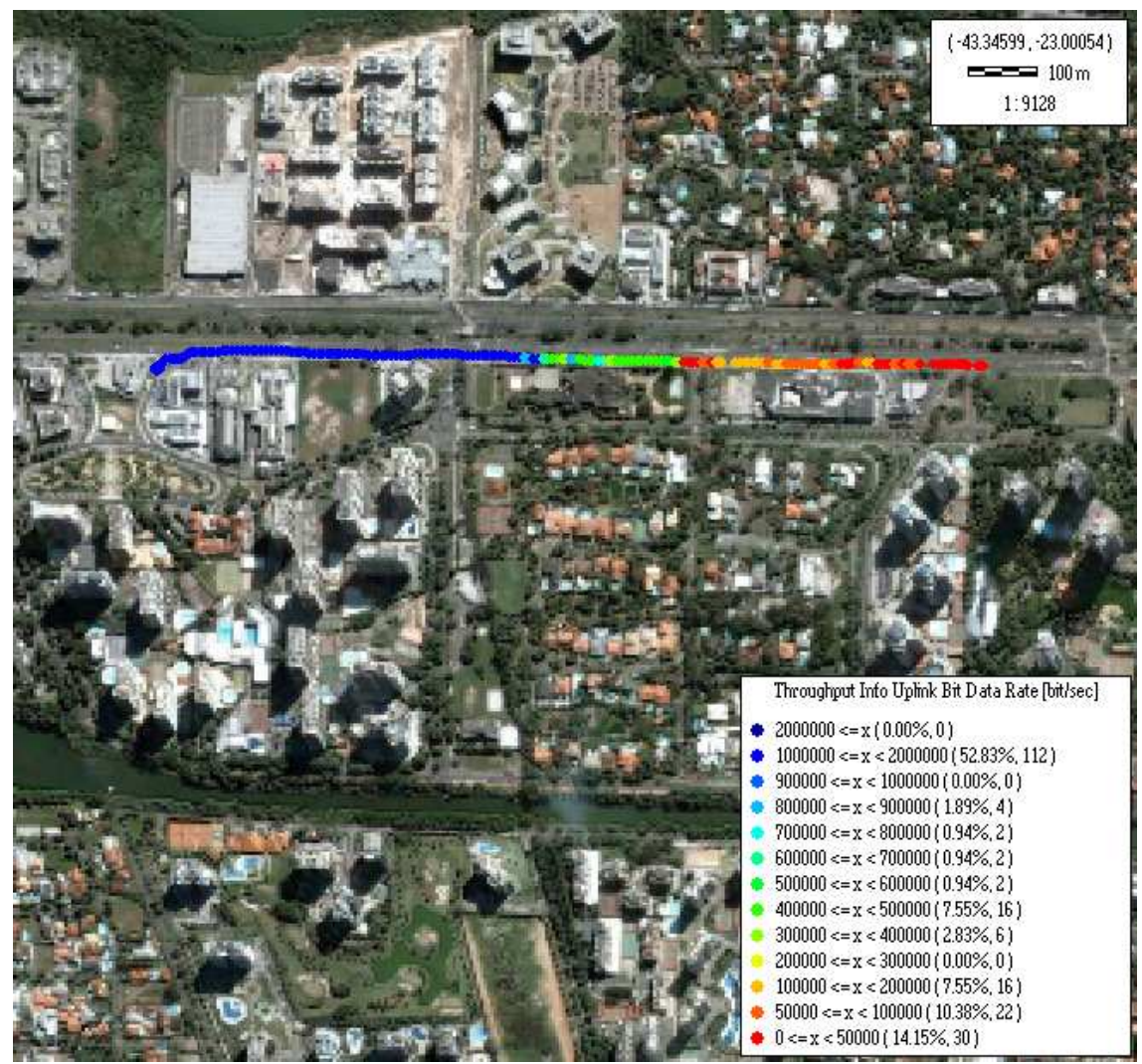

Figura 4.40: Ilustração dos resultados de throughput no uplink para uma velocidade de $20 \mathrm{~km} / \mathrm{h}$

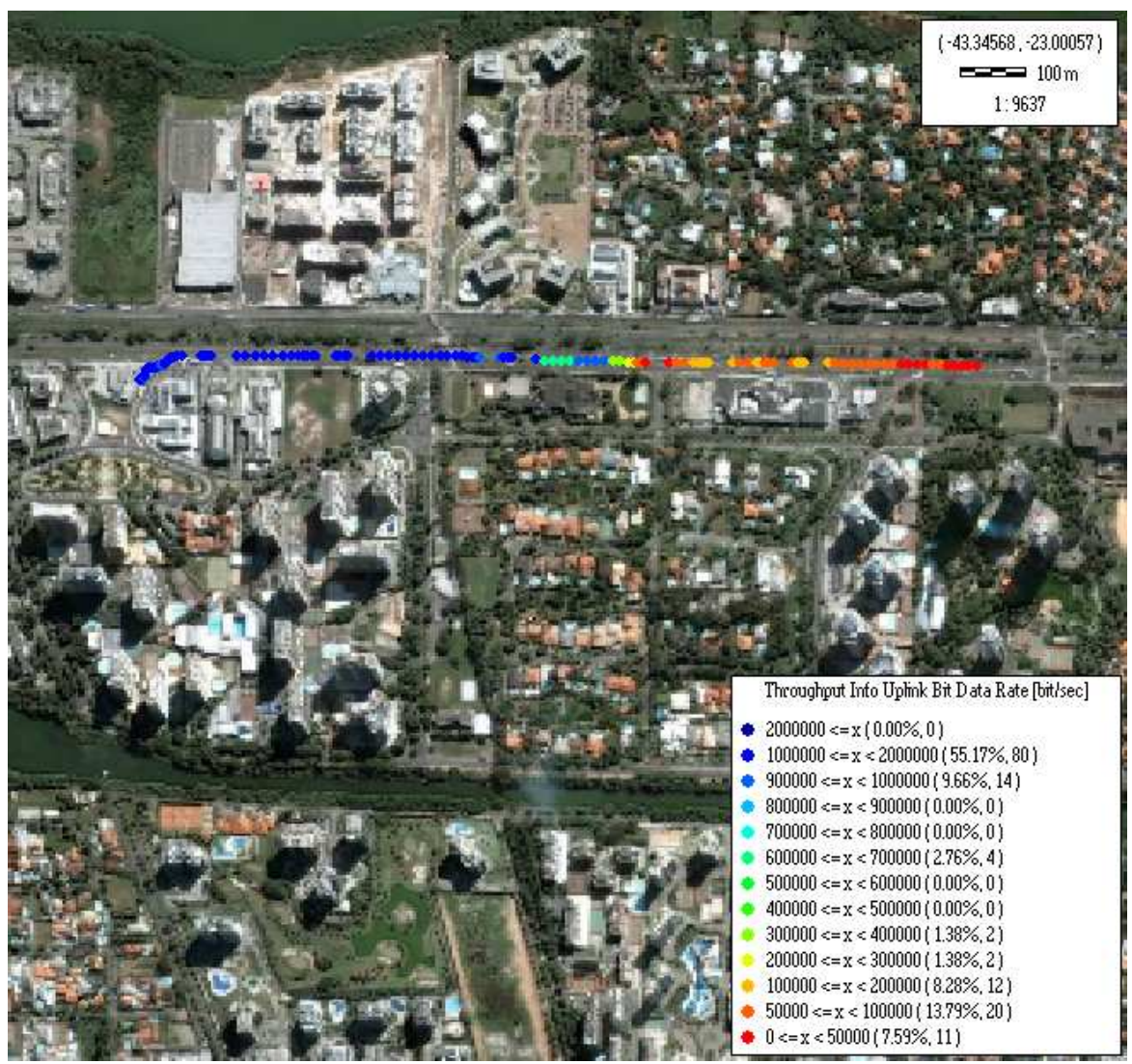

Figura 4.41: Ilustração dos resultados de throughput no uplink para uma velocidade de $40 \mathrm{~km} / \mathrm{h}$ 


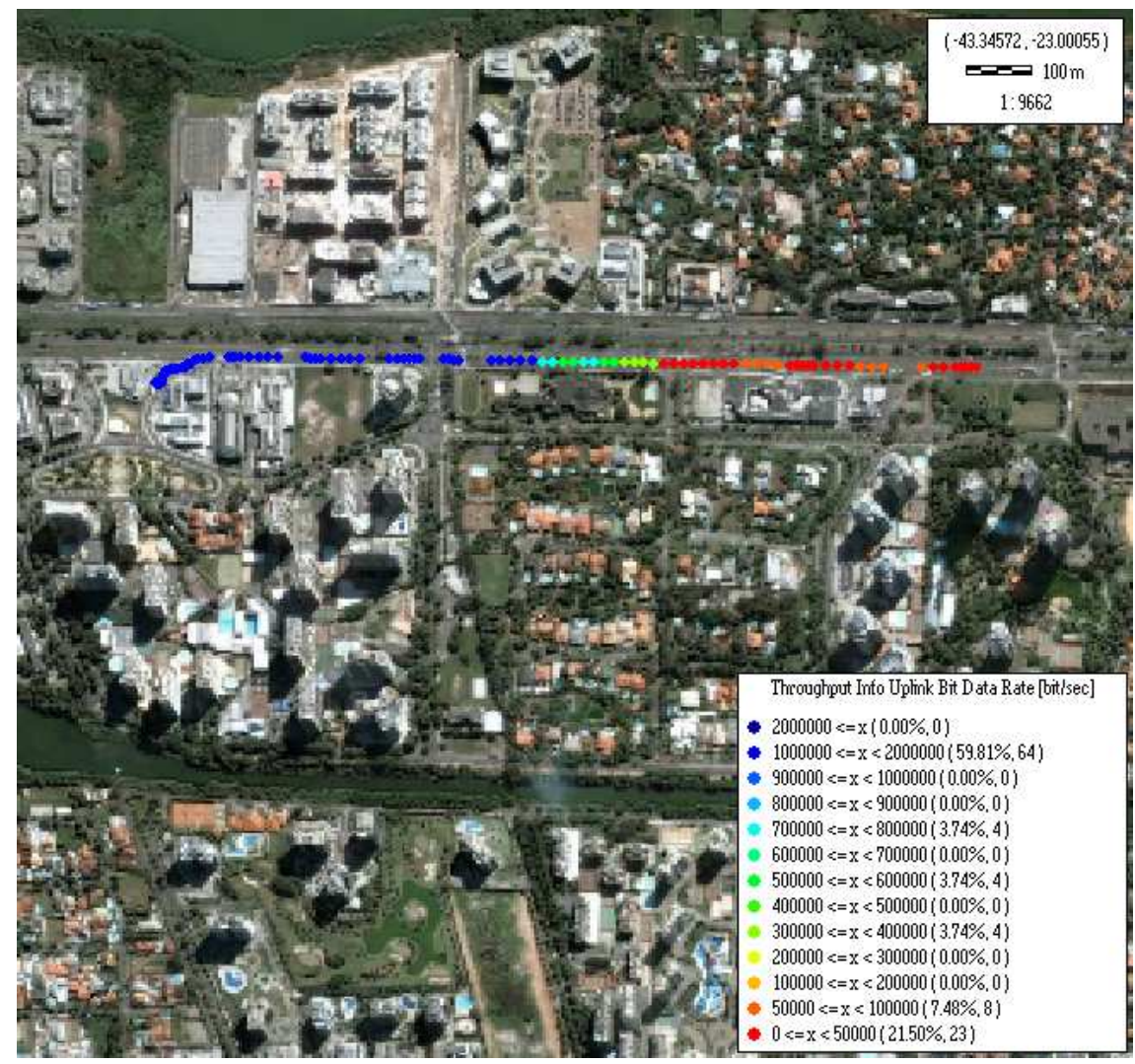

Figura 4.42: Ilustração dos resultados de throughput no uplink para uma velocidade de $60 \mathrm{~km} / \mathrm{h}$

Das Figuras 4.10, 4.11, 4.12, 4.13, 4.14 e 4.15 e dos resultados apresentados nas Tabelas 4.15 a 4.20, podemos observar que houve uma enorme evolução de um software para o outro, pois as taxas de dados alcançadas no downlink foram superiores nas várias velocidades e bem próximas ao determinado pelo fornecedor do software V2, pois o mesmo se mostrou mais estável. Outro ponto que podemos observar é que o sistema WiMAX possui throughputs competitivos em relação aos serviços presentes atualmente no mercado brasileiro.

Para averiguar se o throughput medido foi satisfatório, esse foi comparado ao valor teórico esperado. A expressão utilizada para calcular o throughput teórico é a mesma do simulador, e no caso a BER considerada foi de $10^{-6}$.

A Figura 4.16 representa o throughput alcançado no downlink com o software V2, durante o percurso ilustrado na Figura 4.12. 


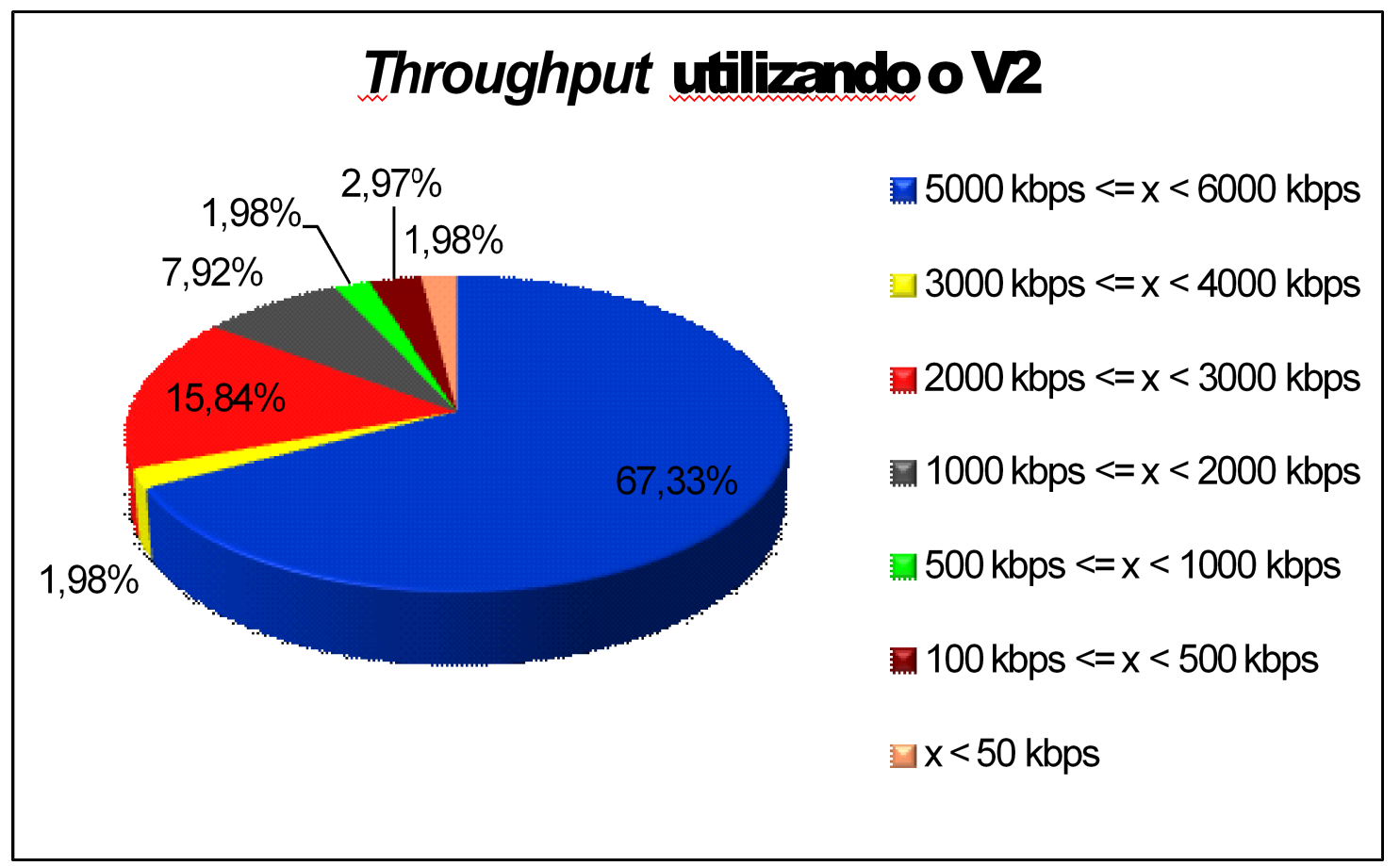

Figura 4.43: Ilustração dos resultados de throughput apresentados na Figura 4.12.

Utilizando os mesmos parâmetros do sistema considerado pela operadora $\mathrm{B}$, foram calculados os valores teóricos esperados. A Tabela 4.21 apresenta os valores teóricos, assim como os obtidos com os softwares V1 e V2.

Tabela 4.36: Valores simulados e medidos para os diferentes tipos de modulação

\begin{tabular}{|c|c|c|c|}
\hline \multicolumn{4}{|c|}{ Canal de 5 MHz } \\
\hline \multirow{2}{*}{$\begin{array}{c}\text { Modulação (Taxa de } \\
\text { Codificação) }\end{array}$} & \multicolumn{3}{|c|}{ Throughput [Mbps] } \\
\cline { 2 - 4 } & Simulador & Operadora B - V1 & Operadora B - V2 \\
\hline BPSK (1/2) & 1,17 & Mínimo & Mínimo \\
\hline QPSK (1/2) & 2,33 & - & 0,26 \\
\hline QPSK (3/4) & 3,5 & Médio & Médio \\
\hline 16-QAM (1/2) & 4,67 & 0,97 & 4,69 \\
\hline 16-QAM (3/4) & 7,01 & Máximo & Máximo \\
\hline 64-QAM (1/2) & 7,01 & 3,94 & 5,36 \\
\hline
\end{tabular}

Conforme pode-se observar na Tabela 4.21, os valores alcançados em campo estão aquém dos valores teóricos, mostrando que os softwares utilizados no mercado podem ser melhorados. 


\subsubsection{Comparação dos testes de throughput das operadoras A e B}

A partir dos dados coletados nos testes de throughput das duas empresas, procurouse fazer uma análise comparativa entre as versões de software utilizadas nos dois sistemas WiMAX implantados. Como as duas operadoras contrataram o mesmo fornecedor para execução dos testes, versões de software idênticas foram utilizadas.

A operadora B utilizou as versões V1 e V2 em seus testes e a operadora A utilizou apenas a primeira. Como analisado anteriormente, a versão V1 mostrou-se instável em termos de throughput para ambas as operadoras, apresentando taxas muito baixas. A versão de software V2 teve um desempenho mais estável, com throughputs maiores e mais próximos do esperado.

\subsection{Conclusão}

Diversos testes foram realizados visando uma detalhada análise dos elementos de rede implantados nas duas cidades. Desta forma, informações demandadas pelas operadoras para otimização de rede foram coletadas, permitindo uma avaliação das diversas dificuldades em se implantar o sistema. 


\section{CONCLUSÃO}

Ao longo deste trabalho, foram estudados os princípios teóricos dos sistemas WiMAX, por meio dos quais buscou-se entender e elucidar os motivos que conferem lugar de destaque a estes sistemas no que tange aos aspectos de cobertura e capacidade.

Baseado nesse estudo teórico, foi proposto um algoritmo para o planejamento inicial de uma rede, que efetua um estudo de cobertura e capacidade. Nesse estudo a estimativa de cobertura levou em consideração efeitos relativos ao ambiente (perda de percurso e sombreamento) e limites impostos pelo padrão IEEE 802.16e (SNR mínima para cada técnica de modulação e codificação), enquanto o estudo de capacidade buscou alcançar a taxa requerida por um perfil de usuário, por meio da implementação do algoritmo de alocação de recursos proposto em [5].

Foram necessárias algumas adaptações para implementação do algoritmo [5]. Uma delas foi estimar um canal, de forma a simular a presença do desvanecimento seletivo em frequiência e diferenciar a relação sinal ruído das subportadoras percebidas por um mesmo usuário. Outra adaptação foi encontrar a relação matemática entre BER e SNR para todas as combinações possíveis de modulação e codificação consideradas, necessárias para encontrar a taxa obtida.

O aplicativo desenvolvido apresentou resultados coerentes com a teoria estudada, de acordo com a variação dos parâmetros de entrada: freqüência e banda do canal. Com o aumento da freqüência de operação, o alcance da célula foi reduzido e o número de células aumentou (com exceção à situação 1), visto que um raio de cobertura menor exige um número superior de torres para cobrir uma mesma região. Na situação 1, esse fato não foi observado, porque todos os usuários da célula estavam sob uma mesma técnica de modulação, mesmo após variação da frequiência. A alteração do tamanho da banda do canal ratificou a proporção direta que há entre taxa e número de subportadoras úteis, além da relação inversamente proporcional entre taxa e período de símbolo.

Uma deficiência do simulador é que ele não leva em consideração a interferência co-canal e entre setores de uma mesma BS. Isso se deve ao fato de não ter sido encontrada 
nenhuma referência que mostrasse como efetuar o cálculo da interferência em sistemas WiMAX.

Na parte seguinte do trabalho, que envolve as análises de testes realizados, notou-se que o sistema implantado pela operadora $\mathrm{A}$ apresentou instabilidades inerentes à versão do software utilizado. Latências elevadas foram obtidas em todas as situações do teste que as avaliou. Ademais foi verificada uma impossibilidade de se utilizar serviços do tipo UGS, visto que ao se aplicar esta classe, todos os demais serviços apresentaram degradação.

Em termos de jitter os testes demonstraram bom desempenho. Os valores obtidos para este parâmetro encontraram-se dentro da faixa definida para o funcionamento adequado dos serviços prestados pelo sistema WiMAX. Nos testes de throughput, as taxas de transmissão obtidas mostraram-se muito aquém dos valores esperados para o sistema, mesmo em situações onde foi utilizada modulação 64-QAM 3/4. Atribui-se este resultado, também, à versão do software utilizado, fato que pode ser inferido da comparação, feita pela operadora B, entre as duas versões do software.

O teste de cobertura mostrou em um primeiro momento que, para a região avaliada nos testes, um raio de $1290 \mathrm{~m}$ pode ser obtido para CINR mínima de $8 \mathrm{~dB}$. Com a utilização de antenas do tipo AAS, segmentação PUSC e alterando-se a posição das antenas, um raio superior foi alcançado $(2375 \mathrm{~m})$ para a mesma CINR mínima. Estes resultados podem ser considerados satisfatórios, apesar de inferiores aos esperados em [12], uma vez que estes podem ser considerados otimistas e não levam em consideração diversos fatores que causam desvanecimento do sinal.

Na operadora B, os testes relativos a chamadas VoIP também foram coerentes com o referencial teórico. Verificou-se que a qualidade de uma chamada para o perfil de serviço UGS, que não utiliza a configuração de "supressão do silêncio", teve uma vantagem significativa em relação à outra classe de serviço. Nos testes de thoughput, os dados coletados para as duas versões de software mostraram que a segunda versão apresentou um grande avanço tecnológico, tendo-se atingido o thoughput pré-estabelecido pelo tipo de serviço avaliado - 6 Mbps de downlink e 2 Mbps uplink -, o que não ocorreu na utilização da versão 1. Em ambos os testes de throughput e cobertura, a comparação entre os valores coletados pelas operadoras e os obtidos por meio do software desenvolvido confirmou a eficiência do programa e sua veracidade quanto aos resultados alcançados. 
Sugere-se, para trabalhos futuros, um aperfeiçoamento do software desenvolvido, incluindo-se os efeitos causados por interferência, pela utilização de antenas AAS e implementação do modo permutação PUSC. Pode-se pensar também no desenvolvimento de um ambiente visual, com mapas que demonstrem a localização de cada célula e seu alcance para as diferentes modulações.

Outra proposta seria a adaptação de um modelo de propagação para o ambiente de Brasília na frequiência de $3,5 \mathrm{GHz}$, para sua posterior implementação no programa, tornando-o ainda mais confiável. 


\section{REFERÊNCIAS BIBLIOGRÁFICAS}

[1] ANDREWS, J. G. GOSH, A. MUHAMED, R. Fundamentals of WiMAX. Westford, Massachusetts: Prentice Hall, Fevereiro 2007.

[2] NUAYMI, L. WiMAX - Technology for Broadband Wireless Access. Chippenham, Inglaterra: John Wiley \& Sons, Ltd, Julho 2007.

[3] IEEE 802.16 Broadband Wireless Access Working Group. "IEEE Standard for Local and Metropolitan Area Networks - Part 16: Air Interface for Fixed and Mobile Wireless Access Systems." Fevereiro 2006.

[4] IEEE 802.16 Broadband Wireless Access Working Group. "IEEE Standard for Local and Metropolitan Area Networks - Part 16: Air Interface for Fixed Wireless Access Systems.” Outubro 2004.

[5] WONG, I. SHEN, Z. EVANS, B. ANDREWS, J. "A low complexity algorithm for proportional resource alocation in OFDMA systems." Proceedings, IEEE Signal Processing Workshop, Outubro 2004.

[6] IEEE 802.16 Broadband Wireless Access Working Group. "Channel Models for Fixed Wireless Applications." Julho 2001.

[7] CHUNG, S. T. GOLDSMITH, A. "Degrees of freedom in adaptive modulation: A unified view." IEEE Trans. Commun, Setembro 2001.

[8] GRAY, D. "A compartive analysis of mobile WiMAX Deployment Alternatives in the Access Network." Wimax Forum, Maio 2007.

[9] GRAY, D. "Mobile Wimax - Part I: A technical overview and performance evaluation." WiMAX Forum, Agosto 2006.

[10] International Communication Union - ITU -R P.800. Method for subjective determination of transmission quality. Agosto de 1996.

[11] International Communication Union - ITU -R P.862. Annex A - Source code for reference implementation and conformance tests. Fevereiro de 2003.

[12] CROZIER, E. KLEIN, A. "WiMAX's technology for LOS and NLOS environments." WiMAX Forum.

[13] PARSONS, J. D. The Mobile radio Propagation Channel. 2nd. ed. John Wiley and Sons, 2000. 


\section{ANEXO A}

\section{A.1. Desvanecimento}

Entende-se por desvanecimento, a atenuação que um sinal de rádio sofre após ter interagido com o ambiente.

O nível de atenuação depende da distância e velocidade entre transmissor e receptor, da configuração e quantidade de elementos existentes entre os dois, das condições climáticas e dos diferentes caminhos que o sinal pode percorrer (multipercurso).

O desvanecimento pode ser dividido em dois tipos: o desvanecimento em larga escala e o desvanecimento em pequena escala, conforme ilustra a Figura A.1.

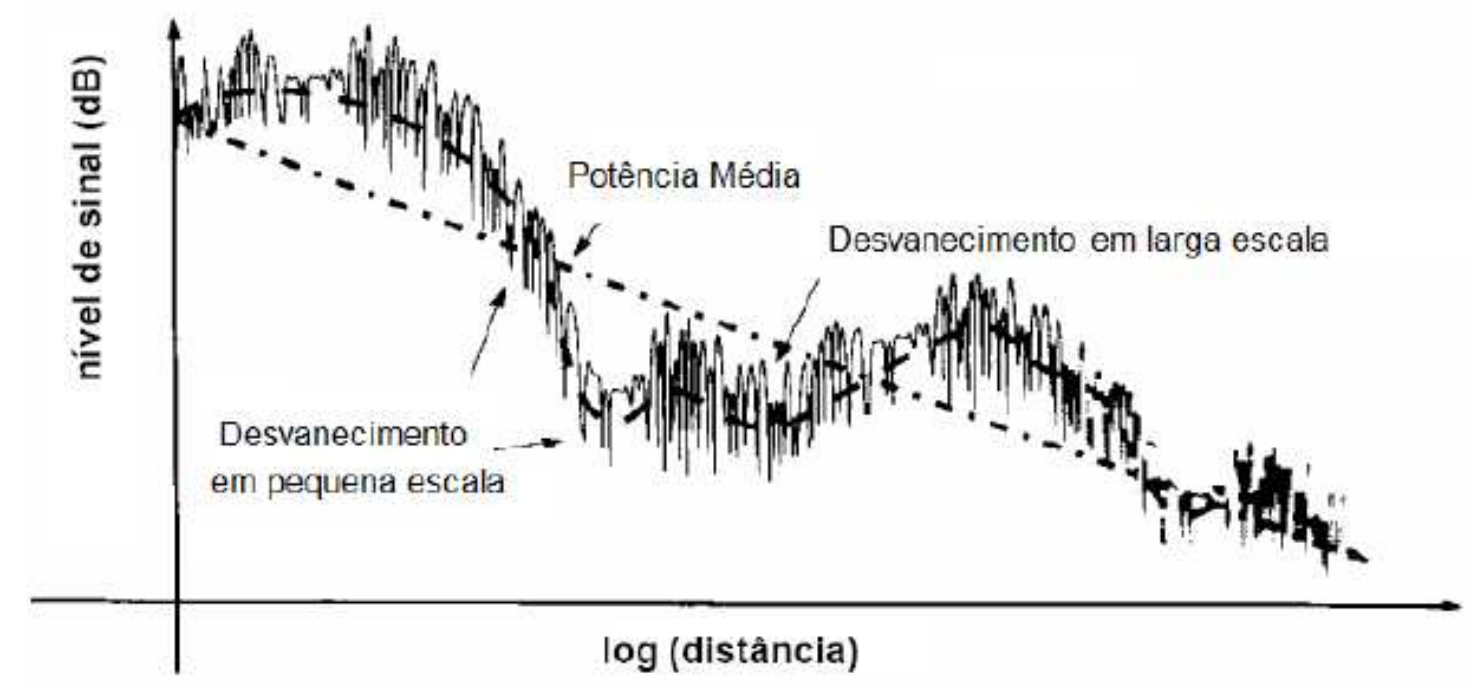

Figura A.44: Comportamento do desvanecimento da envoltória de um sinal. Adaptado de [13]

\section{A.2. Desvanecimento em larga escala}

O desvanecimento em larga escala representa a componente do desvanecimento que varia de forma lenta. É composto pela perda de percurso (pathloss) e pelo sombreamento (shadowing). 
A perda de percurso representa a variação média na potênca do sinal à medida que este se propaga pelo ambiente. Para prevê-la, existem modelos de predição, dentre os quais se destacam o modelo de espaço livre, Okumura-Hata, SUI e Ikegami-Walfisch. Cada um desses modelos possui restrições (faixa de freqüência, distância entre transmissor e receptor, altura das antenas, tipo de ambiente) quanto sua utilização.

Já o sombreamento caracteriza variações na densidade de potência em diferentes locais para uma mesma distância, ou seja, um usuário se deslocando ao redor da BS, sob um mesmo raio, perceberá níveis de potência distintos. Esses níveis de potência seguem uma distribuição gaussiana com desvio padrão $\sigma$, que varia de acordo com o ambiente, e média dada pela perda de percurso. Portanto, $50 \%$ dos valores estarão acima da média e o restante estará abaixo.

O nome sombreamento existe porque, normalmente, há obstáculos naturais (vegetação, relevo) e artificiais (edifícios, construções) entre o transmissor e o receptor, e isso, faz com que o receptor fique numa região de sombra. Nesse caso, o sinal captado é proveniente de difração e espalhamento.

\section{A.2.1. Modelo SUI (Stanford University Interim)}

Trata-se de um modelo desenvolvido pelo grupo de trabalho IEEE $802.16 \mathrm{em}$ conjunto com a Universidade de Stanford, para predição das perdas de percurso (pathloss) em Sistemas de Acesso Fixos e Wireless (FWA).

O modelo SUI define três tipos de terrenos: A, B e C. Dentre os 3, o terreno A é o que apresenta as maiores perdas sendo considerado montanhoso e com uma vegetação bem densa. $\mathrm{O}$ B possui perdas moderadas, sendo maiores que as do terreno $\mathrm{C}$ e inferiores ao $\mathrm{A}$. É caracterizado por terrenos planos com uma vegetação mais ou menos densa ou então como montanhoso e pouca vegetação. Já o terreno $\mathrm{C}$ possui o menor pathloss e é caracterizado por locais planos e com pouquíssimas árvores.

A expressão que caracteriza as perdas $(L)$ é:

$$
\left.L\right|_{d B}=A+10 \cdot \gamma \cdot \log _{10}\left(\frac{d}{d_{0}}\right)+X_{f}+X_{h}+s, \text { para } d>d_{0}
$$


Onde $d$ representa a distância [m] entre a BS e a SS, $d_{0}$ é um ponto de referência e vale $100 \mathrm{~m}, \quad s$ é um fator de distribuição lognormal usado para contabilizar desvanecimentos devido a árvores, sombras e objetos, também chamado de shadowing. Seu valor depende do terreno e varia de $8.2 \mathrm{~dB}$ a $10.6 \mathrm{~dB}$. Os demais parâmetros são definidos como:

$$
A=20 \cdot \log _{10}\left(\frac{4 \cdot \pi \cdot d_{0}}{\lambda}\right)
$$

Em (A.2), $\lambda$ representa o comprimento de onda.

$$
\gamma=a-b \cdot H_{B S}+\frac{c}{H_{B S}}
$$

Sendo $H_{B S}$ a altura da antena da BS e com valor limitado $10 m \leq H_{B S} \leq 80 m$. Já os termos $a, b$ e $c$ são constantes que variam de acordo com o tipo de terreno. Seus valores são dados na Tabela A.1.

Tabela A.37: Valores dos parâmetros quanto ao tipo de terreno

\begin{tabular}{|c|c|c|c|}
\hline Parâmetro & Terreno A & Terreno B & Terreno C \\
\hline$a$ & 4.6 & 4.0 & 3.6 \\
\hline$b\left(m^{-1}\right)$ & 0.0075 & 0.0065 & 0.005 \\
\hline$c(m)$ & 12.6 & 17.1 & 20 \\
\hline
\end{tabular}

$X_{f}$ e $X_{h}$ são fatores de correção referentes a frequência ( $\left.f[\mathrm{MHz}]\right)$ e a altura da antena $\left(H_{S S}[\mathrm{~m}]\right)$ da SS, respectivamente. São definidos como:

$$
X_{f}=6 \cdot \log _{10}\left(\frac{f}{2000}\right)
$$

No caso do terreno ser tipo A ou tipo B:

$$
X_{h}=-10,8 \cdot \log _{10}\left(\frac{H_{S S}}{2}\right)
$$

Para o caso do terreno ser tipo C: 


$$
X_{h}=-20 \cdot \log _{10}\left(\frac{H_{S S}}{2}\right)
$$

\section{A.2.2. Margem de Sombreamento}

Para neutralizar o efeito de sombreamento, o algoritmo desenvolvido nesta monografia, calcula uma margem de sombreamento a partir da probabilidade de cobertura espacial que o sistema deseja ter.

A probabilidade de cobertura ( $\left.P_{\text {cobertura }}\right)$ é dada por:

$$
\begin{gathered}
P_{\text {cobertura }}=\frac{1}{2} \cdot\left\{1-\operatorname{erf}(m)+\exp \left(\frac{1-2 \cdot m \cdot g}{(g)^{2}}\right) \cdot\left[1-\operatorname{erf}\left(\frac{1-m \cdot g}{g}\right)\right]\right\} \\
m=\frac{M D}{\sigma \cdot \sqrt{2}} \\
g=\frac{10 \cdot \gamma \cdot \log _{10} e}{\sigma \cdot \sqrt{2}}
\end{gathered}
$$

Em Eq. (A.7), erf representa a função erro, $M D$ a margem de sombreamento, $\gamma$ o expoente de perda do percurso proveniente do modelo SUI (Eq.(A.3)), e $\sigma$ o desvio padrão.

A margem de sombreamento é encontrada a partir do método de Newton-Rapson, visto que o comando solve do Matlab não consegue resolver a Eq. (A.7), mesmo tendo como única incógnita, o termo $M D$.

\section{A.3. Desvanecimento em pequena escala}

Diferentemente da perda de percurso e do sombreamento, que são efeitos de atenuação em larga escala devido à distância ou a obstáculos, o desvanecimento em pequena escala (desvanecimento rápido) é causado pela recepção de múltiplas versões do mesmo sinal (multipercursos), que podem chegar quase que simultaneamente - por 
exemplo, se houverem espalhadores ao redor do receptor - ou em intervalos de tempo mais longos. Observando a Figura A.1, o desvanecimento em pequena escala seria a componente do desvanecimento que se altera de forma abrupta e drástica.

Quando alguns sinais que percorrem diferentes caminhos chegam, aproximadamente, ao mesmo tempo, a combinação destes pode ser destrutiva, Figura A.2 (b), ou construtiva, Figura A.2 (a), dependendo da diferença de fase entre eles. O movimento relativo entre o transmissor e o receptor, mesmo que seja um pequeno deslocamento, pode ocasionar diferenças significativas na amplitude do sinal recebido, ainda que os efeitos de perda de percurso e do sombreamento não mudem.

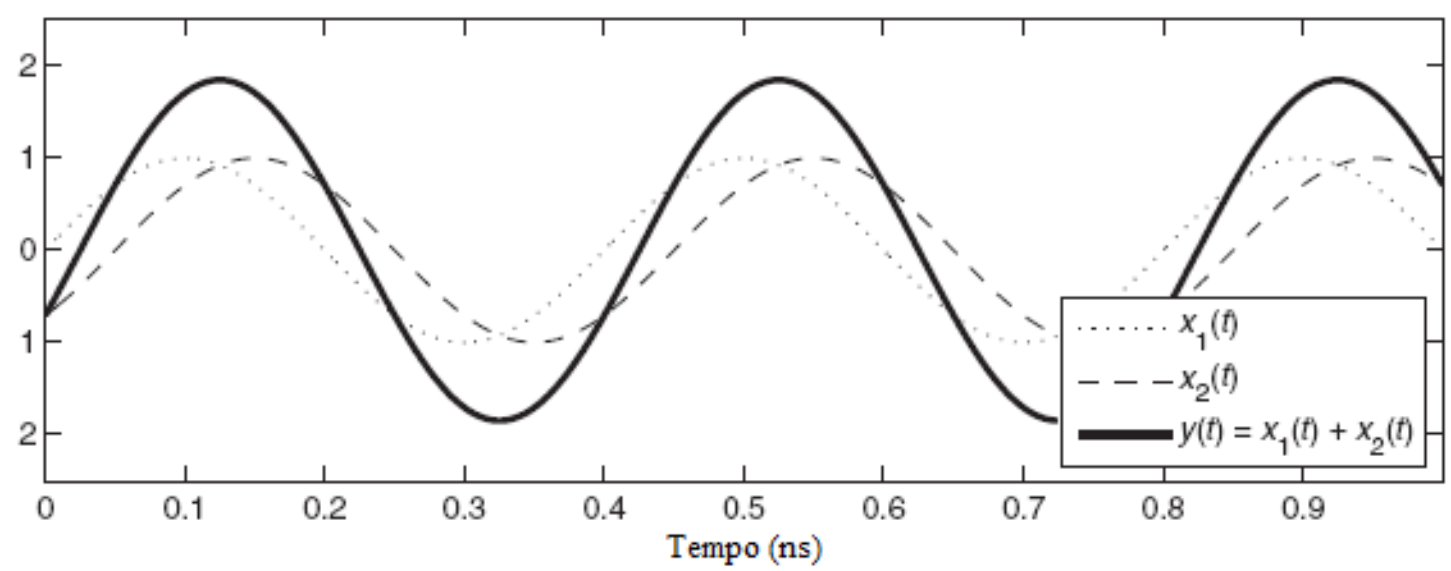

(a)

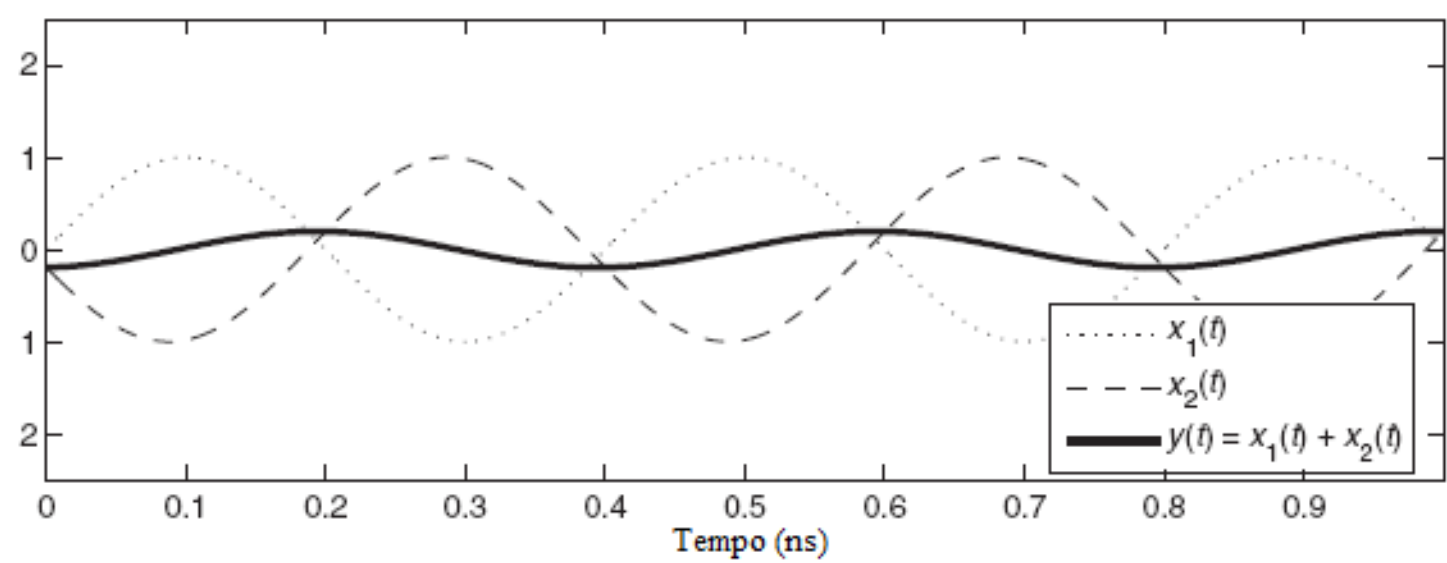

(b)

Figura A.45: Interferência construtiva(a) e destrutiva(b). Adaptado de [1] 
